\title{
Long-term Monitoring Plan for the Central Nevada Test Area
}

\author{
Prepared by \\ Ahmed E. Hassan \\ submitted to \\ Nevada Site Office \\ National Nuclear Security Administration \\ U.S. Department of Energy \\ Las Vegas, Nevada
}

SEPTEMBER 2003

Publication No. 45201 
Reference herein to any specific commercial product, process, or service by trade name, trademark, manufacturer, or otherwise, does not necessarily constitute or imply its endorsement, recommendation, or favoring by the United States Government or any agency thereof or its contractors or subcontractors. The views and opinions of authors expressed herein do not necessarily state or reflect those of the United States Government or any agency thereof.

This report has been reproduced directly from the best available copy.

Available for sale to the public from:

\author{
U.S. Department of Commerce \\ National Technical Information Service \\ 5285 Port Royal Road \\ Springfield, VA 22161 \\ Phone: 800.553 .6847 \\ Fax: 703.605.6900 \\ Email: orders@ntis.gov \\ Online ordering: http://www.ntis.gov/ordering.htm
}

Available electronically at http://www.osti.gov/bridge

Available for a processing fee to the U.S. Department of Energy and its contractors, in paper, from:

U.S. Department of Energy

Office of Scientific and Technical Information

P.O. Box 62

Oak Ridge, TN 37831-0062

Phone: 865.576 .8401

Fax: 865.576.5728

Email: reports@adonis.osti.gov 


\title{
Long-term Monitoring Plan for the Central Nevada Test Area
}

\author{
Prepared by \\ Ahmed E. Hassan \\ Division of Hydrologic Sciences \\ Desert Research Institute \\ University and Community College System of Nevada
}

Publication No. 45201

\author{
Submitted to \\ Nevada Site Office \\ National Nuclear Security Administration \\ U.S. Department of Energy \\ Las Vegas, Nevada
}

September 2003

The work upon which this report is based was supported by the U.S. Department of Energy under Contract \#DE-AC08-00NV13609. Approved for public release; further dissemination unlimited. 



\section{EXECUTIVE SUMMARY}

The groundwater flow and transport model of the Faultless underground nuclear test conducted at the Central Nevada Test Area (CNTA) was accepted by the state regulator and the environmental remediation efforts at the site have progressed to the stages of model validation and long-term monitoring design. This report discusses the long-term monitoring strategy developed for CNTA. Subsurface monitoring is an expensive and time-consuming process, and the design approach should be based on a solid foundation. As such, a thorough literature review of monitoring network design is first presented. Monitoring well networks can be designed for a number of objectives including aquifer characterization, parameter estimation, compliance monitoring, detection monitoring, ambient monitoring, and research monitoring, to name a few. Design methodologies also range from simple hydrogeologic intuition-based tools to sophisticated statistical- and optimization-based tools.

When designing the long-term monitoring well network for CNTA, a number of issues are carefully considered. These are the uncertainty associated with the subsurface environment and its implication for monitoring design, the cost associated with monitoring well installation and operation, the design criteria that should be used to select well locations, and the potential conflict between different objectives such as early detection versus impracticality of placing wells in the vicinity of the test cavity. Given these considerations and the literature review of monitoring design studies, a multi-staged approach for development of the long-term monitoring well network for CNTA is proposed. This multi-staged approach will proceed in parallel with the validation efforts for the groundwater flow and transport model of CNTA. Two main stages are identified as necessary for the development of the final long-term monitoring well network for the site.

The first stage is to use hydrogeologic expertise combined with model simulations and probability based approaches to select the first set of monitoring wells that will serve two purposes. The first is to place the wells in areas likely to encounter migration pathways thereby enhancing the probability of detecting radionuclide migration in the long run. The second objective is crucial in the short run and is aimed at using this set of wells to collect validation data for the model. The selection criteria should thus balance these two objectives. Based on the results of the validation process that progresses concurrently with the first monitoring stage, either more wells will be needed in this first stage or the second stage will be initiated. The second monitoring design stage will be based on an optimum design methodology that uses a suitable statistical approach, combined with an optimization approach, to augment the initial set of wells and develop the final long-term monitoring network.

The first-stage probabilistic analysis conducted using the CNTA model indicates that the likelihood of migration away from the test cavity is very low and the probability of detecting radionuclides in the next 100 years is extremely low. Therefore, it is recommended to place one well in the downstream direction along the model longitudinal centerline (i.e., directly north of the working point), which is the location with the highest probability of encountering the plume. Lack of significant plume spreading, coupled with the extremely low velocities, suggests that this one well is sufficient for the first stage. Data from this well, and from additional wells located with validation as the prime objective, will benefit the model validation process. In the long run, this first monitoring well is going to be crucial for the long-term monitoring of the site (assuming that the flow model is validated), as it will be the most likely place to detect any plume migration away from the cavity. 


\section{ACKNOWLEDGEMENTS}

The author wishes to thank a number of technical reviewers whose comments improved the draft version of this report. These include Jenny Chapman, Karl Pohlmann, Greg Pohll, and Michael Young of DRI. Jenny Chapman is also thanked for her valuable contributions to the different sections of this report and for many stimulating discussions that resulted in improving the quality of this report. The help of Hesham Bekhit in creating some of the figures in this report is appreciated. Many thanks go to Debi Noack for her highly skillful electronic publishing support. Marjory Jones and Jennifer Lease are also thanked for providing editorial support. Funding was provided by the U.S. Department of Energy, National Nuclear Security Administration, Nevada Site Office. 


\section{CONTENTS}

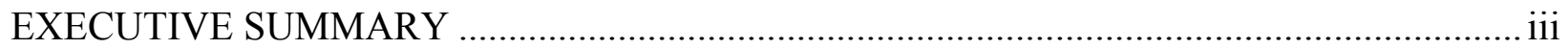

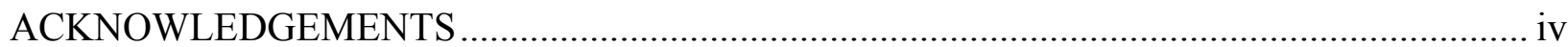

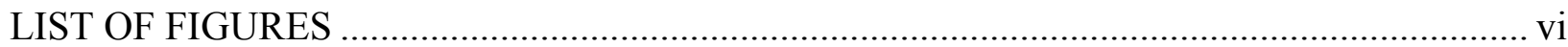

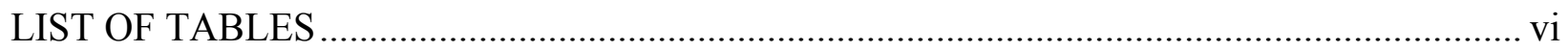

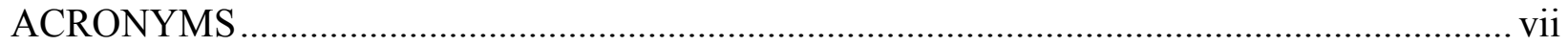

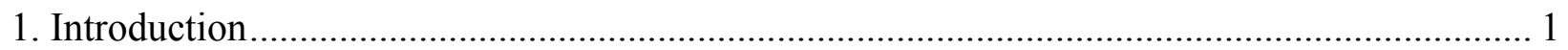

2. Review of Monitoring Network Objectives..................................................................... 2

2.1 Objectives of Monitoring Networks ........................................................................... 2

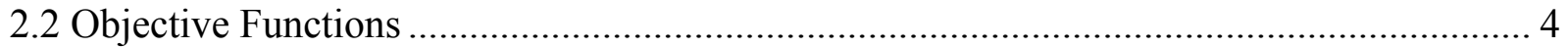

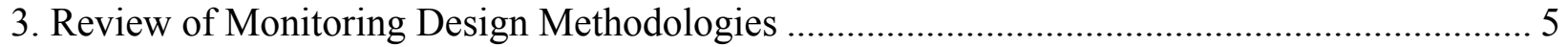

3.1 Classification of Network Design Methodologies....................................................... 5

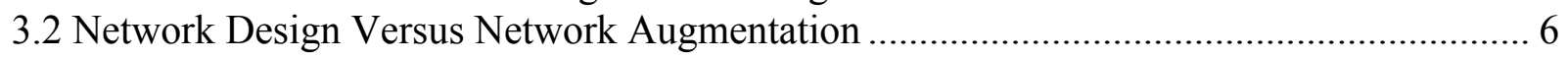

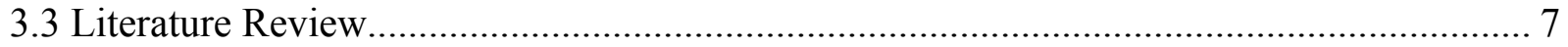

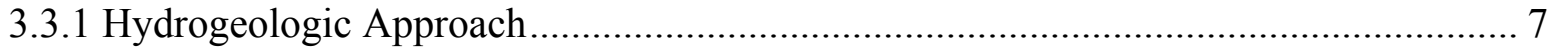

3.3.2 Statistical (or Geostatistical) Approaches ..................................................... 7

3.3.2.1 Simulation Approach .............................................................................. 7

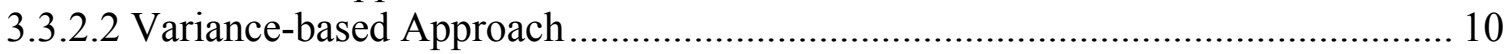

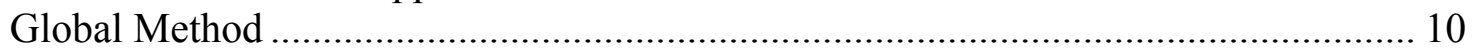

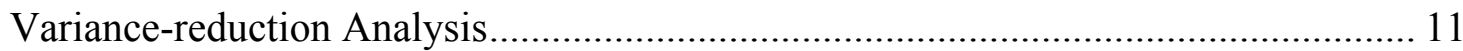

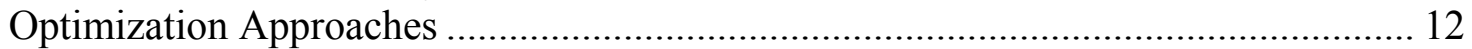

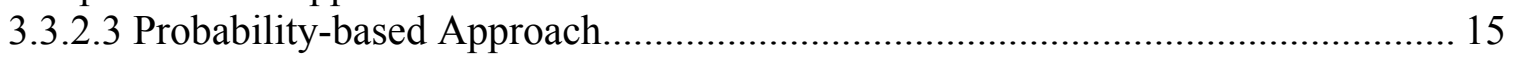

3.3.3 Bayesian Decision Analysis.......................................................................... 17

3.3.4 Transfer Function Approach .......................................................................... 17

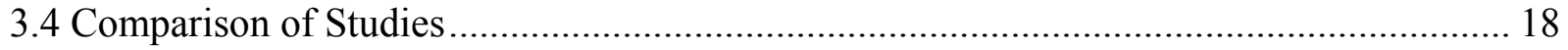

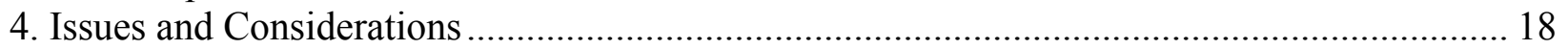

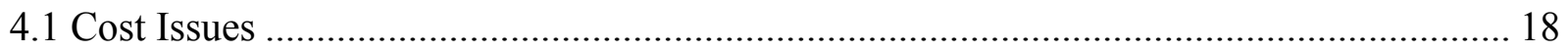

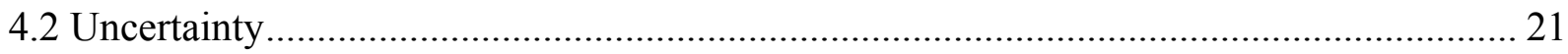

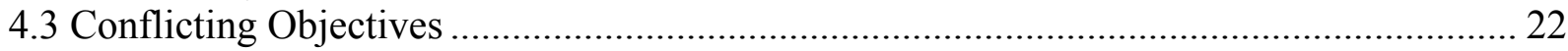

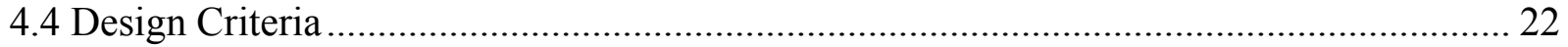

5. Proposed Monitoring Strategy for CNTA ....................................................................... 23

5.1 First-stage Monitoring Design Approach ..................................................................... 23

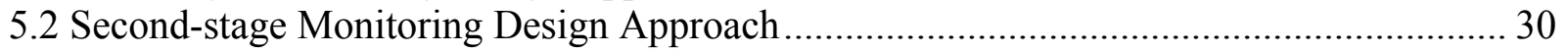

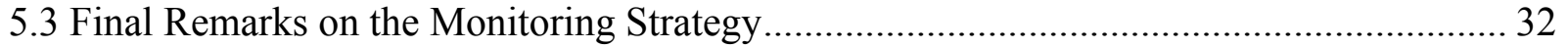

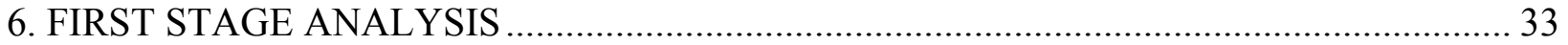

6.1 Model Simulation and Probability-Based Approaches.............................................. 33

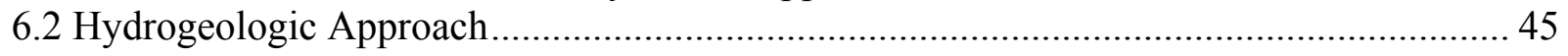

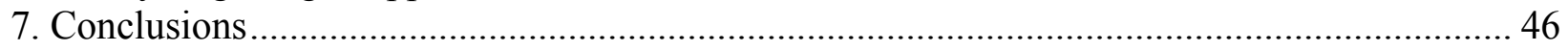

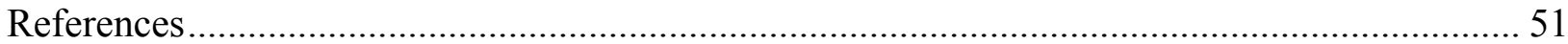




\section{LIST OF FIGURES}

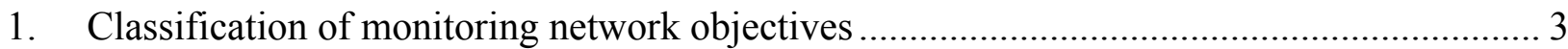

2. Classification of monitoring network design methodologies. .............................................. 6

3. The multi-staged approach for the long-term monitoring network design at CNTA and the link to the validation approach.............................................................................. 24

4. Schematic diagram showing the location of contaminant plume, monitoring wells, and the distances and definitions used in Equations (2) through (4)................................... 26

5. A step-by-step description of the first-stage design methodology......................................... 29

6. A step-by-step description for the second-stage design approach........................................ 31

7. Map view of model domain showing the finite difference mesh, the locations of the UC-1 land withdrawal boundary and the related CNTA boreholes.

8. A three-dimensional view (top - to scale) showing the model domain, the cavity and the five $\mathrm{CPs}$ (CP \# 1 through $\mathrm{CP} \#$ 5), a zoom-in around the cavity and the CPs (right - distorted scale), and a two-dimensional plan view showing the location of the five CPs relative to the cavity (bottom - distorted scale).

9. A three-dimensional view (top - to scale) showing the model domain, the cavity and the five CPs (CP \# 6 through CP \# 10), a zoom-in around the cavity and the CPs (right - distorted scale), and a two-dimensional plan view showing the location of the five CPs relative to the cavity (bottom - distorted scale)...................................................... 37

10. Schematic representation of the plume width and height as particles cross the CP. ............ 37

11. Distribution of the total mass crossing CP \# 1 through CP \# 5 at different times................. 39

12. Distribution of the total mass crossing CP \# 6 through CP \# 10 at different times............... 40

13. Plume width distribution for $\mathrm{CP} \# 1$ through $\mathrm{CP} \# 5$ at different times.................................. 41

14. Plume width distribution for $\mathrm{CP} \# 6$ through $\mathrm{CP} \# 10$ at different times............................... 42

15. Plume height distribution for $\mathrm{CP} \# 1$ through $\mathrm{CP} \# 5$ at different times................................. 43

16. Plume height distribution for $\mathrm{CP} \# 6$ through $\mathrm{CP} \# 10$ at different times............................. 44

17. Distribution of the $X$ location of the plume center of mass when crossing CP \# 1 through CP \# 5 as average values from time zero to the given times................................... 47

18. Distribution of the $X$ location of the plume center of mass when crossing CP \# 6 through $\mathrm{CP} \# 10$ as average values from time zero to the given times. 48

19. Distribution of the $Z$ location of the plume center of mass when crossing CP \# 1 through CP \# 5 as average values from time zero to the given times.

20. Distribution of the $Z$ location of the plume center of mass when crossing CP \# 6 through CP \# 10 as average values from time zero to the given times.

\section{LIST OF TABLES}

1. Summary of a number of studies on monitoring network design. 19

2. Values of parameters that describe the configuration of the transport model and values of deterministic parameters 


\section{ACRONYMS}

$\begin{array}{ll}\text { ANN } & \text { Artificial Neural Networks } \\ \text { CERCLA } & \text { Comprehensive Environmental Response, Compensation and Liability Act } \\ \text { CNTA } & \text { Central Nevada Test Area } \\ \text { CP } & \text { control plane } \\ \text { DOE } & \text { U.S. Department of Energy } \\ \text { DRI } & \text { Desert Research Institute } \\ \text { GA } & \text { Genetic Algorithms } \\ \text { MCLP } & \text { maximal covering location problem } \\ \text { NDEP } & \text { State of Nevada Division of Environmental Protection } \\ \text { RCRA } & \text { Resource Conservation and Recovery Act } \\ \text { RWPT } & \text { random walk particle tracking }\end{array}$


THIS PAGE LEFT INTENTIONALLY BLANK. 


\section{INTRODUCTION}

The Faultless underground nuclear test, conducted in central Nevada, is the site of an ongoing environmental remediation effort that has successfully progressed through numerous technical challenges. The challenges faced are mainly caused by the substantial uncertainties and the lack of sufficient data to characterize a highly heterogeneous subsurface environment. A variety of numerical modeling techniques and statistical tools are used to provide the information needed to confidently move forward along the remediation path to site closure (Chapman et al., 2002). Close cooperation between the U.S. Department of Energy (DOE), National Nuclear Security Administration; the State of Nevada Division of Environmental Protection (NDEP); and supporting scientists from the Desert Research Institute (DRI) has resulted in mutual understanding and credible ways of moving forward to site closure despite knowing uncertainty will remain.

Though not immediately obvious, there is an advantage presented by the great depth of underground nuclear tests, as compared to more common groundwater pollution problems (Chapman et al., 2002). The practical limitations of trying to reduce uncertainty through installing and testing characterization wells are more readily accepted when the source of contamination is located $1,000 \mathrm{~m}$ below ground surface. This is in contrast to some shallow groundwater-contaminated sites where the acceptance of uncertainty may be inhibited by the ability to install dozens of wells. Yet even at such shallow sites, it is impossible to eliminate the uncertainty inherent in subsurface transport calculations and the increase in the number of wells may threaten the site's integrity.

Validating the stochastic Faultless model will not eliminate uncertainty from the model calculations. Confidence in the model must be explained to the public and translated into an easy-to-understand statement of acceptable risk, the risk of the incorrect decision (Chapman et al., 2002). Key to public acceptance is monitoring. Monitoring can be viewed as the final step addressing uncertainty in environmental problems. Groundwater monitoring not only serves to build confidence that the system is performing as predicted, it acknowledges the uncertainties inherent in the modeling process and the possibility, however remote, of unexpected outcomes. Designing a technically robust groundwater monitoring network that samples at optimum locations, times, and parameter scales is another nontrivial task (the first being the validation of the stochastic CNTA model) ahead for the Faultless site.

Subsurface monitoring is an expensive, time-consuming, and uncertain process. Because of these challenges, monitoring networks should be carefully designed so that the maximum amount of information is obtained with available resources. The design of a monitoring network consists of defining the number, locations, and sample pattern of sampling sites (Olea, 1984). When temporal sampling is relevant, the sampling plan must specify the sampling frequency as well. However, prior to any sampling design, one should establish the objective of the monitoring program to deal with the question of data collection.

As pointed out by McLaughlin and Graham (1986), there is frequently confusion over the goals of monitoring programs. Major institutional data-gathering efforts, without clearly stated goals and objectives, lead to passive groundwater quality monitoring programs that are "datarich but information-poor" (Ward et al., 1986; Lee and Jones, 1983a, b). Therefore, defining quantifiable objectives is a first step in the design of cost-effective monitoring programs (Mar et al., 1986; Bernstein and Zalinski, 1983). Here, second questions can be asked: will field data be 
used only to characterize the scope of an existing problem, or will they also be used to make predictions? Should the monitoring program concentrate on geology, hydrology, or chemistry? Often, a single program must simultaneously serve several objectives, which exert conflicting demands on limited resources (McLaughlin and Graham, 1986). This, therefore, suggests that any systematic approach to monitoring design should be flexible enough to accommodate a number of different objectives that are likely to change as more data are collected.

Once the objectives of the monitoring network have been determined, the next step is to decide on the design methodology to best meet these objectives. A large body of literature exists proposing different approaches for designing groundwater monitoring networks. Different methodologies have been developed for designing monitoring networks that meet a single objective, and other methodologies have been developed for meeting multiple objectives. It is important to distinguish between the monitoring network objective (or the purpose of the monitoring program) and the objective functions that result from the mathematical formulation of the design problem.

Following this introduction, we present in Section 2 a thorough discussion of the different monitoring objectives or purposes and how they may impact the choice of the design methodology. Section 3 presents a literature review of the different design methodologies that have been developed and used for subsurface monitoring. The important issues and considerations that should be accounted for in the monitoring network design are discussed in Section 4, highlighting the implications for the CNTA site. A general overview of the proposed monitoring plan for CNTA is presented in Section 5, with a discussion of how the monitoring plan is linked to the validation plan.

\section{REVIEW OF MONITORING NETWORK OBJECTIVES}

\subsection{Objectives of Monitoring Networks}

There is a common need to monitor the subsurface environment with a cost-effective network of wells. However, a common need does not imply common objectives. It is the set of objectives of a network that determines its specific design (Knopman et al., 1991). These objectives are the main factor determining the cost, the level of detail, and the appropriate method for the design of a monitoring network (Loaiciga et al., 1992). In general, the well network design and selection of well locations should satisfy two broad categories of objectives: 1) sampling of spatially distributed hydrogeologic variables for the purposes of aquifer characterization, and 2) sampling for subsurface pollution monitoring. However, other monitoring network objectives include such things as model discrimination (e.g., Knopman et al., 1991) and source identification (e.g., Mahar and Datta, 1997).

Under the general objective of subsurface characterization, monitoring network design may be performed for the purpose of characterizing the physical properties of the aquifer (e.g., hydraulic conductivity), mapping regional variables (e.g., potentiometric map, water table elevation map, or regional groundwater flow), or for parameter estimation. Except for mapping regional variables, the other objectives under the physical characterization aspect do not receive much attention in terms of sophisticated network design efforts. More often, characterizing physical properties or estimating certain parameters is done by selecting sampling locations based on hydrogeologic expertise and general knowledge of the site under consideration.

The more common objective of monitoring networks is related to groundwater quality monitoring. Loaiciga et al. (1992) evaluate the various methods for network design available in 
the hydrologic literature by considering, among other aspects, the objective of sampling. Their review article focuses on groundwater quality monitoring networks. As mentioned earlier, other objectives can drive the monitoring network design such as parameter estimation, model discrimination, and aquifer characterization. Since the analysis here focuses on the long-term monitoring of the CNTA with radionuclide contamination, the review of Loaiciga et al. (1992) provides a good starting framework to help understand the issues involved in the long-term monitoring of CNTA. Figure 1 shows an augmented classification of the different objectives of monitoring networks, which builds around the classification given by Loaiciga et al. (1992) for quality monitoring networks and extends it to include the other objectives discussed above.

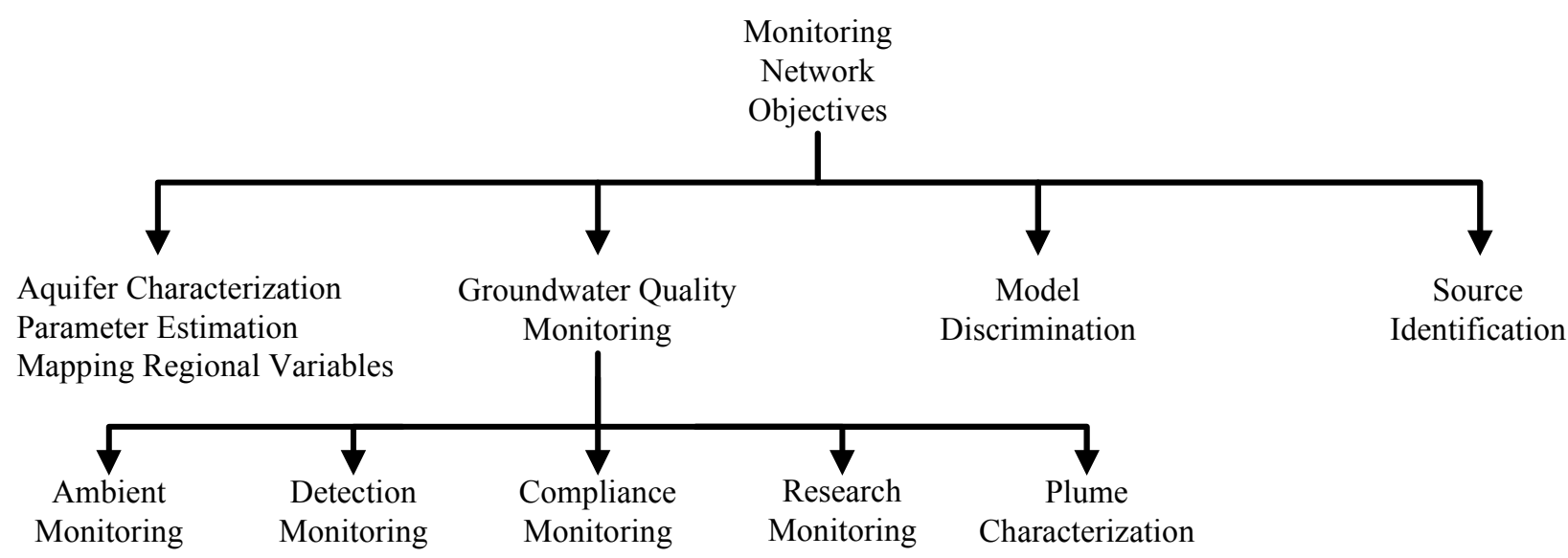

Figure 1. Classification of monitoring network objectives (or the purposes of having a monitoring well network)

As cited by Loaiciga et al. (1992), Todd et al. (1976) identified four objectives for groundwater quality monitoring activities: 1) ambient monitoring, 2) detection monitoring, 3) compliance monitoring, and 4) research monitoring. Ambient monitoring focuses on understanding the characteristics of regional groundwater quality variations over time. This type of monitoring is accomplished through routine sampling of wells on a regional basis. The wells sampled are often used for public water supply, industrial, or domestic purposes, rather than specialized monitoring wells (Loaiciga et al., 1992). Detection monitoring is aimed at identifying the presence of certain contaminants as soon as their concentrations exceed background or established levels. This type of monitoring is required at and around point and nonpoint sources of groundwater contamination.

Compliance monitoring denotes a stringent set of groundwater quality monitoring requirements for chemical compounds at a disposal facility after detecting their presence in monitoring wells. Compliance monitoring is enforced to verify the progress and success of groundwater cleanup and remediation works. Research monitoring consists of the detailed spatial and temporal groundwater quality sampling tailored to meet specific research goals (e.g., Knopman et al., 1991).

A monitoring network for plume characterization is designed such that an existing plume is well characterized. The objective here is to delineate the plume extent and the amount of contaminant mass within the plume area. The network design objective entails both the determination of well locations and of a sampling schedule representing sampling activities for 
individual wells as a function of time. The goal is to obtain monitoring networks that maximize contaminant plume characterization accuracy with a small number of active wells and a small total number of wells.

It is apparent that the long-term monitoring for the CNTA site combines the second and third objectives of the groundwater quality-monitoring theme. Detection monitoring provides early indications of the migration of radionuclides from the test cavity to the downstream direction. At the same time, these data also fall under the compliance monitoring for the purpose of assuring that the presence of certain radioactive elements, if confirmed, is characterized and understood.

\subsection{Objective Functions}

Given a monitoring objective, the next step is to select a methodology to design the sampling network. Some methods for groundwater monitoring network design result in mathematical models that yield sampling locations (i.e., the network) and frequency of sampling times. Such mathematical models typically seek to optimize a specific criterion of performance, or objective function, but the major difficulty in the design process using these models is to choose the objective functions that faithfully represent a monitoring objective (Loaiciga et al., 1992). The main reasons for this difficulty are: 1) the existence of competing criteria that could express, at least partly, the monitoring objective, and 2) the dynamic nature of groundwater quality monitoring, with possible changes of the monitoring objective over time (Loaiciga et al., 1992).

Objective functions that are being used in monitoring network design can be classified as either ultimate objectives or surrogate objectives (Loaiciga et al., 1992). Ultimate objectives explicitly consider the value of groundwater quality information in achieving monitoring goals such as environmental protection (Hsueh and Rajagopal, 1988), the reduction of remediation costs, and minimizing exposure risks (Massmann and Freeze, 1987a) or health hazards. Surrogate objectives are substitutes for ultimate objectives, and are used in many cases to bypass the difficulties posed by the formulation of network design problems in terms of ultimate objectives. Examples of surrogate objectives are the minimization of statistical parameters such as the variance of contaminant concentrations (Rouhani, 1985) or the minimization of the maximum absolute deviation between actual and predicted variables (Loaiciga and Church, 1990).

Another important consideration in network design is the dynamic nature of groundwater quality programs. In many instances, the network design depends upon the spatial (and also temporal) distribution of chemical concentrations in the subsurface, which are often unknown before sampling is undertaken. Therefore, network design is typically an iterative process, whereby the sampling program (in space and time) must be revised and updated in response to changes in information needs and in the gathered data (Loaiciga et al., 1992). This is consistent with our proposed iterative validation-monitoring-refinement cycle, which will be discussed later in Section 5.

In summary, the choice of a criterion of performance, or objective function, is perhaps the most important step in the design of groundwater quality monitoring networks. Although there is not a single best criterion, the selected criterion must be intimately linked to the overall monitoring objective (ambient, compliance, detection, or research), and it must reflect the tradeoffs between competing functions (e.g., exposure assessment or prediction of concentration) and 
account for the uncertainties commonly plaguing the data used in network design (Loaiciga et al., 1992).

\section{REVIEW OF MONITORING DESIGN METHODOLOGIES}

The interest in groundwater quality monitoring has increased significantly in the United States since the mid-1970s, fueled primarily by federal legislation that includes the Clean Water Act, the Safe Drinking Water Act, the Toxic Substances Control Act, the Resource Conservation Recovery Act (RCRA), and the Comprehensive Environmental Response, Compensation and Liability Act (CERCLA or "Superfund") (Loaiciga et al., 1992). Loaiciga et al. (1992) present a thorough review of groundwater quality monitoring network design. The review performed in this report builds on that review and extends it to include the progress made in monitoring network design during the past decade. First, is the classification of monitoring network design methodologies, provided by different authors, and augmented into a single chart. Then, a literature review is presented that covers the description of the basic idea of each of these methods and discusses some of the studies that proposed, developed, or used these methodologies.

\subsection{Classification of Network Design Methodologies}

A number of methodologies have been proposed over the years for groundwater monitoring network design. Loaiciga (1989) identifies three approaches to the design of groundwater quality networks: 1) optimization, 2) simulation, and 3) variance reduction. Andricevic (1990) indicates that the two commonly used approaches to analyze and design monitoring networks are optimization and simulation. Andricevic and Foufoula-Georgiou (1991) categorize the monitoring network design approaches into mixed-integer programming approaches (Hsu and Yeh, 1989), kriging and co-kriging application (Carrera et al., 1984; McLaughlin and Graham, 1986), variance-reduction analysis (Rouhani, 1985), nearest neighbor approach (Olea, 1984), and methods based on optimization (e.g., Hsueh and Rajagopal, 1988; Loaiciga, 1989; Andricevic, 1990) and simulation (e.g., Meyer and Brill, 1988; Massmann and Freeze, 1987a, b).

At the site-specific or local scale, approaches for locating groundwater quality monitoring wells can be classified as either network design or network augmentation (Hudak and Loaiciga, 1992). The difference between these two approaches will be explained later in this section. A comprehensive review of the concepts, models, and methodologies used to design groundwater quality monitoring networks is available in Loaiciga et al. (1992). They listed two general types of approaches to network design, namely the hydrogeologic and the statistical approaches, where the latter type can be further divided into simulation, variance-based, and probability- (or risk-) based techniques.

Andricevic (1996) pointed out that the monitoring network design approaches can in general be based on geostatistical methods (e.g., Carrera et al., 1984; McLaughlin and Graham, 1986; Rouhani, 1985; Rouhani and Hall, 1988), optimization methods (e.g., Olea, 1984; Loaiciga, 1989; Andricevic, 1990; Hudak and Loaiciga, 1992; Hsueh and Rajagopal, 1988; Hsu and Yeh, 1989), methods based on extensive simulation (e.g., Meyer and Brill, 1988; Massmann and Freeze, 1987b), the transfer function method (e.g., Andricevic and Foufoula-Georgiou, 1991), or the Bayesian decision theory methods (e.g., Grosser and Goodman, 1985; James and Freeze, 1993; James and Gorelick, 1994).

These different classifications are combined and this review built on the classification shown in Figure 2. The two main categories and their branches identified by Loaiciga et al. 
(1992) form the basic structure of the classification. However, the different methodologies developed under each of the general themes of Loaiciga et al. (1992) are added and each methodology associated with either a network design theme or a network augmentation theme. It is also important to note that many of the developed approaches belong to more than one of the categories in the figure. For example, a probability-based approach may be cast in an optimization framework, a variance-reduction approach may be based on kriging or co-kriging, and a simulation approach may be linked to an optimization technique.

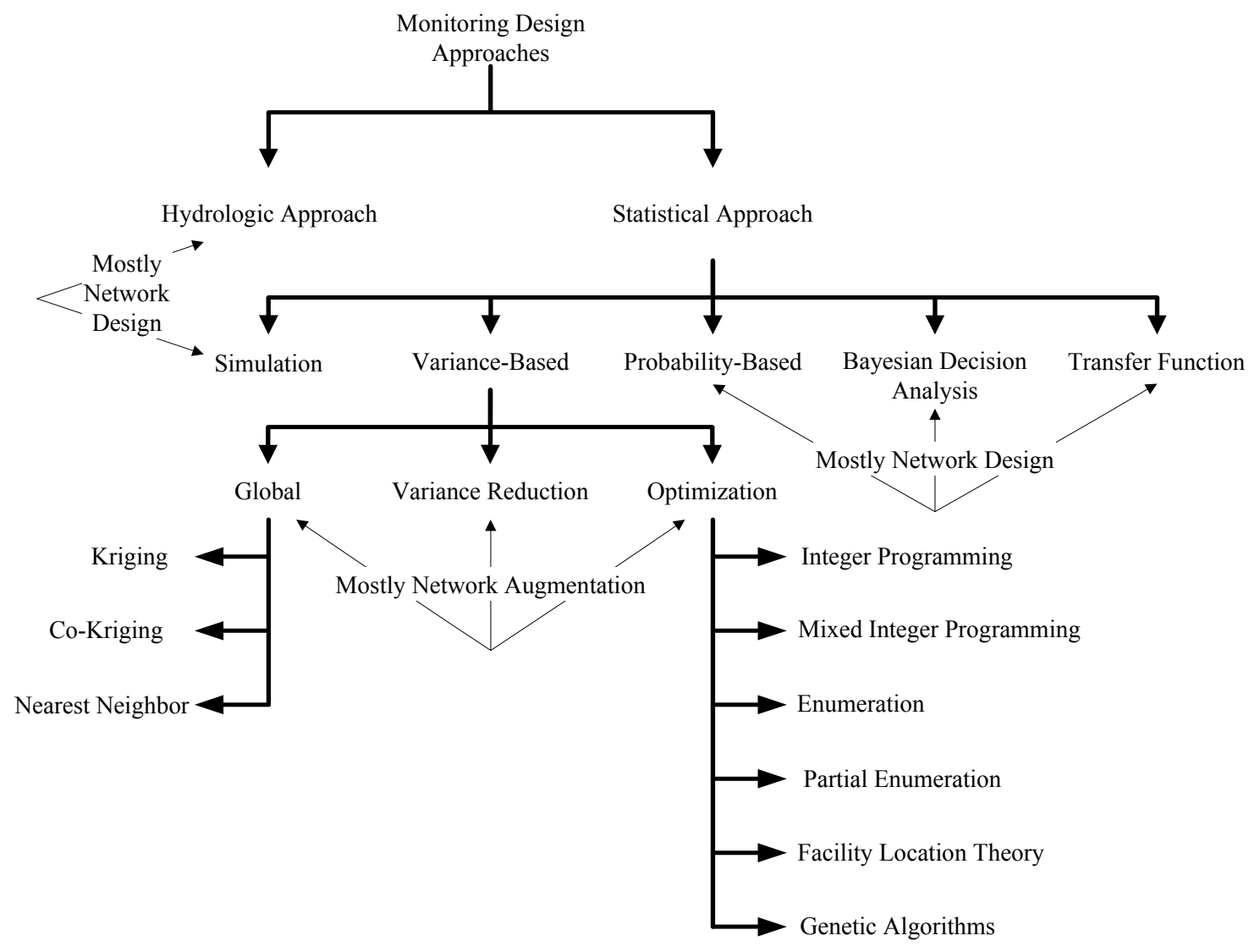

Figure 2. Classification of monitoring network design methodologies.

\subsection{Network Design Versus Network Augmentation}

Network design involves the determination of a configuration of monitoring wells for a site not characterized by existing wells. Network augmentation is a distinctly different problem. In the augmentation problem, monitoring wells are added to a pre-existing network for more efficient plume characterization. Information on aquifer properties and contaminant concentrations obtained from pre-existing wells, and the locations of these wells, are considered in the augmentation process. Variance-based approaches (e.g., Rouhani, 1985; Loaiciga, 1989; Graham and McLaughlin, 1989a, b) have been established for the problem of groundwater quality monitoring network augmentation in local-scale settings. A heuristic approach for network augmentation was proposed by Hudak and Loaiciga (1992). The objective of monitoring network augmentation is to locate additional wells to gain further information on maximum contaminant concentrations and the spatial extent of the contaminant field. 


\subsection{Literature Review}

The basic idea of each design methodology, in the categories shown in Figure 2, is briefly discussed in this section. Examples of studies that used these methodologies for monitoring network design are presented.

\subsubsection{Hydrogeologic Approach}

The term "hydrogeological approach" is used by Loaiciga et al. (1992) to describe the case where the network is designed based on the calculations and judgment of the hydrogeologist without the use of advanced statistical methods. More specifically, the number and locations of sampling sites (i.e., wells) are strictly determined by the hydrogeologic conditions near the source of contamination. As an example, the RCRA guidelines for groundwater monitoring (EPA, 1986) require, at a minimum, four groundwater monitoring wells: one well upgradient and three wells downgradient from the source of contaminants.

The hydrogeologic approach is better suited for site-specific studies where a welldelineated source of contamination exists (Loaiciga et al., 1992). The main objective of the hydrogeologic approach is to detect pollution as soon as the contaminant plume leaves the confinements of a waste disposal site. Geologic features such as aquifer layering and the presence of fractures determine the need for the vertical placement of sampling points. These needs are also determined based on the results of the hydrogeological analysis of the groundwater flow and contaminant migration from the source.

\subsubsection{Statistical (or Geostatistical) Approaches}

Commonly, geostatistical sampling procedures are based on the maximization of incremental information subject to budget constraints. Various geostatistical techniques have been used for groundwater quality monitoring network design that may be grouped into three classes: simulation, variance-based, and risk- or probability-based approaches (Loaiciga et al., 1992). However, as shown in Figure 2, other geostatistical approaches have been developed that do not belong to these categories. These include the Bayesian decision analysis and the transfer function approach. Also, some of the different methods developed within each of the geostatistical categories are shown in Figure 2. As mentioned earlier, some of the approaches developed and the studies discussed in the following sections belong to more than one of the categories shown in Figure 2. The placement of any study or methodology in any of the design methodology categories is done mainly for ease of presentation and for facilitating the comparison between different methods.

\subsubsection{Simulation Approach}

The conceptual backbone of the simulation approach is based on the traditional Monte Carlo analysis of flow and transport in the subsurface. That is, by generating multiple synthetic fields of hydraulic conductivity (normally conditioned on field data), for each of which there will be a corresponding contaminant field, it is possible to determine the statistical properties of mass transport in an aquifer, and thus the reliability of a monitoring network. For any given arrangement of monitoring wells and sampling frequency, the simulation approach yields important quantities, such as the probability that a contaminant plume might miss all of the sampling points and go undetected, i.e., the probability of a false negative.

Examples of simulation applications in groundwater quality monitoring network design can be found in such works as Massmann and Freeze (1987a, b), Meyer and Brill (1988), Ahlfeld and Pinder (1988), and Meyer et al. (1989, 1994). The simulation approach to groundwater 
quality monitoring network design offers an appealing flexibility to examine the efficiency of alternative network configurations and sampling frequencies.

Due to the linked nature of hydraulic conductivity and mass transport distribution generation, and the computational requirements, the simulation approach seems better tailored for problems involving contaminant monitoring at the field scale, as indicated by previous studies (e.g., Massmann and Freeze, 1987a, b). These authors presented a comprehensive framework for landfill design that incorporated uncertainty and allowed for the evaluation of selected network alternatives. Meyer and Brill (1988) presented a method to generate optimal network alternatives in the framework of Massmann and Freeze that maximized the probability of detection while minimizing the number of monitoring wells. Some detailed review of the studies by Massmann and Freeze (1987a, b) and Meyer and Brill (1988) is provided, as these are among the prominent studies that have been published on monitoring network design and will form the basic framework for the proposed monitoring design plan.

Massmann and Freeze (1987a, b) detail a comprehensive framework for design of a landfill operation, including monitoring design for release (or failure) detection. Their objective is to maximize the net present value of a stream of costs, benefits, and risks. The risks are associated with the costs sustained in the event of failure, with failure defined as a concentration measured in excess of a standard at the compliance surface. The probability of failure is reduced by the presence of a monitoring network operated by the owner/operator of the landfill and located between the source and the regulatory compliance surface. Monitoring contributes to the objective function by reducing the probability of failure, or equivalently, increasing the probability of detection. This framework reflects the notion that, in designing a monitoring network, the objective is not merely the acquisition of information but rather the improvement of the overall decisions that are made (Meyer and Brill, 1988).

Massmann and Freeze (1987a, b) integrate monitoring into their framework by calculating the probability of detection given a particular monitoring network. Due to the uncertainties in the physical system, a deterministic prediction of detection is precluded, and as such, Massmann and Freeze $(1987 \mathrm{a}, \mathrm{b})$ consider uncertainty in the hydraulic conductivity field. Translating uncertainty in the parameters into uncertainty in the model output (hydraulic head or concentration) is carried out using Monte Carlo simulations. Massmann and Freeze (1987b) use limited trade-off information to illustrate a landfill owner/operator's response to different monitoring alternatives.

While Massmann and Freeze's framework is quite general, the development of their study is specifically suited for a landfill in which the primary design feature is one or more synthetic liners in parallel. Also, the emphasis is placed on the design of new facilities and the regulatory policies for licensing new facilities rather than on remedial actions at facilities that have already caused contamination.

The monitoring alternatives considered by Massmann and Freeze (1987a, b), however, do not seem to be optimal with respect to maximizing the probability of detection. Meyer and Brill (1988) thus built on this framework and developed a methodology that can be used to select networks that maximize the probability of detection in the face of uncertainty. This method could easily be integrated into the framework of Massmann and Freeze (1987a) to generate optimal monitoring alternatives (Meyer and Brill, 1988). In addition, the method can be used to obtain a detailed description of the trade-off between different network designs and the probability of detection. Massmann and Freeze (1987a, b) and Meyer and Brill (1988) define failure of the 
monitoring system as nondetection of a plume before reaching the compliance boundary. Failure, under this definition, can only be avoided if the monitoring wells are located between the landfill and the compliance boundary.

The method developed by Meyer and Brill (1988) involves the use of two independent but linked models, a groundwater contaminant transport simulation model and an optimization model. The optimization model used is a form of the $p$-median facility location problem known as the maximal covering location problem (MCLP). The Monte Carlo technique is used with the simulation model to translate uncertainty in the simulation model parameters into uncertainty in the contaminant concentration distribution. The simulation model determines which well locations would detect a given realization of a contaminant plume with a concentration above a specified limit. The facility location model is then used to select a fixed number of well locations so that a maximum number of such plume realizations are detected. The selected well network maximizes the probability of detection.

The work by Meyer and Brill (1988) introduced an iterative method that combines simulation and optimization to arrive at a network configuration that maximizes the probability of contaminant plume detection. In their approach, Meyer and Brill (1988) transform a problem of decision under uncertainty (i.e., selection of the best sampling sites given the imperfect knowledge of contaminant distribution) into a deterministic optimization problem. This is done by first identifying the best set of plausible sampling sites via Monte Carlo simulation. Having identified those plausible sampling sites, an integer mathematical programming level was developed to select those sites that maximize the likelihood of detection of the occurrence of contaminants in the subsurface, while maintaining the size of the sampling network within acceptable limits.

Failure in Meyer and Brill's (1988) methodology is defined as the detection of a contaminant at or outside the compliance boundary, with a concentration higher than a predetermined maximum value (a standard). Any plume that will cause a failure should be detected inside the boundary before failure occurs. The algorithm, however, distinguishes between the detection of plumes that exceed the standard at the boundary and the detection of plumes that exceed the standard inside but not at the boundary. In practice, a single well sample that exceeds the standard inside the boundary would not be sufficient to determine if the plume would exceed the standard at or outside the boundary. Once a plume is detected, the monitoring strategy may be reevaluated with respect to new objectives, such as determining the extent of the plume.

It would be feasible to design the monitoring network to maximize the probability of detecting only those plumes that would exceed the standard at or outside the boundary. The optimal network for this objective, however, will likely be different from the optimal network obtained by maximizing the probability of detecting all plumes that exceed the standard, both inside and at or outside the boundary.

In general, there is no economically feasible monitoring network that can be expected to detect all possible plumes arising from a particular contaminant source under uncertain conditions. There is a probability of detection associated with any specific monitoring network and it can be expected to increase with increased density of the network and/or increased frequency of sampling. Increasing the probability of detection requires that either more monitoring wells be used or that the wells be located farther from the source. The latter case results in an increase in the average detected plume area (Meyer et al., 1994). 
As cited in Meyer et al. (1994), Haug et al. (1990) presented a method for determining well spacing around a landfill site based on the simulation of random hydraulic conductivity fields. The single objective considered was the probability that a well is located in a high-conductivity lens, thereby focusing on fast migration pathways for detecting any contaminant leaks from the landfill.

\subsubsection{Variance-based Approach}

The second group of statistical techniques uses additional statistical properties of the estimated values and their basis is the estimation variance. Thus in variance-based methods, the objective is to minimize the estimation variance or some function of it, subject to various constraints. The estimation variance has some useful properties, including the fact that it does not depend on the values of individual observations, which allow the planner to pose such questions as "how much accuracy is gained if additional observations are made at location $\boldsymbol{x}$ or $\boldsymbol{y}$ ?" Among variance-based approaches are the global method, the variance-reduction analysis, and the optimization methods (Loaiciga et al., 1992).

Global Method

The aim of this method is to identify the best pattern (e.g., square, triangular, or other geometric arrangement) and the best density (the number of points per unit area) of the sampling sites. The works of such authors as Olea (1984), Yfantis et al. (1987), and Christakos and Olea (1988) present some global (i.e., over the entire sampling domain) indices for the performance of a monitoring program, including the average or maximum variance of estimation. Among the approaches that can be described as global geostatistical methods are the random search method, the systematic search method, kriging-based methods, and co-kriging-based methods. These are discussed in the following.

Frequently, measurement points in network design are located by random search procedures. The estimation variance is computed for each set of measurement points and the set that gives the smallest estimation variance is accepted (Journel and Huijbregts, 1978). An alternative method is the systematic search method, first suggested by Delhomme and Delfiner (1973), which is based on the sequential choice of one additional measurement point at each stage (Carrera et al., 1984). These two methods do not yield optimal solutions since the selection of the measurement points is not performed simultaneously for the final solution to be optimal. Hughes and Lettenmaier (1981) suggested the linearization of the estimation variance and the solution of a linear programming problem, but this linearization results in suboptimal solution. Szidarovszky (1983) then developed an optimization algorithm where the optimal measurement point location is selected from a finite set of alternatives.

Kriging has been extensively applied to groundwater hydrology (e.g., Delhomme, 1979; Gambolati and Volpi, 1979; Chirlin and Dagan, 1980; Sophocleous et al., 1982; Clifton and Neuman, 1982; Aboufirassi and Marino, 1983; Yeh et al., 1983). In these studies, kriging was used mainly as a tool for the interpolation of either hydraulic conductivities or heads. The kriging variance can be utilized as a guideline for optimal sampling. For instance, the area with the highest level of estimation uncertainty can be targeted for further monitoring.

It is well known that one of the most advantageous features of the kriging is that the estimation variance, which measures the uncertainty of the estimation, can be computed before the actual measurements are taken. This feature suggests its application to the design of 
monitoring networks for locating points at which the measurements would minimize the estimation variance.

In a general case the procedure involved in the kriging-based network design would be: 1) selection of a finite set of points as potential (additional) measurement points, which can be done based on actual possibility of sampling, such as in the case of existing wells, or legal limitations, such as in the case of private properties, etc., 2) Estimation of the variogram through available data, prior experience, etc., and validating it, if possible, 3) solving for optimal set of measurement points, and 4) performing a sensitivity analysis.

Olea (1984) used universal kriging, an unbiased linear estimator with minimum estimation variance properties based upon the theory of regionalized variables for sampling design, and considered the average standard error and maximum standard error of estimation over the sampling domain as global indices of sampling efficiency. This study treated the specific problem of sampling mappable geologic properties, the large class of regionalized variables whose observations can be regarded as points in two-dimensional space.

One of the main advantages of the variance reduction or kriging-based approach is that the estimation variance does not depend on the measured parameter values, but only on the location of the measurement points. Also, this method does not impose any restriction on the kriging method, and thus it can be applied to the design of measurement networks of any variable that can be considered regionalized. Carrera et al. (1984) also show that this method is not very sensitive to small variations in the variogram parameters because it does not rely on the absolute value of the variance, but on its relative variation from point to point.

McLaughlin and Graham (1986) approach the monitoring network design problem by estimating information return due to the decrease in predicted concentration uncertainty, which is achieved when new wells are added to an existing network. Their study focuses on the problem of defining the extent of an existing three-dimensional contaminant plume that is changing slowly, compared to the time scale of the monitoring program. Predicted concentration uncertainty is derived from a co-kriging algorithm, which estimates the concentration field from point measurements of hydraulic conductivity, head, and concentration. The only prior information required for implementing this approach is the form of the covariance function assumed for the hydraulic conductivity field, and its parameters, the variance, and correlation scales.

Variance-reduction Analysis

The kriging approach ignores the overall effect of a new measurement on the level of accuracy of the estimated field as a whole. In particular, it overlooks the influence of added data on the estimation variances of other interpolated values. Rouhani (1985) proposes an algorithm to establish a measure for such an influence. This study presents an algorithm for optimal data collection in random fields, the so-called variance-reduction analysis, which is an extension of kriging. The variance-reduction analysis is usually used to select a sequence of $n$ points from $m$ potential sites to maximize reduction in the total variance of estimates. In these procedures, the criteria of site selection are such that they give more priority to points with high estimation variances, regardless of their estimated magnitudes. These criteria are suitable for cases where the estimated value of the variable of concern is not of primary importance.

The approach adds the sampling site that contributes most to the reduction of the variance of estimation error (of the variable of interest) associated with a set of established sampling 
locations. This is an iterative technique, which adds the additional sampling location that reduces the estimation variance the most. The addition continues until the variance of estimation cannot be further reduced, or when some other constraints are violated.

The purpose of the monitoring design in this case is the mapping and understanding of regional variables or random fields. The basis of this approach is the use of information response functions, which give the amount of information gain at an arbitrary point due to a measurement at another site. The search for a groundwater monitoring network configuration starts with a number of existing sample wells to which additional wells from a pool of potential sites are added, one at a time. The site of each additional well is chosen to produce the largest added information until the estimation variance can no longer be (or can only marginally be) reduced, or when the marginal gain in statistical accuracy is outweighed by other constraints, such as limited budgets.

Two optimality criteria are utilized for the ranking of potential sampling sites. The first one reflects the amount of information gain (i.e., the variance reduction) due to a new measurement. The second function is proportional to the expected economic gains (i.e., the loss reduction) due to further sampling. Rouhani (1985) proposes the use of loss functions to convert the increase in accuracy into a tangible monetary term. The derivation of a realistic loss function, however, is not an easy task, as is shown in such works as Bras and Rodriquez-Iturbe (1976a, 1976b) and Bogardi and Bardossy (1985). Marin et al. (1989) presented a method for making regulatory decisions regarding waste disposal facilities that incorporated uncertainty and allowed for a small set of monitoring alternatives to be evaluated based on the predicted reduction in the concentration variance.

Variance-reduction analysis depends only on the covariance function and the geometry of points. This property, in turn, implies that the new added values should comply with the estimated covariance function. The statistical nature of the variance-reduction approach limits its capability to incorporate complex hydrogeologic settings, and it is most useful when the environmental variable of interest has a homogeneous and isotropic spatial behavior (Loaiciga et al., 1992).

\section{Optimization Approaches}

In these approaches, the groundwater quality monitoring network design is posed as a mathematical programming problem. Therefore, there is always an objective function, such as minimizing the estimation variance of groundwater quality indicators such as contaminant concentration (Knopman and Voss, 1988a; Loaiciga, 1989). The objective function is normally subject to different constraints such as resource constraints, the governing equations of the physical processes (e.g., hydrodynamic dispersion), the statistical constraints (e.g., accuracy of groundwater quality parameter estimates (Hsueh and Rajagopal, 1988)), and areal coverage of the monitoring network. The mathematical programming problem, represented by the optimization of the objective function, subject to these constraints, is then solved by appropriate algorithms. In cases where the key outputs of the optimization approach are the location of sampling sites from a pool of potential sites, the corresponding programming problem usually requires the use of integer or binary variables.

Hudak and Loaiciga (1992) provide an alternative approach to the statistically based variance-reduction approaches for groundwater quality monitoring network augmentation. Their heuristic approach, based on facility location theory, is defined by the sequence of steps: 1) defining a grid containing possible monitoring sites, 2) locating the existing well sites on the 
grid, 3) calibrating the groundwater flow and mass transport model to concentrations obtained from existing wells, 4) using the calibrated concentrations as nodal weights in a modified MCLP formulation, and 5) solving the formulation for progressively higher values of a covering distance threshold until a specified areal coverage is achieved. They used this approach to augment an existing network in an aquifer contaminated by an older landfill.

Meyer and Brill (1988) presented a simulation-optimization method for the optimal design of a monitoring network using the MCLP formulation. The groundwater monitoring network design presented by Meyer and Brill (1988) considers two objectives only: minimization of the monitoring network cost and maximization of the probability of detecting a contaminant before it reaches a compliance boundary (Meyer et al., 1994). A third network design objective often considered important is minimizing the extent of contamination; a network should detect a contaminant leak while the plume is still small.

Meyer et al. (1994) presented a method that incorporates system uncertainty in monitoring network design and provides network alternatives that are noninferior with respect to several objectives. A noninferior solution to a multi-objective problem is a solution for which the value of any objective cannot be improved without simultaneously making the value of another objective worse. That is, noninferior solutions can only be ranked by applying relative preferences for the multiple objectives. The design objectives they considered are 1) to minimize the number of monitoring wells, 2) to maximize the probability of detecting a contaminant leak, and 3) to minimize the expected area of contamination at the time of detection. Meyer et al. (1994) argue that few monitoring network design methods presented in the literature have incorporated all of the features mentioned above: multiple objectives, uncertainty analysis, and generation of noninferior alternatives.

Meyer et al. (1994) formulated their network design problem as a multi-objective, integer programming problem and used simulated annealing to solve it. They also performed a sensitivity analysis, which showed that the predicted performance of a given number of wells decreases significantly as the heterogeneity of the porous medium increases. In addition, a poor estimate of hydraulic conductivity was shown to result in optimistic estimates of network performance. One limitation of this method is its large computational requirement.

Storck et al. (1997) extended the approach of Meyer et al. (1994) to include a fully threedimensional model of the aquifer, contaminant transport, and monitoring wells. Each well in Storck et al.'s (1997) method is restricted to only one continuous screened interval; however, the screened length for each candidate well need not be the same.

Hsueh and Rajagopal (1988) tried to formulate certain decision components of a groundwater quality monitoring strategy in an optimization model and tried to test and compare two configurations of this model in the case of the Cambrian-Ordovician aquifer in Iowa. Their study has indicated that there is no single or a globally optimal set of sampling decisions that is superior to all others under any circumstances.

Knopman and Voss (1988) developed an approach based on statistical analysis and the onedimensional advection equation and applied it to the choice of sampling locations and the sampling times in one-dimensional settings. They proposed a multi-objective formulation of sampling network design for site characterization and considered three objectives: model discrimination, parameter estimation, and cost minimization. Cleveland and Yeh (1991) proposed a dynamic programming approach for configuring and scheduling a monitoring network. Other studies (Andricevic, 1990; Tucciarelli and Pinder, 1991; Lee and Kitanidis, 1991; 
McKinney and Loucks, 1992) have emphasized the role and utility of monitoring network design in remediation.

Hsueh and Rajagopal (1988) used an analytical optimization in the selection of sampling sites. The simulation approach was used by Meyer and Brill (1988) and Massmann and Freeze (1987), who focused on the problem of sampling well locations. Besides sampling sites, van Geer (1987) and Andricevic (1989) used the simulation to account for a temporal sampling, by specifying sampling frequency as well.

Loaiciga (1989) developed a similar approach using a mixed integer-programming framework for the optimization problem and applied the approach to a two-dimensional conceptualization of a buried valley aquifer in Butler County, Ohio. Loaiciga (1989) used two mixed-integer programming models for designing time-dependent and time-independent groundwater quality monitoring networks. The method represents a generalization of the timeindependent kriging formulation to account for time dependence, by specifying the fixed measurement frequency within the sampling horizon.

The optimization techniques employed in Loiciga's (1989) approach is analytical in nature. Whereas the analytical approach is based on a derivation of the first two moments (mean and covariance) of spatial-temporal solute concentration, the simulation approach (e.g., Massmann and Freeze, 1987a, b; Meyer and Brill, 1988) attempts to reproduce the statistical behavior of solute distribution by repeated generation of synthetic plume realizations.

Andricevic (1990) tried to address the problem of designing a cost-effective groundwater flow monitoring network with focus on temporal sampling. He proposed a methodology that couples three methods: 1) stochastic groundwater flow simulation with first- and second-moment analysis to evaluate the effects of parameter uncertainty, 2) simulation algorithm for obtaining the variances of the piezometric level estimates at the end of the sampling horizon, and 3) branch-and-bound algorithm for solving the mathematical programming problem of finding an optimal temporal monitoring network design. Carrera et al. (1984) used the branch-and-bound algorithm for the spatial sampling design.

Purwar (1991) and Datta and Purwar (1992) presented modifications to the MCLP formulation of Meyer and Brill (1988). Hudak and Loaiciga (1993) presented a methodology to design a quality monitoring network for early detection of contamination in an uncontaminated multi-layered aquifer system, but uncertainty was not considered in the analysis. Hsu and Yeh (1988) proposed a mixed-integer programming method and used it for sampling aquifer properties. Ben-Jemaa et al. (1994) proposed a multivariate, geostatistical approach for the design of monitoring networks and showed its successful application in a real-case study to observe aquifer transmissivity and specific capacity. Hudak et al. (1995) presented a monitoring network design method in multi-layered regional aquifers by extending the approach of Hudak and Loaiciga (1993).

Montas et al. (2000) used an optimization technique to characterize contaminant plumes in stochastic flow fields. The approach incorporated the time dimension directly into the objective function, which is maximized using direct partial enumeration guided by physical considerations related to transport processes. The result of the model is a set of monitoring well locations and a sampling schedule that minimizes plume characterization errors (in terms of plume spatial moments) while satisfying constraints on the maximum number of wells and allowable number of active wells. 
Reed et al. (2000) developed an optimization methodology for sampling plan design for the purpose of reducing the costs associated with long-term monitoring of sites with groundwater contamination. The method combines a transport model, plume interpolation, and a genetic algorithm technique to identify cost-effective monitoring plans that accurately quantify the total mass of dissolved contaminant. Application of this methodology to an actual field site indicated that sampling costs could be reduced by as much as 60 percent without significant loss in accuracy of the global mass estimates (Reed et al., 2000).

The optimization approach is appealing because, in principle at least, it yields optimal sampling locations and sampling times while considering a variety of restrictions on the sampling plan (Loaiciga et al., 1992). However, some of the most advanced applications reported to date (that incorporate the contaminant transport equations as constraints) have obvious limitations. Such limitations concern mainly the required simplifications of the hydrogeological setting that must be conducted to prevent the network design problem from becoming cumbersome.

A shortcoming of many optimization-based methods for groundwater quality monitoring network design is their static nature, i.e., they yield sampling networks that do not consider the iterative nature of many typical groundwater quality monitoring activities. It should be noted that in all variance-based techniques (i.e., global, variance reduction, or optimization), it is implicitly assumed that the results of new measurement do not cause any significant change in the assumed statistical structure (e.g., covariance or semi-variogram) of the variable of interest. The assumption of the constancy of the statistical structure has been tested by Rouhani and Fiering (1986) for variance-reduction analysis. They observed that "even slight levels of simulated noise in the input data cause significant changes in the general pattern of the estimated covariance function. On the contrary, the instability of the parameter space has a negligible effect on the action space (i.e., the results of sampling network design)." Therefore, it may be concluded that despite the questionable nature of the covariance constancy assumption, it does not necessarily influence the results significantly (Loaiciga et al., 1992).

Finally, one of the major disadvantages of variance-based techniques stems from the fact that in a practical sense, the objective of minimizing the estimation variance is practically intangible and not easily understood by decision makers. For example, while a planner can easily evaluate the cost of an additional sampling, the resulting benefits (i.e., improvement in accuracy) remain rather elusive (Loaiciga et al., 1992). In other words, minimization of the estimation variance, as desirable as it may be, is not necessarily a realistic goal in sampling design.

\subsubsection{Probability-based Approach}

In the presented variance-based approaches, the primary objective is to maximize the information gain, represented by the minimization of the estimation variance. However, as stated by Rouhani and Hall (1988), these approaches give more priority to points with high estimation variance, regardless of their estimated magnitudes. Such variance-based criteria are not suitable for a typical groundwater quality monitoring activity, where planners not only desire to gain as much information as possible, but also to be able to monitor areas where the variable of concern exhibits critical values. This implies that the selection criterion should be modified to include both accuracy (represented by the estimation variance) and the magnitude of the estimated values (such as contaminant concentrations). 
Rouhani and Hall (1988) proposed a network design problem that incorporates the level of the variable in question (e.g., contaminant concentration) and its variance of estimation. To accomplish this task, Rouhani and Hall (1988) propose a sampling scheme that is based on three ranking criteria. The first one is a variance-reduction criterion, which ranks the potential sampling points according to their variance-reduction capabilities. This criterion is primarily concerned with the accuracy of the estimated values. The second criterion is the median ranking, which considers only the magnitude of the estimates. The third sampling criterion is the risk ranking, which is based on both the accuracy and the magnitude of the estimated values. This implies that the selection criterion includes both the accuracy and the magnitude of the estimated values of the variable of interest.

This objective can be accomplished by utilizing the risk value as an alternative selection criterion. The risk value is defined as the value of the variable of interest whose probability of exceedence is $\alpha$ percent. For example, the risk value for a log-normally distributed variable can be written as (Rouhani and Hall, 1988):

$$
Z_{\alpha}(\boldsymbol{x})=\exp \left\lfloor E\{\ln [Z(\boldsymbol{x})]\}+z_{\alpha}(\operatorname{Var}\{\ln [Z(\boldsymbol{x})]\})^{1 / 2}\right\rfloor
$$

where $Z_{\alpha}(\boldsymbol{x})$ defines the risk value at location $\boldsymbol{x}$ with the probability of exceedence of $\alpha$ percent, $Z(x)$ is the random variable of interest at location $\boldsymbol{x}$, $\operatorname{Var}()$ is the variance, and $z_{\alpha}$ is the standard normal variable with a probability of exceedence of $\alpha$ percent.

Therefore, at each round of kriging, the point with maximal risk value is identified as the next best sampling site, which will yield an ordered list of points for site selections. As the level of risk, $\alpha$, is reduced, more weight will be given to the variance. It can thus be inferred that variance-reduction analysis is an extreme case of risk ranking when variance has the complete weight. On the other extreme, when $\alpha=50$ percent, we have the median ranking that totally ignores the accuracy of the estimates (Rouhani and Hall, 1988). The method is flexible and by, for instance, reducing the exceedence probability level, Rouhani and Hall (1988) showed that their method would become similar to minimizing the estimation variance. They also showed that their method could identify critical sampling sites, i.e., those with a high likelihood of detecting high concentration levels.

Morisawa and Inoue (1991) presented a network design method that incorporated uncertainty and multiple objectives, including the minimization of cost, maximization of the probability of detection, and minimization of the expected time to detect a contaminant leak. They reduced the problem to a single objective using multi-attribute utility theory (Keeney and Raiffa, 1976) and solved for the network with the greatest expected utility using an enumerative search procedure. Their procedure guarantees detection of the contaminants given data on the probability of detection at different points in the saturated zone. The well selection is accomplished using a two-step procedure: 1) a Monte Carlo simulation of flow and contaminant transport in the saturated zone, and 2) utilization of "fuzzy" theory, comprised of a set of mathematical techniques to deal with uncertainty in a wide range of man-machine interface issues, to assist in the design of a monitoring well network. The procedure requires a mathematical description of a four-attribute design problem using fuzzy utility functions and fuzzy weights. An optimum monitoring well network is then defined as the network having maximum total utility, which is evaluated as a fuzzy expectation of weighted arithmetic sums of the four utilities. One result of the simulation is the definition of relationships between the 
contaminant of interest and precursor materials. The precursor material can then serve as an "indicator" for faster detection of contaminant leaked from solid-waste landfill sites.

Wilson et al. (1992) presented a method that incorporated uncertainty in the contaminant source location and can be used to evaluate network alternatives with respect to the probability of detection. Datta and Dhiman (1996) proposed a chance-constrained model to design a groundwater quality monitoring network. They used the objective of maximizing the probability of detecting contamination at locations where a specified standard concentration was exceeded. They incorporated the uncertainties by perturbing the response matrix.

Warrick et al. (1998) probabilistically analyzed monitoring systems for detecting subsurface contaminant plumes. They place irregular arrays of monitoring wells in the simulation domain and try to evaluate their detection probability of random contaminant releases (or releases with nonuniform probabilities of occurring at a particular location) that are elliptical in shape. Their analysis results in statistical probabilities of detecting releases of different sizes by the set of sampling points.

\section{$\underline{\text { 3.3.3 Bayesian Decision Analysis }}$}

Decision analysis is the branch of systems analysis that allows for the determination of the best alternative from a set of alternative courses of action. It does not claim to provide an optimal solution across all the system variables, as do more sophisticated optimization techniques such as linear and nonlinear programming; only the best alternative from a finite set of possibilities is identified.

A major difference, in general, between work in sampling network design and work based on Bayesian decision analysis, such as the work by James and Gorelick (1994), lies in their goals. The goal in optimal network design has been to minimize sampling costs while estimating some quantity, such as the water table elevation, to a specified precision. The goal in Bayesian decision analysis is to estimate whether additional information will save more money than it costs (James and Gorelick, 1994).

This analysis may become useful in cases when the modeling results are highly uncertain and new field activities for data collection are to be designed. Also, in cases when the collected validation data indicate model deficiencies and new data are needed to better conceptualize the problem at hand. In such cases, the Bayesian decision analysis is used to determine the most cost-beneficial characterization activities for reducing model uncertainty or enhancing system understanding and conceptualization.

\subsubsection{Transfer Function Approach}

In classical optimization-simulation approaches, numerical modeling of flow and transport cannot be avoided and therefore the numerical grid configuration employed in these models has a direct implication on the design of the monitoring network. In the geostatistical method (e.g., kriging and co-kriging) sampling network design is based on estimating the point or spatial averaged variances of the variable of interest. This requires a substantial amount of existing data to estimate the sample variogram, particularly to estimate the variogram range (Andricevic and Foufoula-Georgiou, 1991). When data are limited, which is usually the case, one alternative is to use covariances to describe spatial statistics. The covariances can be estimated either through first-order analysis of the flow and transport equations (e.g., Loaiciga, 1989; Andricevic, 1990) or by applying inverse Fourier transform on spectra of concentration, head, and hydraulic conductivity (McLaughlin and Graham, 1986). To avoid the computational burden involved in 
these alternatives, Andricevic and Foufoula-Georgiou (1991) presented a sampling design methodology that relies on using a transfer function in the frequency domain to act upon the concentration spectrum and provide the sampling error variance, which is used as a measure of sampling performance. Their methodology does not require numerical solution of either flow or transport equations and it relies mainly on the statistics of the concentration field evaluated using spectral representation.

\subsection{Comparison of Studies}

Table 1 shows a summary of about 20 studies that focus on monitoring network design. The studies are classified in terms of the objective of the monitoring network and the design approach developed or implemented. Also, the table provides the information about the application of the monitoring design approach to real field problems or hypothetical ones. In particular, the size of the studied domain in each study as well as the size of existing and developed monitoring networks are presented whenever applicable in Table 1.

As can be seen from the table, many of the presented studies deal with regional aquifers where large numbers of wells exist and provide important data to aid the network design or the network augmentation analysis. Also, it is important to mention that all of the studies in the table deal with very shallow aquifers (at most $30 \mathrm{~m}$ deep) and thus can propose monitoring networks with size in the range of tens of wells. The shallow depth of contamination and the associated low well installation costs are an advantage when it comes to monitoring network design as will be discussed in Section 4.1.

It is also important to note that most of the studies listed rely on a combination of tools in the design process. The classification of design methodologies presented earlier was aimed at organizing the discussion and recognizing the breadth of tools and approaches proposed and used for network design or network augmentation. It may, therefore, be expected that efficient design methodologies rely on combining many of the tools shown in Figure 2.

\section{ISSUES AND CONSIDERATIONS}

It is well known that the collection of data in the subsurface is a time-consuming and expensive activity. Limited resources are very often the reason for the inadequate site characterization, such that resulting management decisions have to be made in the face of incomplete data and insufficient resources (Andricevic, 1996). These decisions can result in a costly over-design to compensate for unavoidable uncertainty or a minimal cost solution, which can lead to further environmental deterioration. In both cases, there is a clear need to get the most out of the data and to allocate future resources for data collection that will provide the largest return. It is hoped that this need will be met by implementing a staged approach to the long-term monitoring design of the CNTA area as will be discussed later in Section 5. A discussion of the major issues and considerations that should be evaluated when designing the long-term monitoring plan for the site follows.

\subsection{Cost Issues}

The cost of data collection is typically one of the largest components of the clean-up cost of a site. Collection and chemical analysis of a single water sample, for instance, may require thousands of dollars (James and Gorelick, 1994). These statements highlight that the cost of running the monitoring program is a major element of consideration in most groundwater contamination problems in shallow aquifers. In deep subsurface contamination, as is the case for 
Table 1. Summary of a number of studies on monitoring network design.

\begin{tabular}{|c|c|c|c|c|c|c|c|}
\hline \multirow{2}{*}{ Study } & \multirow{2}{*}{$\begin{array}{l}\text { Monitoring } \\
\text { Objective }\end{array}$} & \multirow{2}{*}{ Design Methodology } & \multirow{2}{*}{ Purpose of Study } & \multirow{2}{*}{$\begin{array}{l}\text { Area of Studied } \\
\text { Domain }\end{array}$} & \multicolumn{2}{|c|}{ Number of Wells } & \multirow{2}{*}{ Comments } \\
\hline & & & & & Existing & $\begin{array}{l}\text { Design } \\
\text { Output }\end{array}$ & \\
\hline $\begin{array}{l}\text { Carrera et al. } \\
\text { (1984) }\end{array}$ & $\begin{array}{l}\text { Characterization } \\
\text { (Augmentation) }\end{array}$ & $\begin{array}{l}\text { Statistical (ordinary } \\
\text { kriging) }\end{array}$ & $\begin{array}{l}\text { Minimize estimation variance of } \\
\text { fluctuating concentration }\end{array}$ & $2.5 \times 5.0 \mathrm{~km}^{2}$ & $\begin{array}{l}5 \mathrm{w} / \text { and } \\
9 \mathrm{w} / \mathrm{o} \\
\text { data }\end{array}$ & $\begin{array}{l}4 \text { out of } 9 \\
\text { available } \\
\text { wells }\end{array}$ & $\begin{array}{l}\text { Case study is the San } \\
\text { Pedro River Basin, } \\
\text { Arizona }\end{array}$ \\
\hline Olea (1984) & $\begin{array}{l}\text { Characterization } \\
\text { (Augmentation) }\end{array}$ & $\begin{array}{l}\text { Statistical (universal } \\
\text { kriging) }\end{array}$ & $\begin{array}{l}\text { Improve sampling pattern for } \\
\text { monitoring water table }\end{array}$ & $800 \mathrm{mi}^{2}$ & 244 & $\begin{array}{l}47 \text { alternative } \\
\text { sampling }\end{array}$ & $\begin{array}{l}\text { Equus Beds Aquifer, } \\
\text { Central Kansas }\end{array}$ \\
\hline Rouhani (1985) & $\begin{array}{l}\text { Characterization } \\
\text { (Mapping water } \\
\text { table level) } \\
\text { (Augmentation) }\end{array}$ & $\begin{array}{l}\text { Statistical (variance- } \\
\text { reduction analysis) }\end{array}$ & $\begin{array}{l}\text { Mapping water table and reducing } \\
\text { its estimation variance }\end{array}$ & $2,048 \mathrm{mi}^{2}$ & 84 & 20 & $\begin{array}{l}\text { Groundwater } \\
\text { Management District } \\
\text { no. } 4 \text { of Kansas }\end{array}$ \\
\hline $\begin{array}{l}\text { McLaughlin and } \\
\text { Graham (1986) }\end{array}$ & $\begin{array}{l}\text { Plume } \\
\text { characterization } \\
\text { (Augmentation) }\end{array}$ & $\begin{array}{l}\text { Co-kriging and first- } \\
\text { order stochastic analysis } \\
\text { to get } \sigma_{C}^{2}\end{array}$ & $\begin{array}{l}\text { Monitoring groundwater } \\
\text { contamination }\end{array}$ & NA & NA & NA & No case study \\
\hline $\begin{array}{l}\text { Massmann and } \\
\text { Freeze }(1987 a, b)\end{array}$ & $\begin{array}{l}\text { Detection } \\
\text { monitoring } \\
\text { (Network design) }\end{array}$ & $\begin{array}{l}\text { Simulation and } \\
\text { probability }\end{array}$ & $\begin{array}{l}\text { Studying interaction between } \\
\text { risk-based engineering design, } \\
\text { monitoring, and regulatory policy }\end{array}$ & $0.4 \times 1.0 \mathrm{~km}^{2}$ & 0 & 9 & $\begin{array}{l}\text { Hypothetical case } \\
\text { study }\end{array}$ \\
\hline $\begin{array}{l}\text { Rouhani and } \\
\text { Fiering (1986) }\end{array}$ & $\begin{array}{l}\text { Characterization } \\
\text { (Mapping water } \\
\text { table level) } \\
\text { (Augmentation) }\end{array}$ & $\begin{array}{l}\text { Variance-reduction } \\
\text { analysis }\end{array}$ & $\begin{array}{l}\text { Testing the resilience and } \\
\text { robustness of variance reduction }\end{array}$ & $40 \times 80 \mathrm{mi}^{2}$ & 84 & 10 & Northwestern Kansas \\
\hline $\begin{array}{l}\text { Rouhani and Hall } \\
\text { (1986) }\end{array}$ & $\begin{array}{l}\text { Ambient } \\
\text { monitoring } \\
\text { (Augmentation }\end{array}$ & $\begin{array}{l}\text { Variance-reduction and } \\
\text { risk-based }\end{array}$ & $\begin{array}{l}\text { Establishing a regional } \\
\text { monitoring of groundwater } \\
\text { quality in a shallow aquifer }\end{array}$ & $90 \times 100 \mathrm{mi}^{2}$ & 29 & $\begin{array}{l}32 \text { potential } \\
\text { sampling }\end{array}$ & $\begin{array}{l}\text { Dougherty Plain, } \\
\text { S.W. Georgia }\end{array}$ \\
\hline $\begin{array}{l}\text { Meyer and Brill } \\
(1988)\end{array}$ & $\begin{array}{l}\text { Detection } \\
\text { monitoring } \\
\text { (Network design) }\end{array}$ & $\begin{array}{l}\text { Simulation MC and } \\
\text { optimization using } \\
\text { MCLP }\end{array}$ & $\begin{array}{l}\text { Design a monitoring network that } \\
\text { maximizes the detection } \\
\text { probability }\end{array}$ & $500 \times 600 \mathrm{~m}^{2}$ & 0 & 4 to 6 & Hypothetical case \\
\hline $\begin{array}{l}\text { Hsueh and } \\
\text { Rajagopal (1988) }\end{array}$ & $\begin{array}{l}\text { Ambient } \\
\text { monitoring } \\
\text { (Network design) }\end{array}$ & $\begin{array}{l}\text { Optimization using } \\
\text { integer programming }\end{array}$ & $\begin{array}{l}\text { Modeling groundwater quality } \\
\text { sampling decisions }\end{array}$ & NA & 669 & $\begin{array}{l}53 \text { to } 124 \text { out } \\
\text { of the } 669 \\
\text { wells }\end{array}$ & $\begin{array}{l}\text { Cambrian-Ordovician } \\
\text { Aquifer, Iowa }\end{array}$ \\
\hline Loaiciga (1989) & $\begin{array}{l}\text { Ambient/detection } \\
\text { monitoring } \\
\text { (Augmentation) }\end{array}$ & $\begin{array}{l}\text { Optimization using } \\
\text { mixed-integer } \\
\text { programming }\end{array}$ & $\begin{array}{l}\text { Design a groundwater quality } \\
\text { temporal monitoring plan }\end{array}$ & $2.5 \times 1.7 \mathrm{~km}^{2}$ & $\begin{array}{l}12 \mathrm{w} / \\
\text { data and } \\
203 \\
\text { possible }\end{array}$ & $\begin{array}{l}76 \text { wells }(12 \\
\text { original }+64)\end{array}$ & $\begin{array}{l}\text { Bulter County } \\
\text { Landfill, Ohio }\end{array}$ \\
\hline Andricevic (1990) & $\begin{array}{l}\text { Ambient } \\
\text { monitoring or } \\
\text { characterization } \\
\text { (Augmentation) }\end{array}$ & $\begin{array}{l}\text { Optimization using } \\
\text { branch-and-bound } \\
\text { technique }\end{array}$ & $\begin{array}{l}\text { Cost-effective network design for } \\
\text { regional groundwater flow } \\
\text { monitoring }\end{array}$ & $7.7 \mathrm{~km}^{2}$ & 8 & $4-12$ & $\begin{array}{l}\text { Pomona County } \\
\text { Basin, California }\end{array}$ \\
\hline
\end{tabular}


Table 1. Summary of a number of studies on monitoring network design (continued).

\begin{tabular}{|c|c|c|c|c|c|c|c|}
\hline \multirow{2}{*}{ Study } & \multirow{2}{*}{$\begin{array}{l}\text { Monitoring } \\
\text { Objective }\end{array}$} & \multirow{2}{*}{ Design Methodology } & \multirow{2}{*}{ Purpose of Study } & \multirow{2}{*}{$\begin{array}{l}\text { Area of Studied } \\
\text { Domain }\end{array}$} & \multicolumn{2}{|c|}{ Number of Wells } & \multirow{2}{*}{ Comments } \\
\hline & & & & & Existing & $\begin{array}{l}\text { Design } \\
\text { Output }\end{array}$ & \\
\hline $\begin{array}{l}\text { Morisawa and } \\
\text { Inoue (1991) }\end{array}$ & $\begin{array}{l}\text { Detection } \\
\text { monitoring } \\
\text { (Network design) }\end{array}$ & $\begin{array}{l}\text { Probability-based using } \\
\text { fuzzy utility }\end{array}$ & $\begin{array}{l}\text { Optimum allocation of } \\
\text { monitoring wells around a landfill } \\
\text { site }\end{array}$ & $580 \times 940 \mathrm{~m}^{2}$ & 0 & 3 to 5 & Hypothetical case \\
\hline $\begin{array}{l}\text { Knopman et al. } \\
\text { (1991) }\end{array}$ & $\begin{array}{l}\text { Research } \\
\text { monitoring } \\
\text { (Network analysis) }\end{array}$ & $\begin{array}{l}\text { Optimization using } \\
\text { direct enumeration }\end{array}$ & $\begin{array}{l}\text { Model discrimination and } \\
\text { parameter estimation }\end{array}$ & $315 \times 75 \mathrm{~m}^{2}$ & 220 & $\begin{array}{l}\text { Subsets of } \\
220 \text { wells } \\
\text { analyzed }\end{array}$ & $\begin{array}{l}\text { Cape Cod Tracer Test } \\
\text { Data }\end{array}$ \\
\hline $\begin{array}{l}\text { Andricevic and } \\
\text { Foufoula- } \\
\text { Georgiou (1991) }\end{array}$ & $\begin{array}{l}\text { Plume } \\
\text { characterization in } \\
\text { 3-D } \\
\text { (Network design) }\end{array}$ & $\begin{array}{l}\text { Transfer function } \\
\text { approach }\end{array}$ & $\begin{array}{l}\text { Design a monitoring network for } \\
\text { solute concentration } \\
\text { characterization }\end{array}$ & $\begin{array}{l}100 \times 65 \mathrm{~m}^{2} \\
\text { depth }=30 \mathrm{~m}\end{array}$ & 0 & 50 to 300 & Hypothetical case \\
\hline $\begin{array}{l}\text { Hudak and } \\
\text { Loaiciga (1992) }\end{array}$ & $\begin{array}{l}\text { Detection } \\
\text { monitoring } \\
\text { (Augmentation) }\end{array}$ & $\begin{array}{l}\text { Optimization using } \\
\text { modified MCLP }\end{array}$ & $\begin{array}{l}\text { Location modeling approach for } \\
\text { network augmentation }\end{array}$ & $2.3 \times 1.15 \mathrm{~km}^{2}$ & 8 & 10 & $\begin{array}{l}\text { Bulter County } \\
\text { Landfill, Ohio }\end{array}$ \\
\hline $\begin{array}{l}\text { Meyer et al. } \\
\text { (1994) }\end{array}$ & $\begin{array}{l}\text { Monitoring } \\
\text { detection (Network } \\
\text { design) }\end{array}$ & $\begin{array}{l}\text { Optimization using } \\
\text { simulated annealing }\end{array}$ & $\begin{array}{l}\text { Network design to provide initial } \\
\text { detection of contaminant release }\end{array}$ & $100 \times 65 \mathrm{~m}^{2}$ & 0 & 1 to 8 & Hypothetical case \\
\hline $\begin{array}{l}\text { Mahar and Datta } \\
\text { (1997) }\end{array}$ & $\begin{array}{l}\text { Source } \\
\text { Identification } \\
\text { (Network design) }\end{array}$ & $\begin{array}{l}\text { Optimization using } \\
\text { nonlinear integer } \\
\text { programming }\end{array}$ & $\begin{array}{l}\text { Optimal design of a sampling } \\
\text { network to identify the source of } \\
\text { groundwater pollution }\end{array}$ & $1300 \times 800 \mathrm{~m}^{2}$ & 0 & 3 to 30 & Hypothetical case \\
\hline $\begin{array}{l}\text { Storck et al. } \\
\text { (1997) }\end{array}$ & $\begin{array}{l}\text { Monitoring } \\
\text { detection (Network } \\
\text { design) } \\
\text { (Augmentation) }\end{array}$ & $\begin{array}{l}\text { Optimization using } \\
\text { simulated annealing }\end{array}$ & $\begin{array}{l}\text { Network design to provide initial } \\
\text { detection of contaminant release }\end{array}$ & $\begin{array}{l}1.0 L \times 0.5 L \times 0.5 L \\
914 \times 610 \times 9 \mathrm{~m}^{3}\end{array}$ & 18 & 5 to 17 & $\begin{array}{l}\text { Hypothetical case } \\
\text { Environ. Salinity } \\
\text { Landfill, Illinois }\end{array}$ \\
\hline $\begin{array}{l}\text { Warrick et al. } \\
\text { (1998) }\end{array}$ & $\begin{array}{l}\text { Monitoring } \\
\text { detection } \\
\text { (Network design) } \\
\end{array}$ & $\begin{array}{l}\text { Probability- and } \\
\text { simulation-based } \\
\text { approach }\end{array}$ & $\begin{array}{l}\text { Analyzing monitoring systems for } \\
\text { detection of subsurface } \\
\text { contaminant plumes }\end{array}$ & $\begin{array}{l}\text { Normalized } \\
1.0 \times 1.0\end{array}$ & 0 & 11 to 224 & Hypothetical case \\
\hline $\begin{array}{l}\text { Montas et al. } \\
(2000)\end{array}$ & $\begin{array}{l}\text { Plume } \\
\text { characterization } \\
\text { (Network design) } \\
\end{array}$ & $\begin{array}{l}\text { Optimization using } \\
\text { partial enumeration }\end{array}$ & $\begin{array}{l}\text { Contaminant plume } \\
\text { characterization in stochastic flow } \\
\text { fields }\end{array}$ & $\begin{array}{l}50 \lambda \times 25 \lambda \\
\lambda \text { is the } \\
\text { correlation scale }\end{array}$ & 0 & 3 to 12 & Hypothetical case \\
\hline Reed et al. (2000) & $\begin{array}{l}\text { Plume } \\
\text { characterization } \\
\text { (Augmentation) }\end{array}$ & $\begin{array}{l}\text { Simulation and } \\
\text { optimization using } \\
\text { Genetic Algorithms }\end{array}$ & $\begin{array}{l}\text { Estimating total plume dissolved } \\
\text { mass at a minimum cost }\end{array}$ & $914 \times 914 \mathrm{~m}^{2}$ & 20 & 12 to 15 & $\begin{array}{l}\text { Hill Air Force Base, } \\
\text { Utah }\end{array}$ \\
\hline
\end{tabular}


nuclear testing sites, the major element of cost is the installation of wells. In most, if not all, of the studies reviewed in this report the depth of the aquifer and thus the well penetration depth does not exceed $30 \mathrm{~m}$ below ground surface. In such cases, the cost of installing a well will typically range from $\$ 10,000$ to $\$ 25,000$. Therefore, when a monitoring program is designed and a number of wells, between 10 and 20, need to be placed in an optimal manner, the cost encountered for installing these wells does not exceed $\$ 0.5$ million. The situation is completely different for deep subsurface contamination.

At CNTA, the depth of the nuclear test cavity is about $975 \mathrm{~m}$ below ground surface. With vertical head gradients identified in the CNTA groundwater model in the vicinity of the test cavity, the plume of radionuclides is expected to be migrating at deeper than one kilometer. Any long-term monitoring wells should therefore be placed to a depth that is at least equivalent to the expected depth to the plume migration path. The cost of installing such a well with the health and safety programs required at a DOE nuclear test site ranges from about $\$ 1$ million to a most likely estimate of about $\$ 1.5$ million. With that high level of installation cost, designing a network with a number of wells similar to the range shown in Table 1 is prohibitive and may not be a wise investment. It should also be noted that the operating costs of a monitoring network for deep subsurface contamination might be less than costs for shallow aquifers, because deeper systems typically have fewer wells compared to shallow aquifers, and because operational costs are insignificant compared to the initial investment in installing the wells.

\subsection{Uncertainty}

A major difficulty in locating monitoring wells stems from the uncertainty that is a typical characteristic of groundwater problems. In relation to monitoring network design, the main types of uncertainty affecting monitoring network design are the hydrogeological uncertainty that governs groundwater flow and contaminant transport, and the uncertainty about the exact location of the contaminant leak (Storck et al., 1997). The latter type of uncertainty is not relevant to CNTA, as the location of the source of contamination is known with certainty. The deep location of the contaminant source for CNTA exacerbates the difficulty imposed by uncertainty in a number of ways. First, having sufficient data to construct the groundwater flow and transport models, and to estimate the values of the model parameters is rather difficult. The cost element plays an important and limiting role when it comes to installing characterization wells. Second, the major assumptions and components of the conceptual models (e.g., boundary conditions and flow directions) cannot be easily verified. Such verification requires major field activities that are both time-consuming and very expensive. There is, therefore, a major element of uncertainty and difficulty associated with deep subsurface contamination that is not dealt with in shallow aquifer contamination.

The uncertainty imposed difficulties and the cost issues discussed above allude to the fact that the long-term monitoring at CNTA should be a multi-staged program in which wells are installed sequentially and model re-evaluation is performed after the collection of new information from these wells. As discussed in Section 4.1, it is not possible from a cost perspective to design a 10- or 15-well network. However, even if there is no budgetary restriction and 10 or 15 wells can be installed, one cannot base this heavy investment on the uncertain model results. The basic aspect of the flow model at CNTA, which is the flow direction, is not fully confirmed with existing data and thus cannot be used to design an extensive monitoring network. Instead, as the validation stage of the CNTA model (Hassan, 2003) progresses through incremental installation of wells, collection of new information, and 
evaluation of the model components, the long-term monitoring network will be based on the collective information from these wells and will be built over a long time frame.

\subsection{Conflicting Objectives}

As discussed earlier, monitoring programs are usually required to achieve multiple objectives, some of which may be conflicting. For example, a monitoring network for the detection of subsurface migration of contaminants from a landfill or a waste disposal facility will need to meet multiple objectives such as low cost, high detection probability, and early detection to minimize contaminated groundwater volume. These objectives conflict because an increase in the detection probability is accomplished by either installing more wells (thus high network cost) or by placing the wells further from the source, thereby increasing the average volume of contaminated groundwater (Storck et al., 1997). Because of this conflict, one optimal solution does not exist, and the trade-offs among these objectives should be considered.

For the CNTA case, the objectives of the monitoring network are to 1) provide a means for evaluating the groundwater transport model and its predictions through the validation process, 2) provide a system for early detection of radionuclide migration rates in excess of what has been predicted by the CNTA model, 3) provide a system with high detection probability that takes into account the uncertainty in the migration pathways, 4) provide assurance to the public and to the regulators that public health is not compromised, 5) achieve site closure and minimize the longterm risk of public exposure to contaminated groundwater, and 6) achieve all of these objectives at a minimum cost, or, alternatively, maximize the return on the invested budget for this effort.

It can be seen that some of these objectives are conflicting with one another. For example, the early detection objective is in conflict with the objective of high detection probability, as the former requires wells to be placed near the test cavity where a well slightly off the true flowpath may miss the plume, whereas the latter requires wells to be placed farther away from the cavity where a more dispersed plume has a higher probability of detection but also contains a larger volume of contamination. Moreover, these two objectives are in conflict with the cost minimization objective, as they require high density of wells to provide the early detection and enhance the probability of detection. It is thus important to prioritize the list of objectives and ensure that high-priority objectives are met first. This is discussed further in the proposed multistaged monitoring network development presented in Section 5.

\subsection{Design Criteria}

Selection of design criteria to assess the network performance translates mathematically into an objective function that should be either minimized (e.g., risk-based or cost-based objective function) or maximized (e.g., benefits-based or information gain-based function). The selection of a certain objective function that reflects all of the competing monitoring network objectives is a major difficulty. This, however, applies to networks that are large enough to warrant the effort for evaluating such mathematical objective functions.

For CNTA, the selection of design criteria will change over a relatively long time frame as the long-term monitoring network is developed. Initially, a number of wells will be placed to verify the flow directions and the existence of certain geologic units below the test cavity. These verification aspects are crucial to the monitoring design process, as they have direct impacts on the direction and speed of radionuclide migration from the test cavity. Also, since transport prediction extends to a 1,000-year time frame at CNTA, it is most likely that the monitoring objectives will change over time, with a hope that the final monitoring network is logically built 
through this proposed multi-staged approach. Each incremental addition to the set of monitoring wells will have to be designed in such a way that most of the objectives are met and that the appropriate mathematical objective function is used when the network becomes large enough to do so.

\section{PROPOSED MONITORING STRATEGY FOR CNTA}

In the analysis of sampling decisions, groundwater professionals wrestle with several subjective and probabilistic notions such as detection probability, acceptable precision in estimates, and the significance of health effects of various compounds. Explicitly identifying, deliberating, and building a consensus around such notions would at least lead to socioeconomically acceptable monitoring decisions (Hsueh and Rajagopal, 1988). Given these aspects, the issues discussed above, and the literature review of monitoring design studies presented in this report, a multi-staged approach for development of the long-term monitoring well network for CNTA is proposed. This multi-staged approach will proceed in parallel with the validation efforts for the groundwater flow and transport model of CNTA. Figure 3 is a schematic flow chart showing the multi-staged monitoring design approach for CNTA.

The first stage of the plan is to use the hydrogeologic approach combined with the simulation and probability based approaches to select the first set of monitoring wells that will serve two purposes or objectives. The first, high-priority objective is the collection of data for the validation of the groundwater flow and transport model. The selection criteria will thus be tailored more toward meeting this objective and facilitating the collection of the most relevant data from the most important locations for evaluating the different model components. The second objective, which has a lower priority, is to place this set of wells in locations likely to encounter fast migration pathways, and thus benefiting from the wells in the long-term monitoring of the site. The first stage will be repeated according to the progress of the CNTA model validation processes.

When the research team (DRI), the model sponsor (DOE), and regulators (NDEP) reach an agreement that sufficient confidence has been built into the model through the validation process, the second and major long-term monitoring stage will start and will be based on an optimum design methodology that uses a suitable statistical approach (e.g., probability based) combined with an optimization approach. The following subsections provide some detailed descriptions of the proposed approaches.

\subsection{First-stage Monitoring Design Approach}

As mentioned above and shown in Figure 3, the first stage monitoring design is intimately linked to the validation process and is used to aid in locating the data collection wells that will be used for evaluating the model and may also be used for long-term monitoring purposes. The design approach relies mainly on the simulation approach (using the existing CNTA model) combined with hydrogeologic expertise and probabilistic design methodology. This first stage is crucial for the following reason: the validation stage should intuitively precede the monitoring stage, because the validation process proposed for CNTA (Hassan, 2003) is a long-term process with an uncertain path, and linking the two processes from the beginning maximizes the benefits from each well drilled at the site. By keeping in mind that the validation wells will also serve the long-term monitoring purpose, one would maximize the benefit from these wells and be able to develop an efficient long-term monitoring program for the site closure. 


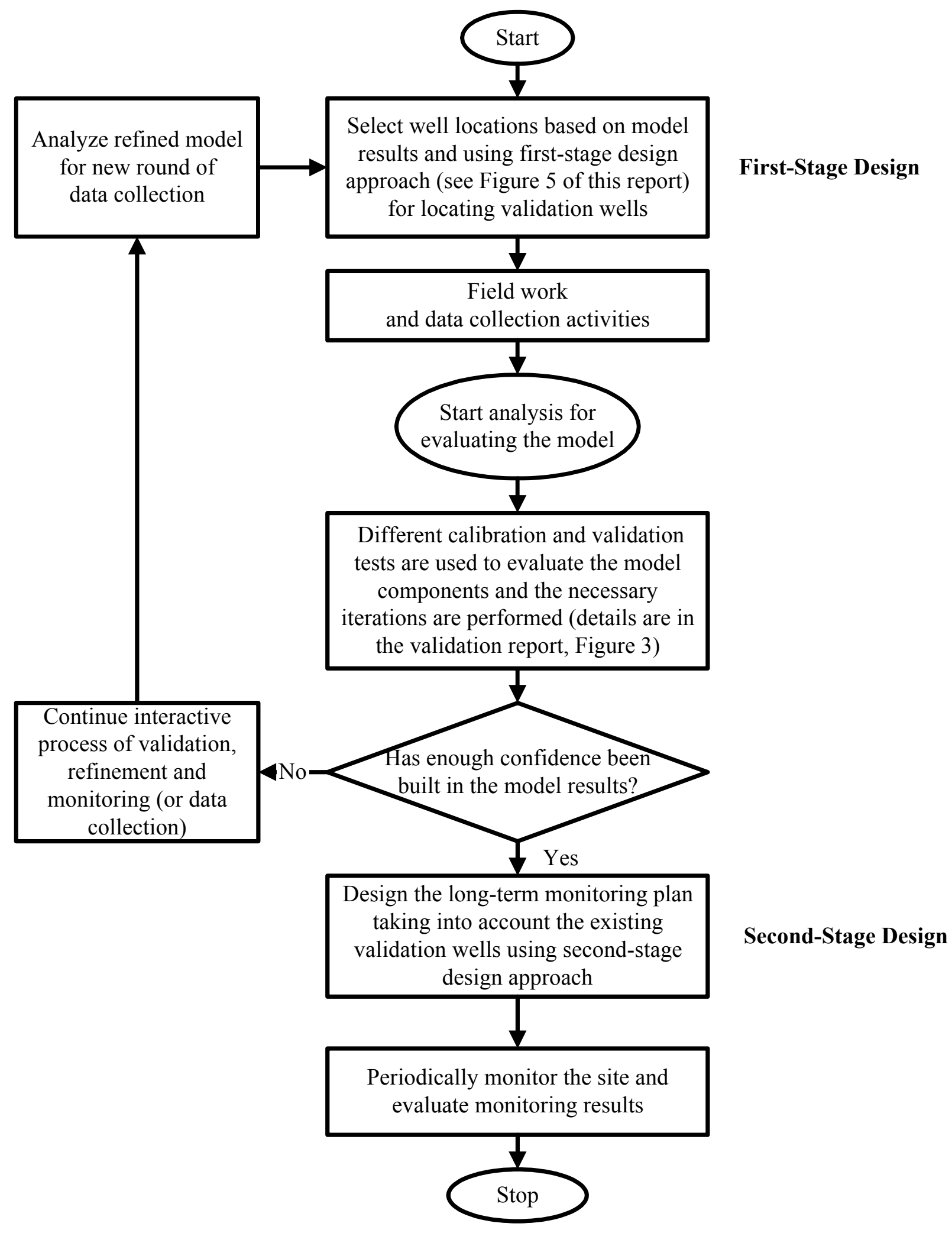

Figure 3. The multi-staged approach for the long-term monitoring network design at CNTA and the link to the validation approach. 
As mentioned earlier, the first stage of the development of the monitoring well network may be repeated depending upon the progress of the validation process. In each round of new well installation and data collection, the hydrogeologic approach combined with the suitable statistical approach will be used to locate new wells. The appropriate statistical approach may differ from one round of well selection to another depending upon the size of the existing well network and whether one can change the problem configuration from that of network design to network augmentation. Also, the objectives of the added wells may change over time leading to certain design methods becoming more suitable than others.

For illustration purposes, we hypothesize the problem of the monitoring network design (selection of the well locations for the first stage) as shown in Figure 4. The radionuclide plume emanating from the source migrates to the north and one would normally place the monitoring wells to intercept the plume. The distance along the flow direction between the working point (center of the cavity) and the control plane (CP) passing through each monitoring well is denoted as $x_{k}$. Massmann and Freeze $(1987 \mathrm{a}, \mathrm{b})$ and Meyer and Brill (1988) consider the failure of a monitoring network to occur when the monitoring network does not detect the contaminant before it reaches a compliance boundary. In fact, the probability of failure in year $t, P_{f}(t)$, is simply the probability that the time until breach of the landfill containment plus the travel time of the plume through the hydrogeological environment lies within year $t$ (Massmann and Freeze, 1987a). If these components of failure are independent, Massmann and Freeze (1987a) write

$$
P_{f}(t)=\sum_{t^{l}=0}^{t-t_{o p}}\left\{P\left(t^{\prime}=t^{l}\right) P\left(t^{\prime \prime}=t-t_{o p}-t^{l}\right)\right\}
$$

where $t$ is the time for which the calculations are carried out (year), $t_{o p}$ is the time at which the facility is put into operation (year), $t^{\prime}$ is the time until containment is breached (year), and $t^{\prime \prime}$ is the time of travel for the contaminant plume to migrate from the containment structure to the compliance surface (year). Massmann and Freeze (1987a) define the probability in Equation (2) as the failure probability of the unmonitored facility. For the monitored facility, they define the failure probability as

$$
P_{f}^{m}(t)=P_{f}(t)\left(1-P_{d}\right)
$$

where $P_{f}^{m}(t)$ is the failure probability of the monitored facility at year $t$ (i.e., the probability that containment is breached and contaminants travel through the system to the compliance boundary within year $t$ without detection), and $P_{d}$ is the probability of detection by the monitoring network.

For the CNTA case, we assume that a monitoring well fails if 1) an arbitrary percentage (e.g., 20 percent) of the plume mass crosses the CP normal to the mean flow direction and passing through the well, and 2) the well does not detect the presence of contaminants. Since these two events are independent of one another, one can define the probability of failure in year $t$ for a monitoring well located at $\mathbf{x}_{j}=\left(x_{j}, y_{j}, z_{j}\right)$, as

$$
P_{f}\left(t ; \boldsymbol{x}_{j k}\right)=P\left(\frac{1}{M_{\text {total }}} \int_{0}^{t} Q\left(\tau ; x_{k}\right) d \tau \geq \alpha\right)\left(1-P_{d j}\right)
$$




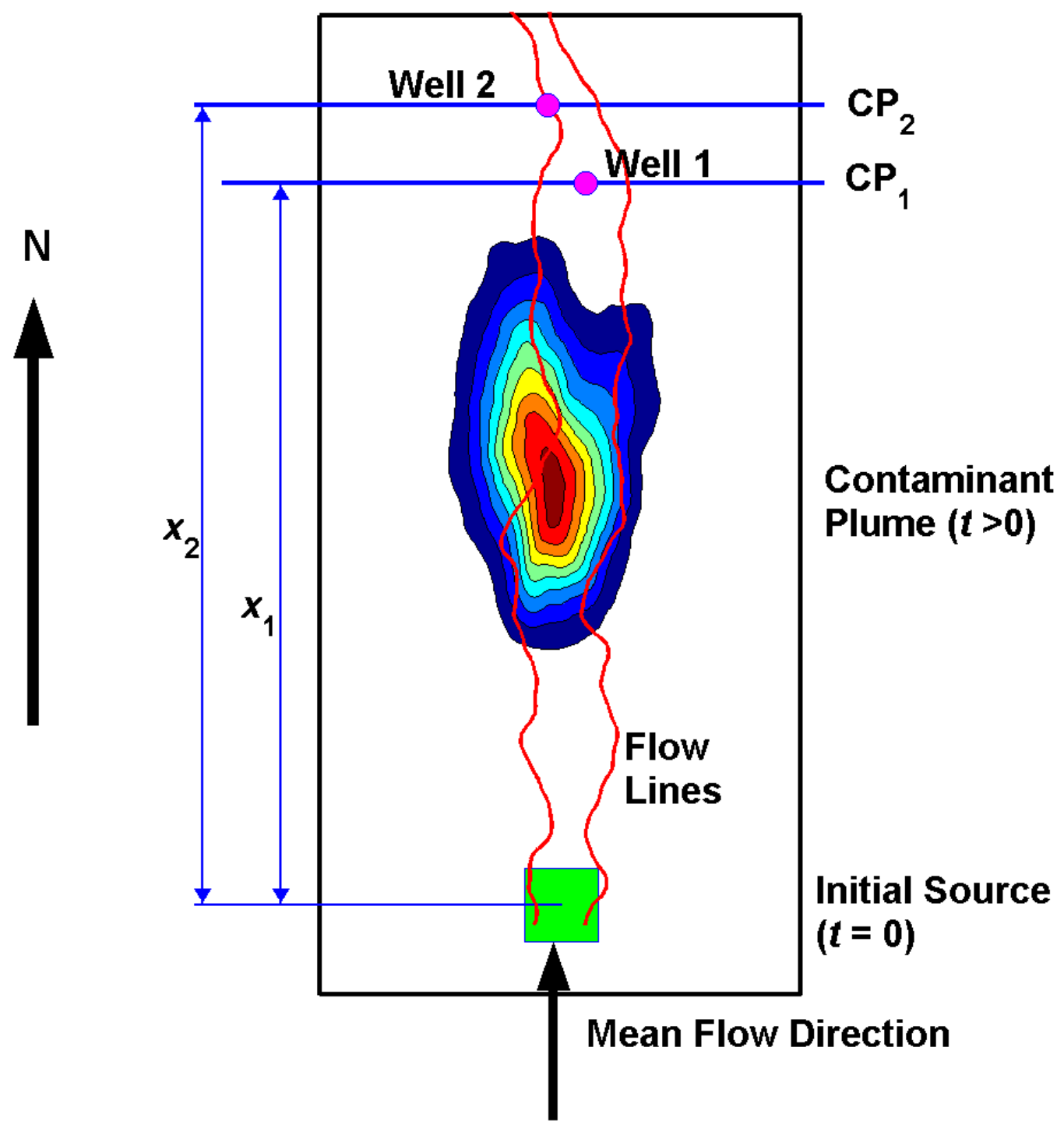

Figure 4. Schematic diagram showing the location of contaminant plume, monitoring wells, and the distances and definitions used in Equations (2) through (4).

where $P_{f}\left(t ; \mathbf{x}_{j k}\right)$ is probability that the well located at $\mathbf{x}_{j}$ will not detect the plume when $\alpha$ percent of its mass crosses the CP located at distance $x_{k}$ from the center of the source along the mean flow direction (to the north for the CNTA model) in a time frame less than or equal to $t$ years, $\int_{0}^{t} Q\left(\tau ; x_{k}\right) d \tau$ is the cumulative mass arrival to the CP located at $x_{k}, M_{\text {total }}$ is the total mass of contaminant available in the aqueous phase, and $P_{d j}$ is the probability of detection by the monitoring well located at $\mathbf{x}_{j}$. For example, if the schematic plume shown in Figure 4 splits along the two flowpaths shown, Well 1 may not detect the plume, giving a false negative. This will 
give a zero value for $P_{d 1}$, which in turn leads to a high failure probability as shown from Equation (4). Analogously, we can define

$$
P_{s}\left(t ; \boldsymbol{x}_{j k}\right)=P\left(\frac{1}{M_{\text {total }}} \int_{0}^{t} Q\left(\tau ; x_{k}\right) d \tau \leq \alpha\right) P_{d j}
$$

where $P_{s}\left(t ; \mathbf{x}_{j k}\right)$ is the success probability, that is, the probability that the monitoring well will detect the plume in year $t$ if $\alpha$ percent of its total mass or less arrives at the CP of the monitoring well by year $t$. It can be seen that for individual wells, the time-dependent probability of failure and probability of success are zero at early times and then they both start to increase when the plume reaches the $\mathrm{CP}$ where the well is located. If a certain percentage of the plume mass crosses the $\mathrm{CP}$ before the monitoring well detects any contaminants, $P_{d j}$ is zero and the success probability is zero. If the well detects contaminants before $\alpha \%$ of the mass crosses the CP, then $P_{d j}$ is 1.0 and the failure probability becomes zero. This binary decision point provides a tangible measure of success, which can be expanded to multiple wells.

The value of $P_{d j}$ can be determined from the plume migration analysis. A plume will be detected by a monitoring system only if the groundwater flow lines passing through the cavity also pass through the monitoring well (Massmann and Freeze, 1987a). In the three-dimensional model of the CNTA, wells are expected to have multi-level samplers and thus the probability of detection is increased, as any plume intersection along the well sampling intervals will lead to contaminant detection. This probability of detection by a monitoring well can be determined from Monte Carlo simulations used to predict plume migration. The detection occurs when particles representing the contaminant mass (using a particle tracking approach for modeling the transport processes) pass through any of the vertical cells where the well is located. However, to account for the temporal aspect, to overcome the issue of the classified initial source mass, and to allow for comparing different well locations, the area of the $t-z$ distribution of the normalized masses (particle masses) for a monitoring well is used as an indicator of the likelihood of detection. Thus the detection probability for a monitoring well $j$ can be obtained using Monte Carlo simulation as

$$
P_{d j}=\sum_{i=1}^{N M C} \frac{W_{j i}}{N M C}
$$

where $N M C$ is the number of Monte Carlo realizations used in the analysis and $W_{j i}$ can be obtained as

$$
W_{j i}=\int_{0}^{t} \int_{z=z_{b}}^{z=z_{t}} M_{j i}(\tau, z) d z d \tau
$$

$M_{j i}(\tau, z)$ is the resident mass in the monitoring well cell located at elevation $z$ and time $\tau, z_{b}$ is the bottom elevation of the lowest cell that can be sampled by the well, and $z_{t}$ is the top elevation of the uppermost cell that can be sampled. 
The implementation of the above analysis is done through the following steps (see Figure 5). The first step is to identify the possible candidate locations, $J$, for the monitoring wells. As mentioned earlier, the validation data collection is the target and thus the general location is based on the data needs for validation. However, the exact location will be determined with this analysis where the different candidate locations are compared and the optimal location with highest success probability (lowest failure probability) is chosen. The second step is to select a time frame for the analysis, which is represented by the simulation time scale, $T$, and the time, $t$, at which probabilities are to be obtained $t$. The simulation time scale $T$ will be selected such that the first-stage wells will be able to detect (or have a high chance of detecting) the plume should the validation tests confirm the flow directions currently identified in the CNTA model. In other words, the total simulation time should be large enough compared to the time at which probabilities are computed, to enable the computation of the first term on the right-hand side of Equations (4) and (5). The purpose of selecting a simulation time, $T$, that is less than the 1,000year time scale of the model, is to reduce computational time and allow for using a sufficient number of particles to represent the initial mass.

The third step is to run Monte Carlo simulations and record for each realization the $t-z$ distribution of the resident mass $\left(M_{j i}(\tau, z)\right.$ in Equation 7) within the cells occupied by each monitoring well. The integration of this mass distribution gives $W_{j i}$ for each realization $i=1$ to $N M C$ and each well $j$. The fourth step is to compute for each candidate well location the probability that $\alpha$ percent of the total plume mass crosses the $\mathrm{CP}, k$, passing through that location in time $t$ or less. This can simply be obtained by integrating the total mass flux breakthrough curve for each CP $(k=1, \ldots K$ with $K \leq J)$ from time zero to time $t$. The fifth step is to use Equation (5) to compute the success probability for each candidate well location (due to the computational burden, only a finite number of candidate locations will be evaluated). The locations with the highest success probability will then be selected as potential well locations.

Although computationally demanding, the approach described above is simple in nature and relies on the simulation approach combined with the hydrogeologic expertise and knowledge about the site. A number of reasons lead to the use of this simplified design approach as opposed to the automated optimization techniques. First, the underlying model structure is generally uncertain to justify an elaborate search for "optimal" designs that may actually be no better than ad hoc strategies proposed based on familiarity with the site. Second, the optimization approaches are sought in cases of designing a monitoring network that consists of many wells and the question becomes where the optimum locations are for these wells. For the CNTA case and this first-stage design, only two wells are proposed to be placed in the northern direction downstream of the test cavity. These two wells are mainly validation wells and the use of the above analysis will aid in optimizing the location of each well to enhance future chances of success of the monitoring network. However, the first-stage probabilistic analysis will dictate how many wells one should place initially and where to place them. 


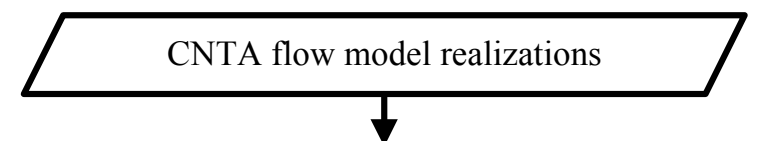

- Select few candidate locations (e.g., 10 to 15 alternatives)

- Select simulation time, $T$

- Select time for computing probabilities, $t$

- Select the parameter $\alpha$

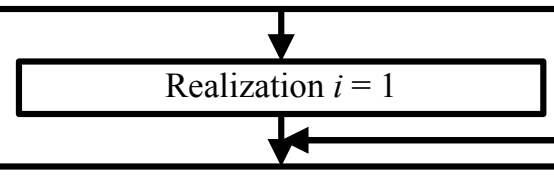

- Run transport simulations using particle tracking from time 0 to time $T$

- Compute total mass flux breakthrough $\left[Q\left(t, x_{k}\right)\right]$ for each $\mathrm{CP}(k=1, \ldots K)$

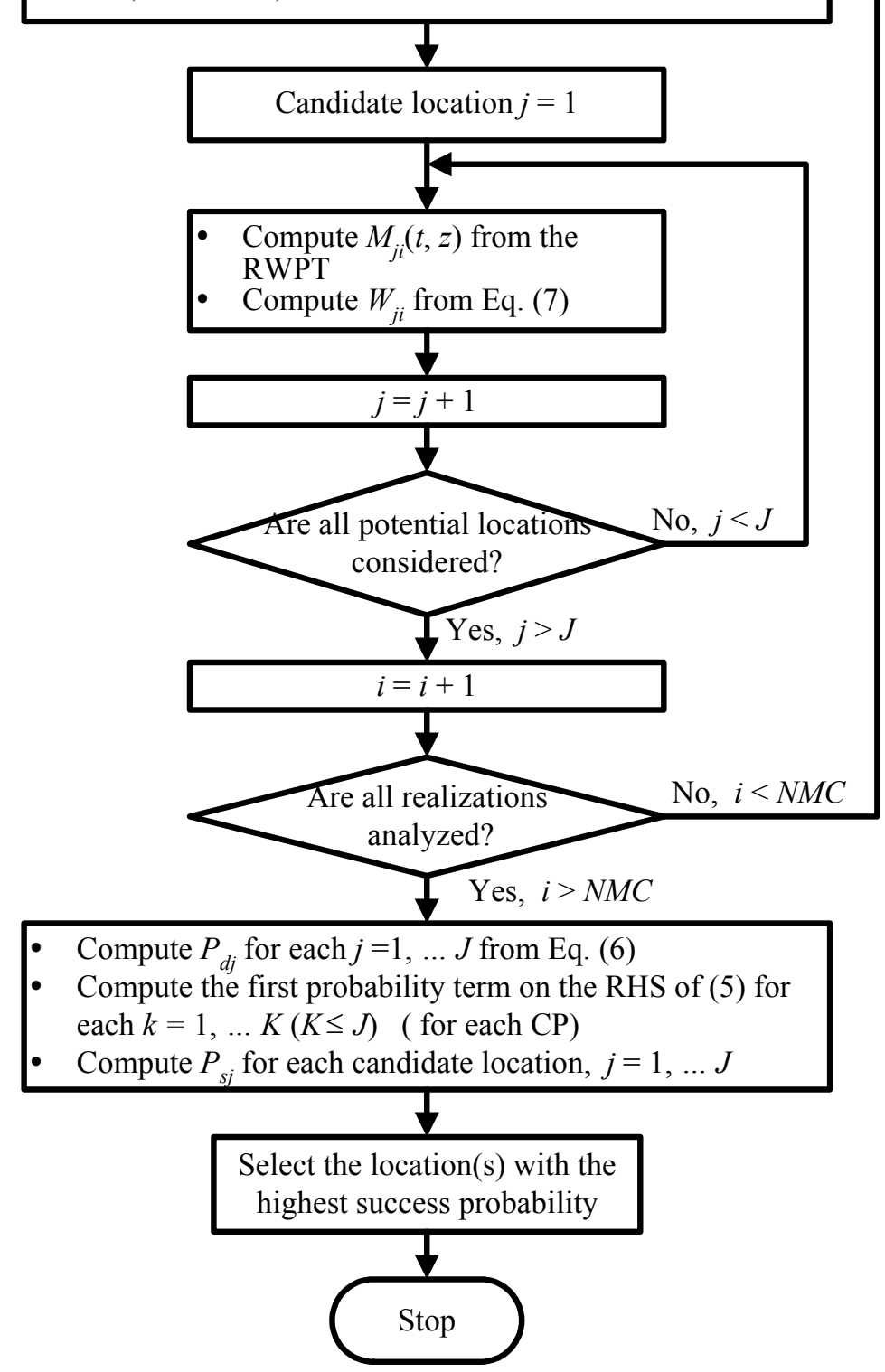

Figure 5. A step-by-step description of the first-stage design methodology. 


\subsection{Second-stage Monitoring Design Approach}

When the validation process has achieved its targeted goals (i.e., sufficient confidence has been built in the predictions of the CNTA groundwater flow and transport model), a final network augmentation problem can be formulated and solved in a sophisticated optimization scheme. Based on the long-term objectives of the monitoring network at this point in the process, a statistical approach combining simulation and optimization techniques can be used to augment the existing set of wells, by selecting new wells for an optimum monitoring network. A promising approach that has recently been adapted for monitoring network design is the use of genetic algorithms (e.g., Reed et al., 2000) and combining it with neural networks (Hassan and Hamed, 2000, 2001) and search theory (Warrick et al., 1998) or probability-based simulation techniques.

A recently proposed long-term monitoring strategy that relies on the capabilities of recent evolutionary computational tools such as Artificial Neural Networks (ANN) and Genetic Algorithms (GA) for optimizing the monitoring network can be used for the second-stage design. Figure 6 shows the proposed second-stage monitoring network design, which is intended to augment the validation wells and form the long-term monitoring network for the site.

The first step of the analysis is to determine the monitoring objectives (for example, detection monitoring) and the constraints on the monitoring system (e.g., budgetary limitations). With these objectives and constraints, an arbitrary monitoring system can be developed (step 2 in Figure 6) and a mathematical objective function will be formulated to incorporate the system's success probability, total cost, and other relevant performance measures.

Step 3 in Figure 6 involves changing the different constraints affecting the monitoring program to obtain a set of monitoring scenarios with associated objective functions. A relatively large number of monitoring scenarios must be generated in this step to allow sufficient coverage of the distribution of possible scenarios and monitoring capabilities. Some of these monitoring scenarios will be highly efficient; some will be highly inefficient; and the rest will fall between the two extremes. It is important that the initial monitoring scenarios cover this range of possibilities so that the ANN can be trained with a representative sample of the space being searched for optimization.

In step 4, these monitoring scenarios will be used to prepare input-output pairs representing details of the monitoring program (e.g., number and location of sampling points, where sampling is taking place, geometry of the monitoring network) on the input side and the value of the objective function representing monitoring program efficiency on the output side. These data will then be divided into three subsets: training data, testing data, and validation data. The training and testing data will be used to determine the architecture and train the neural network (step 5 in Figure 6). The validation data will be used to test and evaluate the ability of the neural network to generalize the learned relationship to unseen patterns.

The initial set of monitoring programs represents the first generation of GA analysis (step 6 in Figure 6) in which multiple spin offs (or generations) can be generated with high probability of large fitness scores (e.g., high likelihood of detection). Because GA will only generate the input part of new scenarios (e.g., locations and numbers of sampling points), the trained ANN can be used to quickly and efficiently predict the objective function associated with those scenarios. 


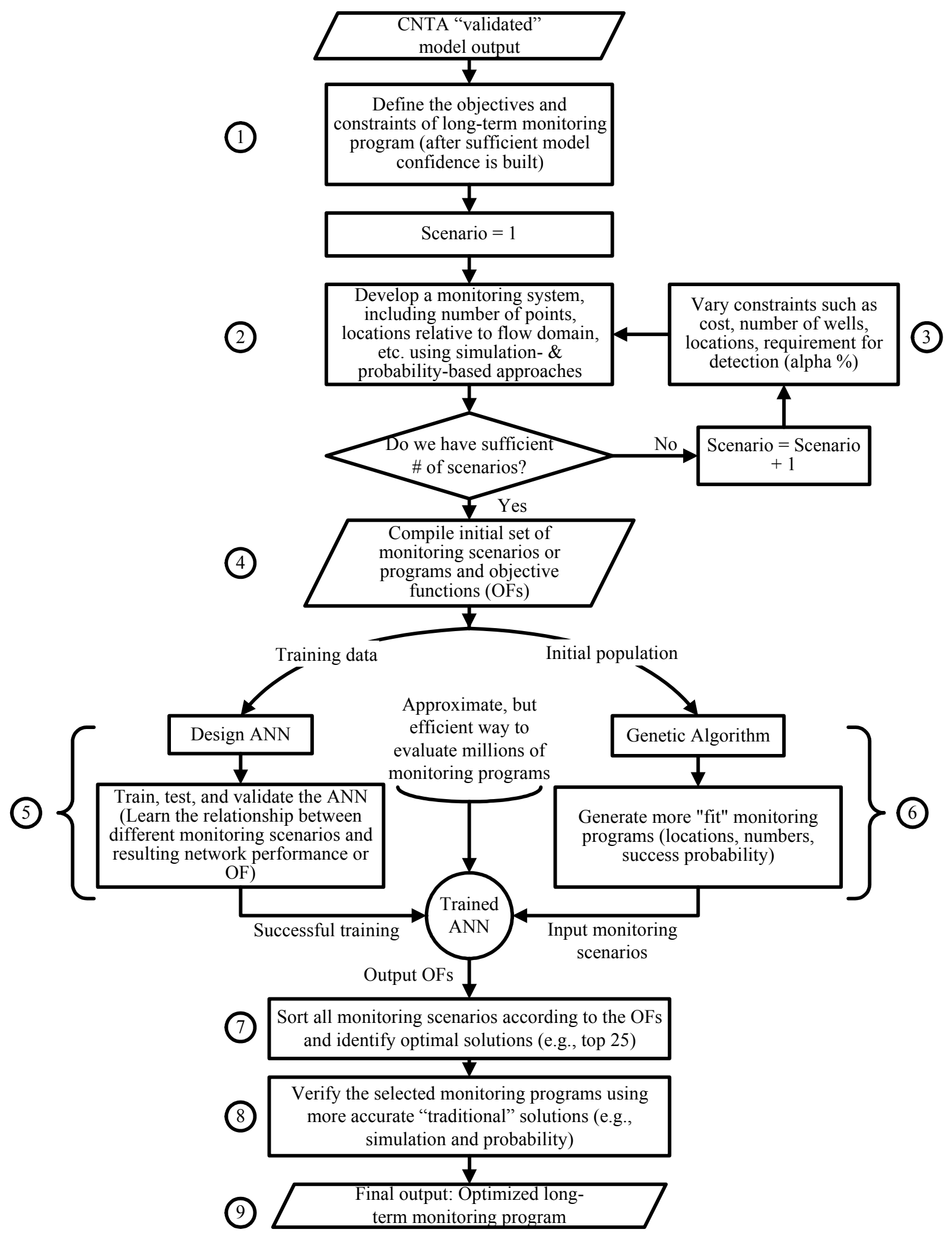

Figure 6. A step-by-step description for the second-stage design approach. 
A large number of GA-generated scenarios can be tested and evaluated using the ANN in a reasonable time, which is one of the powerful advantages of combining the two techniques and using them in conjunction with the statistical design methodology. The GA model can generate an infinite number of generations with progressively increasing fitness scores. Given the complexity of the studied problem, we need to fully explore the search space to the extent possible. Using the GA will allow creation of a very large number of monitoring programs in the close neighborhood of the optimal solution. Computing the fitness score for each of these scenarios would require the Monte Carlo solution of the transport problem as well as the application of the first-stage design methodology to obtain the detection probability needed to evaluate each scenario's objective function. This is a prohibitive task from both time and budgetary perspectives. Therefore, the power of the proposed tools lies in their computationally efficient ability to evaluate the extremely large number of scenarios and to compute their fitness scores (using the trained ANN model). This results in saving thousands of CPU hours, dramatic reduction in the cost of the analysis, and a high likelihood of designing a close-to-optimum monitoring program in this stage.

Step 7 in Figure 6 involves sorting the fitness scores (e.g., objective functions) obtained using the trained ANN. This sorting will allow the selection of the top few scenarios that achieved the highest performance or objective functions (i.e., high success probability and low total cost). These "efficient" monitoring programs will be individually analyzed using the statistical approach (simulation- and probability-based approach) as shown in step 8 in Figure 6. Finally, the most efficient monitoring program is selected (step 9 in Figure 6) as the final result of second-stage design.

\subsection{Final Remarks on the Monitoring Strategy}

Figures 3 through 6 show a step-by-step description of the general framework of the proposed monitoring design approach and its relation to the validation approach for CNTA. The multi-staged nature of the approach provides great flexibility to incorporate new information into the design approach and new objectives as they develop over time. Hsueh and Rajagopal (1998) point out that cost-effective solutions are often attained by systems that are built in an adaptive framework, constantly changing yet having a basic structure. The proposed approach embraces this philosophy, as the basic structure is to build the monitoring network around and including the validation wells and to refine the model predictions whenever new data become available before locating any new wells.

An important aspect to recognize here is that the multi-staged approach includes feedback loops for feeding the collected data into the model for refining its predictions and reducing uncertainty. As a result of these feedback loops and the two-stage design, it is possible that the final network may include early wells that are determined later to not provide optimum monitoring data. However, such wells will have provided valuable information for validating the model and reducing uncertainty in the final monitoring system. 


\section{FIRST STAGE ANALYSIS}

\subsection{Model Simulation and Probability-Based Approaches}

In the first stage, a preliminary analysis is performed to locate one well that will serve the dual purpose of collecting validation data and serving as a long-term monitoring well. The latter objective is achieved by placing the well in a location with high likelihood of detecting the migration of radionuclides according to the flow and transport model predictions. The probabilistic analysis performed is based on the size-reduced Faultless model as described in Pohll et al. (2002).

The model described in Pohll et al. (2002) is reduced in size from the original model (Pohlmann et al., 1999) because previous modeling demonstrated that areas east, west, and south of the Faultless land withdrawal area (UC-1) do not contribute to predictions of radionuclide migration. The horizontal dimensions of the new domain are $3.6 \mathrm{~km} \times 3.6 \mathrm{~km}$, whereas the thickness of the domain is about 1,350 m.. The model domain is centered over UC-1, and like the 1999 model, is aligned in the north-south direction (Figure 7). Also consistent with the 1999 model, each cell in the uniform mesh is a cube having an edge dimension of $50 \mathrm{~m}$.

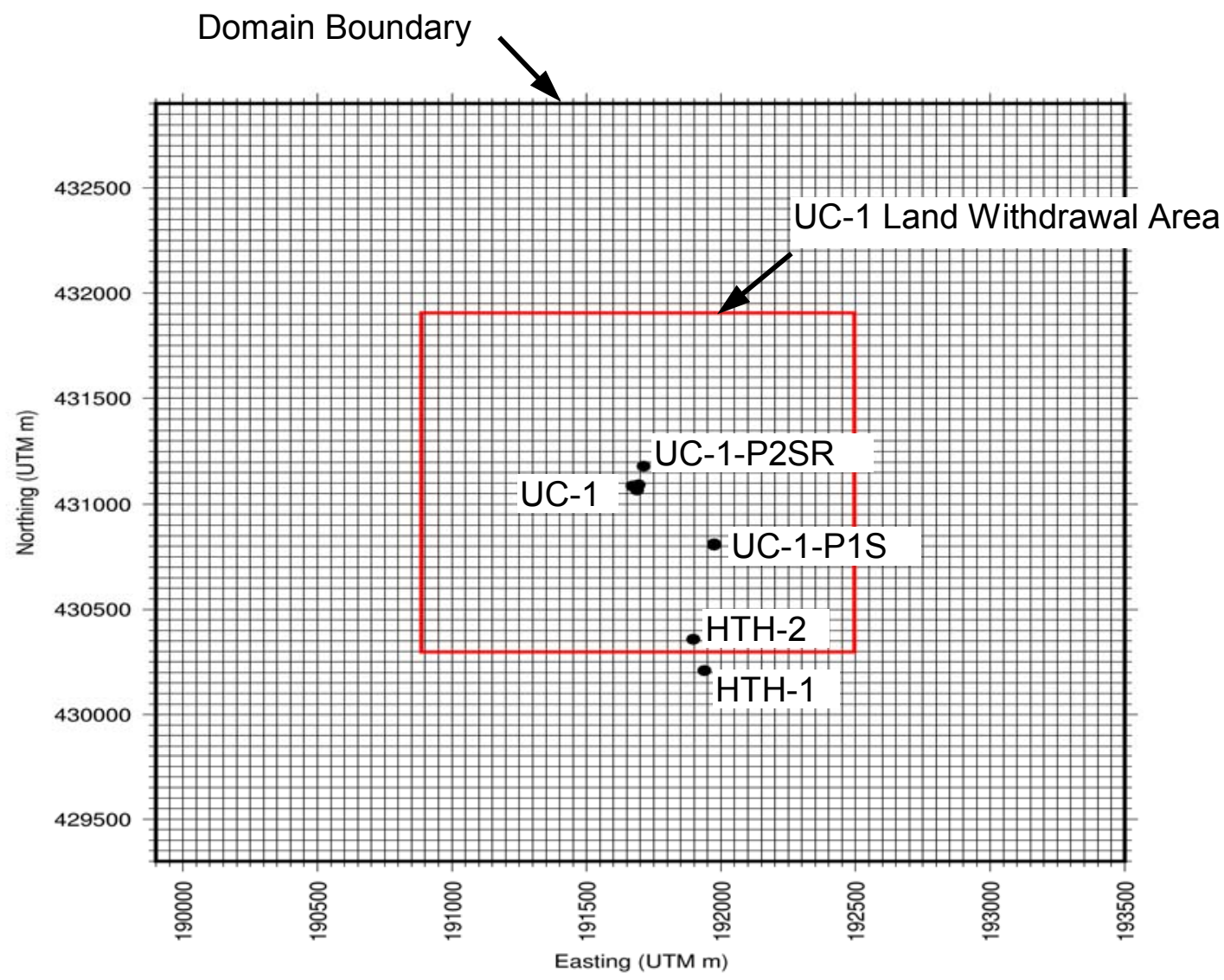

Figure 7. Map view of model domain showing the finite difference mesh, the locations of the UC-1 land withdrawal boundary and the related CNTA boreholes (from Pohll et al., 2002). 
The flow realizations of this new model were used to perform transport simulations and obtain the geometric characteristics of the plume as it crosses a number of CPs (CPs). Transport simulations are performed using the random walk particle tracking (RWPT) method. The RWPT code used in the 1999 model has been substantially updated to improve the handling of the spatial variability of dispersion and porosity, improve the velocity interpolation scheme, and incorporate a new approach for simulating the matrix diffusion process. This improved code was applied to the 2002 model presented in Pohll et al. (2002).

Traditional random walk methods (e.g., Kinzelbach, 1988; Tompson and Gelhar, 1990) usually rely on the assumption that medium properties such as porosity, $\theta$, and dispersion coefficient, $D$, are sufficiently smooth in space. Discontinuities in effective subsurface transport properties that may arise in discrete velocity fields of numerical groundwater flow models violate this smoothness assumption (LaBolle et al., 2000). Therefore, when $\theta$ or $D$ is discontinuous, these standard methods fail (LaBolle et al., 1996) because the gradient terms of $D$ and/or $\theta$ cannot be formally defined. LaBolle et al., (2000) developed generalized stochastic differential equations applicable to the case of discontinuous coefficients (e.g., dispersion coefficients) and developed a new random walk method that numerically integrates these equations. That method is applicable for cases of abrupt changes in transport parameters and velocity values. The new random-walk equations proposed by LaBolle et al. (2000) can be written as

$$
\boldsymbol{X}_{t+\Delta t}=\boldsymbol{X}_{t}+\left[\boldsymbol{V}\left(\boldsymbol{X}_{t}, t\right)\right] \Delta t+\left[2 \mathbf{D}\left(\boldsymbol{V}\left(\boldsymbol{X}_{t}+\delta \boldsymbol{X}\right), t\right) \Delta t\right]^{1 / 2} \cdot \boldsymbol{Z}
$$

where the displacement vector $\delta \boldsymbol{X}$ is defined as

$$
\delta \boldsymbol{X}=\left[2 \mathbf{D}\left(\boldsymbol{V}\left(\boldsymbol{X}_{t}, t\right)\right) \Delta t\right]^{1 / 2} \cdot \boldsymbol{Z}
$$

The approach evaluates the advective component of particle movement using the velocity at the current particle position, $\left(x_{t}, y_{t}, z_{t}\right)$, and at time $t$. The dispersive component is performed using dispersive coefficients evaluated at an intermediate location, $\left(x_{t}+\delta x, y_{t}+\delta y, z_{t}+\delta z\right)$, where the increments $\delta x, \delta y$, and $\delta z$ represent dispersive steps from the current location, $\left(x_{t}, y_{t}, z_{t}\right)$ to the intermediate location $\left(x_{t}+\delta x, y_{t}+\delta y, z_{t}+\delta z\right)$. The details of the approach and how it is incorporated in the RWPT code are described in Pohll et al. (2002).

The transport approach described thus far is appropriate for a porous medium; however, the conceptualization of the flow system at Faultless includes highly fractured zones, which have correspondingly high flow velocities adjacent to unfractured porous zones. A continuum approach is applied in the sense that effective fracture properties (high $K$ and low porosity) are assigned to the model cells rather than direct incorporation of discrete fractures. As a result, particles are tracked through space in the same manner as for a porous medium, but they experience high flow velocities when they pass through a fracture cell.

Although the RWPT code accounts for matrix diffusion and the interaction between fluids in the fractures and fluids in the matrix, for the monitoring design analysis here, this process is not included in the analysis. This is simply because the interest here is in the geometric characteristics of the plume without regard to the values of the mass flux breakthrough curves or the values of contaminant concentrations. The results presented here could essentially be obtained with matrix diffusion included but with a much larger number of particles than used here, which would unnecessarily increase computation time. 
Many of the transport parameters are treated as uncertain. These parameters include effective porosity for each of the three hydrogeologic categories of the Faultless model, porosity of the welded tuff matrix, and dissolution from the nuclear melt glass. Additionally, sorption and geochemical release parameters are treated as uncertain for transport cases that include sorbing radionuclides. However, the focus here is only on the non-sorbing transport (Class \#1's radionuclides) and as such no retardation is considered. This is again due to the focus on the physical and geometric aspects of the plume as it crosses the selected CPs.

The transport calculations employ the RWPT method and the three-dimensional Darcy flux fields using the same grid discretization and domain size as the groundwater flow model (Pohll et al., 2002). The radionuclide source is assumed to be the entire Faultless cavity, which is simulated in the model as a cube having edge lengths of $200 \mathrm{~m}$, and within which particles are uniformly distributed. The values of the transport parameters that are not treated as uncertain are listed in Table 2. The time step length for each realization is calculated within the RWPT code using the values of porosity for the three categories associated with that realization. Time step lengths are chosen so that the Courant numbers for any realization are less than one to ensure that particles are not transported a distance equal to the dimension of one grid cell $(50 \mathrm{~m})$ in a single time step.

Table 2. Values of parameters that describe the configuration of the transport model and values of deterministic parameters. Time step length is variable because it is determined for each realization from the maximum velocity.

\begin{tabular}{|c|c|c|c|}
\hline \multirow{2}{*}{$\begin{array}{c}\text { Parameter } \\
\text { Location of Source, Nevada Central Coordinate }\end{array}$} & \multicolumn{3}{|c|}{ Value } \\
\hline & & \multirow{2}{*}{\multicolumn{2}{|c|}{191675}} \\
\hline Easting (m) & & & \\
\hline Northing (m) & \multicolumn{2}{|r|}{431075} & \\
\hline Elevation (m AMSL) & \multicolumn{3}{|c|}{885} \\
\hline Edge Length of Source (m) & \multicolumn{3}{|c|}{200} \\
\hline Source Mass, $M_{0}$ & \multicolumn{3}{|c|}{1.0} \\
\hline \multirow[t]{2}{*}{ Northing Coordinates of CPs (m) } & $431,275 \quad 431,325$ & $431,375 \quad 431,425$ & 431,475 \\
\hline & $431,525 \quad 431,575$ & $431,675 \quad 431,775$ & 431,875 \\
\hline Infill Time (years) & \multicolumn{3}{|c|}{30} \\
\hline Total Simulation Time (years) & \multicolumn{3}{|c|}{1,000} \\
\hline Time Step Length, $\Delta t$ (days) & \multicolumn{3}{|c|}{2.5 to $1,526.8$} \\
\hline Times at which Output is Analyzed (years) & \multicolumn{3}{|c|}{$100,200,500,1000$} \\
\hline Longitudinal Dispersivity $(\mathrm{m})$ & \multicolumn{3}{|c|}{0.05} \\
\hline Transverse Dispersivity (m) & \multicolumn{3}{|c|}{0.005} \\
\hline Molecular Diffusion & \multicolumn{3}{|c|}{0.0} \\
\hline Number of Realizations & \multicolumn{3}{|c|}{500} \\
\hline
\end{tabular}

The simulation layout is shown schematically in Figures 8 through 10. Figure 8 shows a toscale, three-dimensional view of the simulation domain, the cavity location and five CPs located at $200,250,300,350$, and $400 \mathrm{~m}$ from the working point normal to the northwardly flow direction (see Table 2 for the northing coordinates of these planes). The figure also shows a zoom-in view showing the source and the five CPs, with the y-axis scale exaggerated to clearly show the five CPs. A plan view is also presented to show the numbering sequence of the CPs, which will help in tying the results to this schematic picture. This plan view is also exaggerated in terms of the y-scale. Figure 9 is similar to Figure 8 except that it shows the other five CPs that are located at 450, 500, 600, 700, and $800 \mathrm{~m}$ from the working point. The last CP that is located 
at $800 \mathrm{~m}$ from the working point is coincident with the northern boundary of the UC-1 land withdrawal area. It should be pointed out that the $(0,0,0)$ origin in the three-dimensional views of Figures 8 and 9 corresponds to the coordinates 189,875 m East, 429,275 m North, and $295 \mathrm{~m}$ elevation.
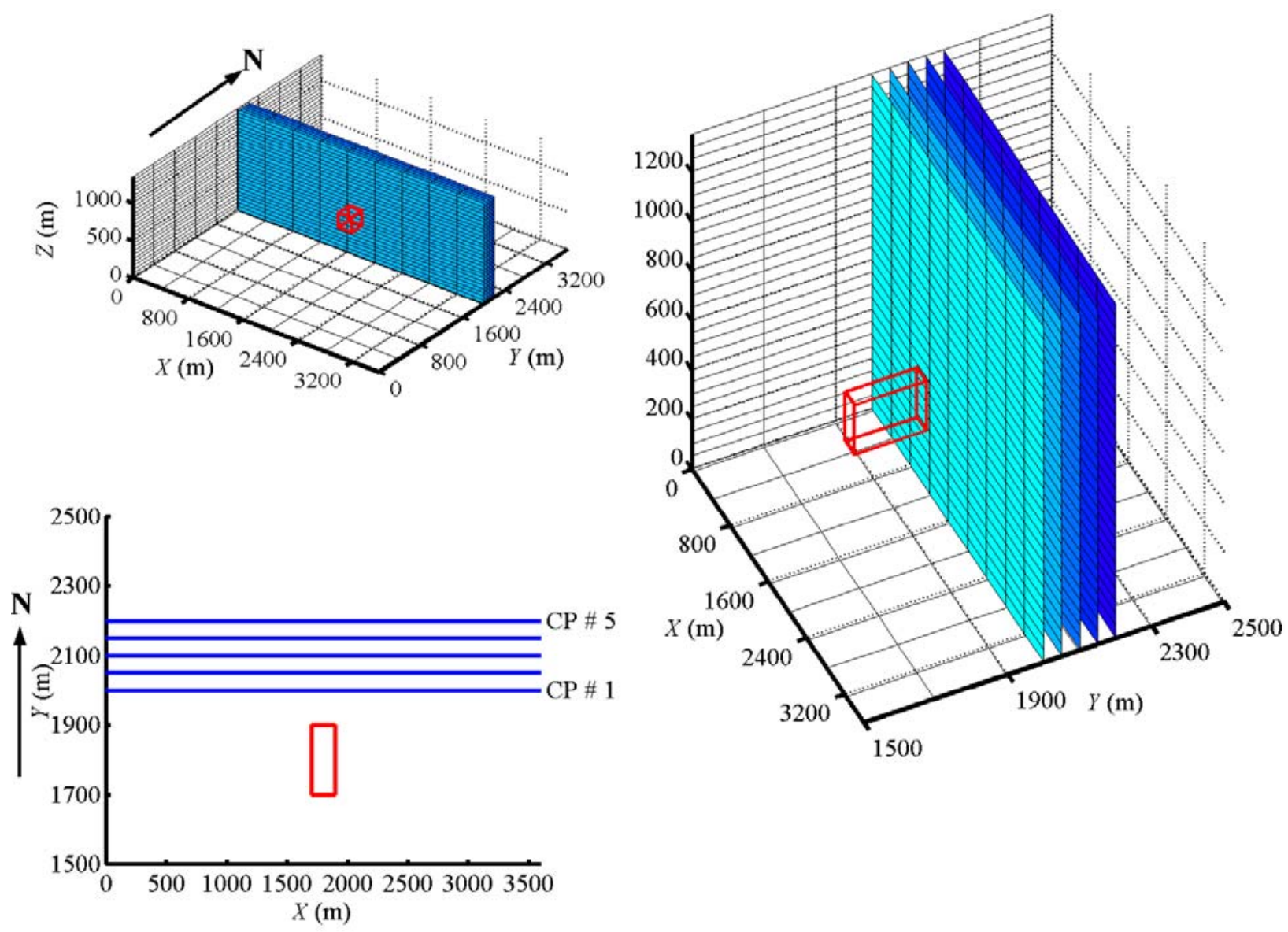

Figure 8. A three-dimensional view (top - to scale) showing the model domain, the cavity and the five CPs (CP \# 1 through CP \# 5), a zoom-in around the cavity and the CPs (right - exaggerated scale in the y-direction to allow distinction between control planes), and a two-dimensional plan view showing the location of the five CPs relative to the cavity (bottom - again with exaggeration in the $y$-scale). 

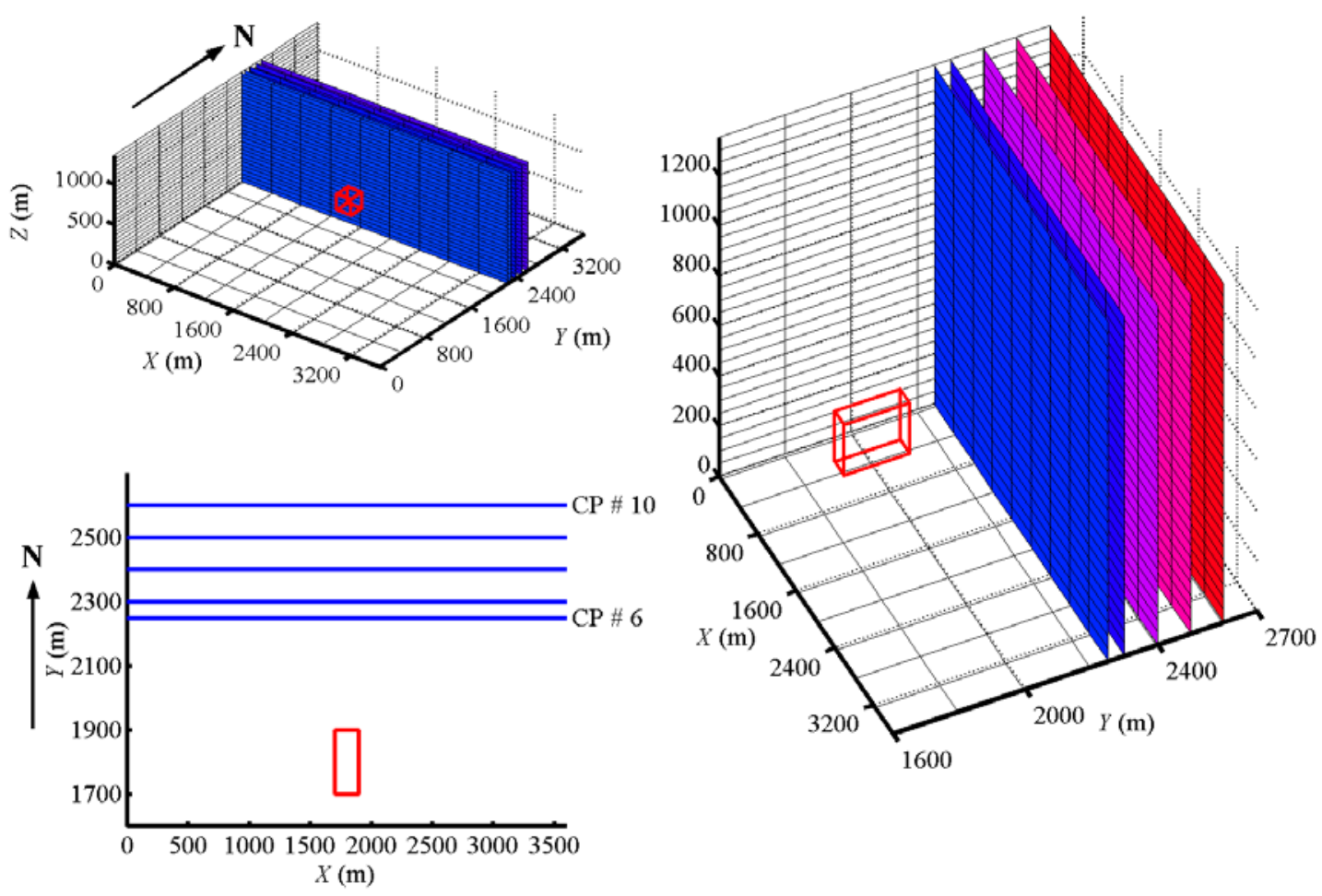

Figure 9. A three-dimensional view (top - to scale) showing the model domain, the cavity and the five CPs (CP \# 6 through CP \# 10), a zoom-in around the cavity and the CPs (right - exaggerated scale in the y-direction to allow distinction between control planes), and a two-dimensional plan view showing the location of the five CPs relative to the cavity (bottom - again with exaggeration in the $y$-scale).

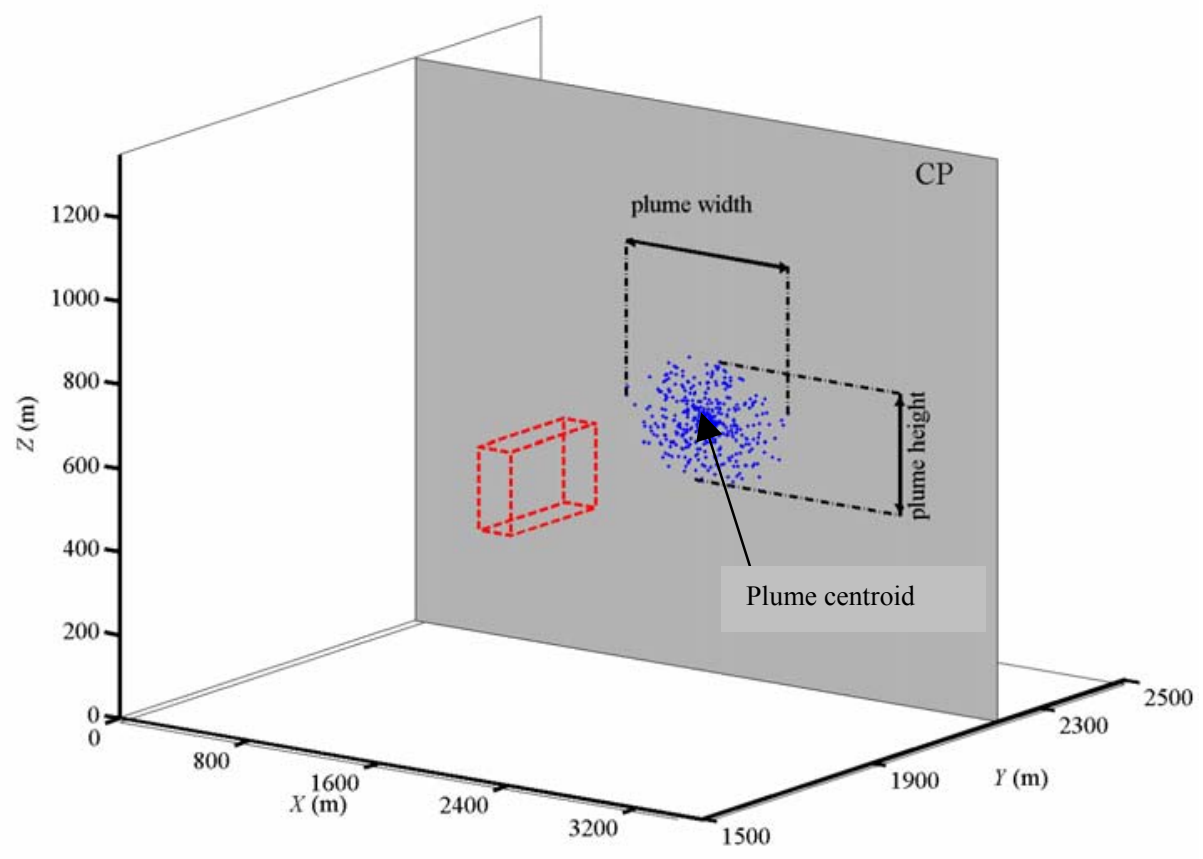

Figure 10. Schematic representation of the plume width and height as particles cross the CP. 
Transport simulations are conducted for the 1,000-year regulatory time frame. The particles representing the radionuclide source are tracked in the space-time domain for the total simulation time of 1,000 years. At every time step and for each $\mathrm{CP}$, the dimensions of the plume as it crosses a particular CP are obtained and recorded. Figure 10 shows how the plume width, height, and centroid (or center of mass) location are obtained for a certain $\mathrm{CP}$. Therefore, for each $\mathrm{CP}$, the plume width, height, and $(X, Z)$ coordinates of the plume center of mass are recorded for every time step. This output is subsequently analyzed at times 100, 200, 500, and 1,000 years after detonation. For any of these four times, the maximum plume width and the maximum plume height that were ever attained from time zero until this time are selected for plotting the histograms discussed shortly. For the center of mass of the plume as it crosses the different CPs, the average value of the center of mass location is obtained by averaging the non-zero values from time zero to the current time. The zero values of the center of mass of the plume are attained when no particles exist in the vicinity of the CP at the current time step. This occurs due to the dispersion of particles and the fact that they do not migrate in a continuous manner.

Figures 11 and 12 show the distribution of the percentage of total mass that crossed each of the $10 \mathrm{CPs}$ at the specific times considered. The number of realizations with mass crossing the control plane is presented on the figures as $N_{\text {tot }}$ for each case. For $t=100$ years from detonation, only 54 realizations (out of 500) had mass arriving at $\mathrm{CP} \# 1$, and the fastest migration rate among these realizations only led to about 12 percent breakthrough. Again this is based on ignoring matrix diffusion, and no radioactive decay is considered. For CP \# 10 that is aligned with the UC-1 land withdrawal area, only seven realizations exhibit a breakthrough with a maximum of less than 2 percent. After 1,000 years, the number of realizations showing breakthrough values at CP \# 1 becomes 163 and at CP \# 10 becomes 95 with a maximum mass arrival of about 50 percent in both cases.

Based on these results, it can be seen that the likelihood of migration (and thus the likelihood of plume detection) away from the Faultless cavity is very low. For the nearest CP that is located only $200 \mathrm{~m}$ north of the working point, only one third of the realizations show breakthrough values within the 1,000-year regulatory time frame. This number is likely to significantly decrease if one accounts for matrix diffusion and radioactive decay. The farther away one gets from the working point the lower the likelihood of detection becomes. Therefore, though the location of the monitoring well is based on the physical and geometric characteristics of the predicted plume, it is actually very unlikely that any radionuclide migration will be detected. However, it is also important to note that this monitoring well will provide valuable information for the validation process of the CNTA model.

In Figures 13 through 16, the distribution of the plume width and plume height as defined in Figure 10 is plotted for the different times and the different CPs. It is seen that the plume width is in many realizations between 100 and $200 \mathrm{~m}$ and the plume height is also around 100 to $200 \mathrm{~m}$ in many realizations. Only in a few realizations does the plume width exceed $500 \mathrm{~m}$. With the fractured nature of the densely welded tuff unit that encounters most of the northern migration, the actual width and height of the plume may in fact be smaller than predicted by the model. This is because the model applies a continuum approach to this problem and for realizations involving flow through fractured tuffs, this may overestimate dispersion. 


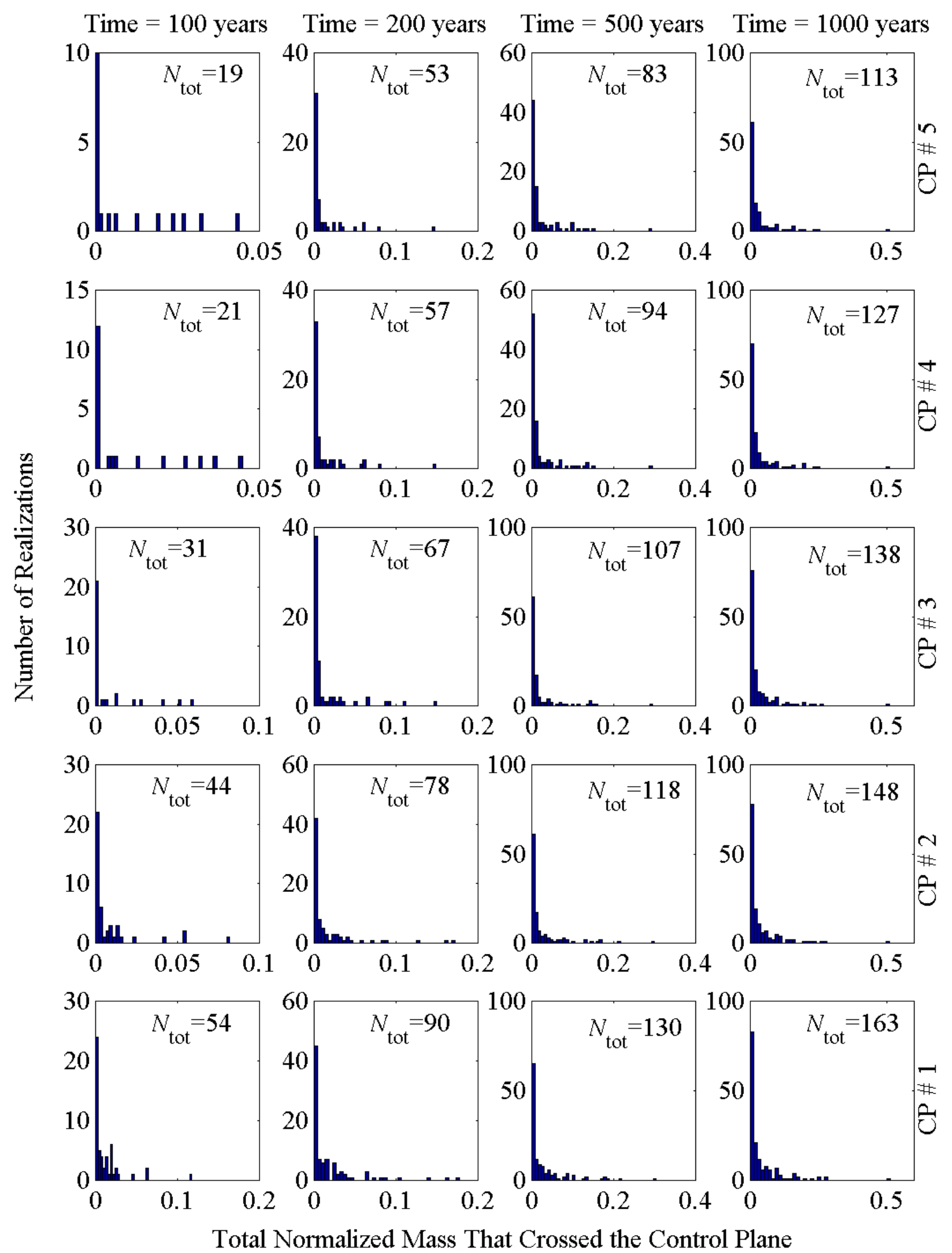

Figure 11. Distribution of the total mass crossing CP \# 1 through CP \# 5 at different times. 


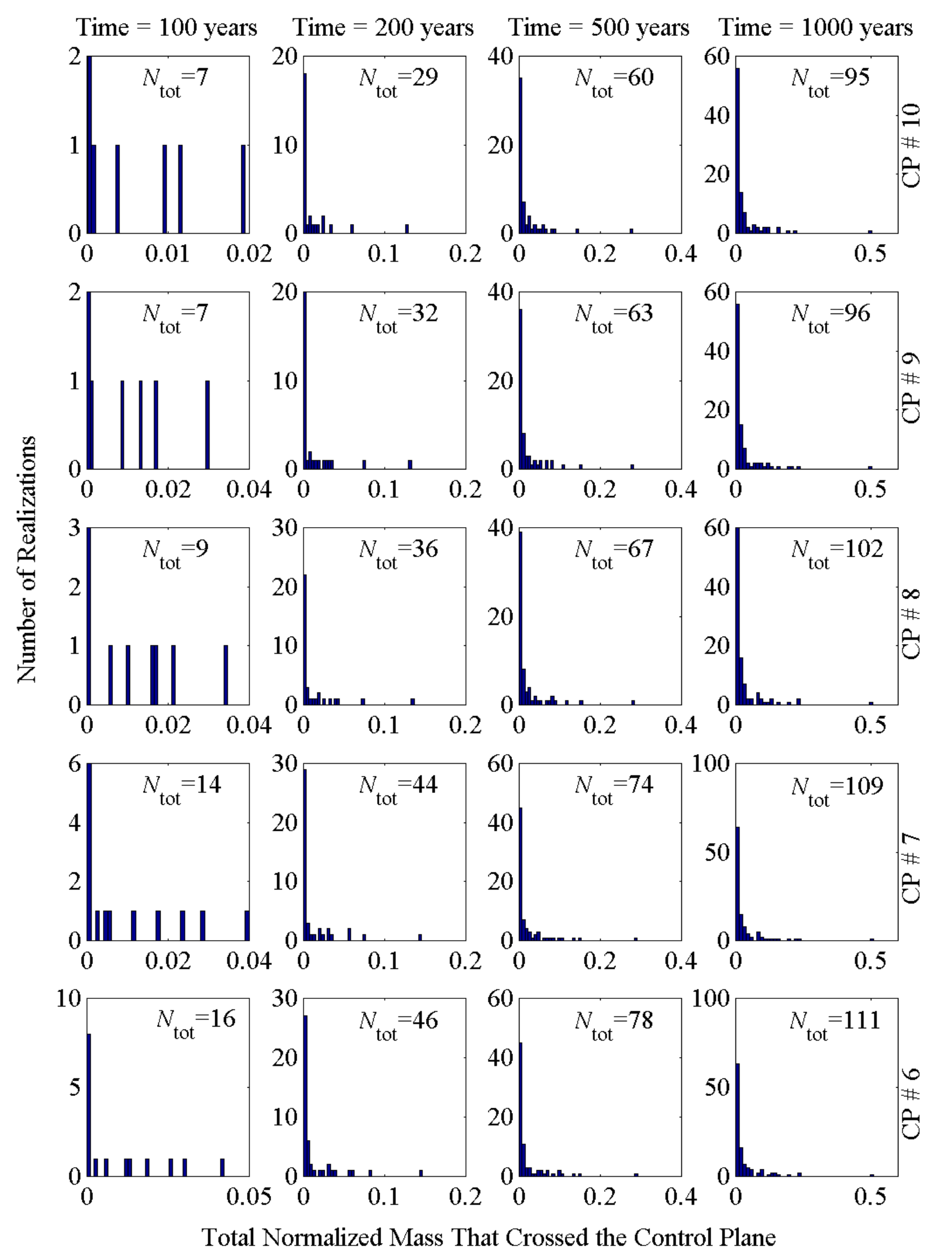

Figure 12. Distribution of the total mass crossing CP \# 6 through CP \# 10 at different times. 


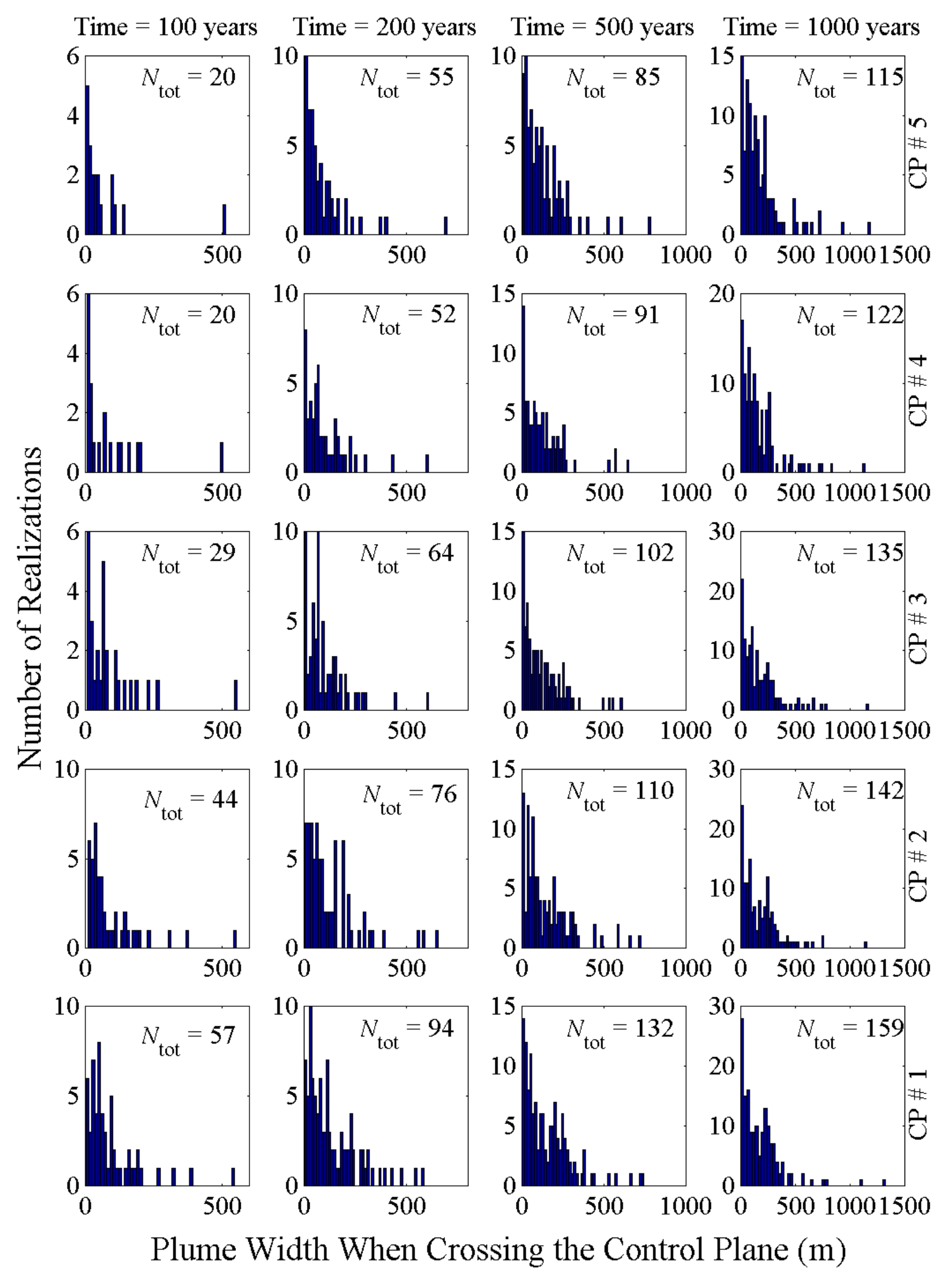

Figure 13. Plume width distribution for CP \# 1 through CP \# 5 at different times. 


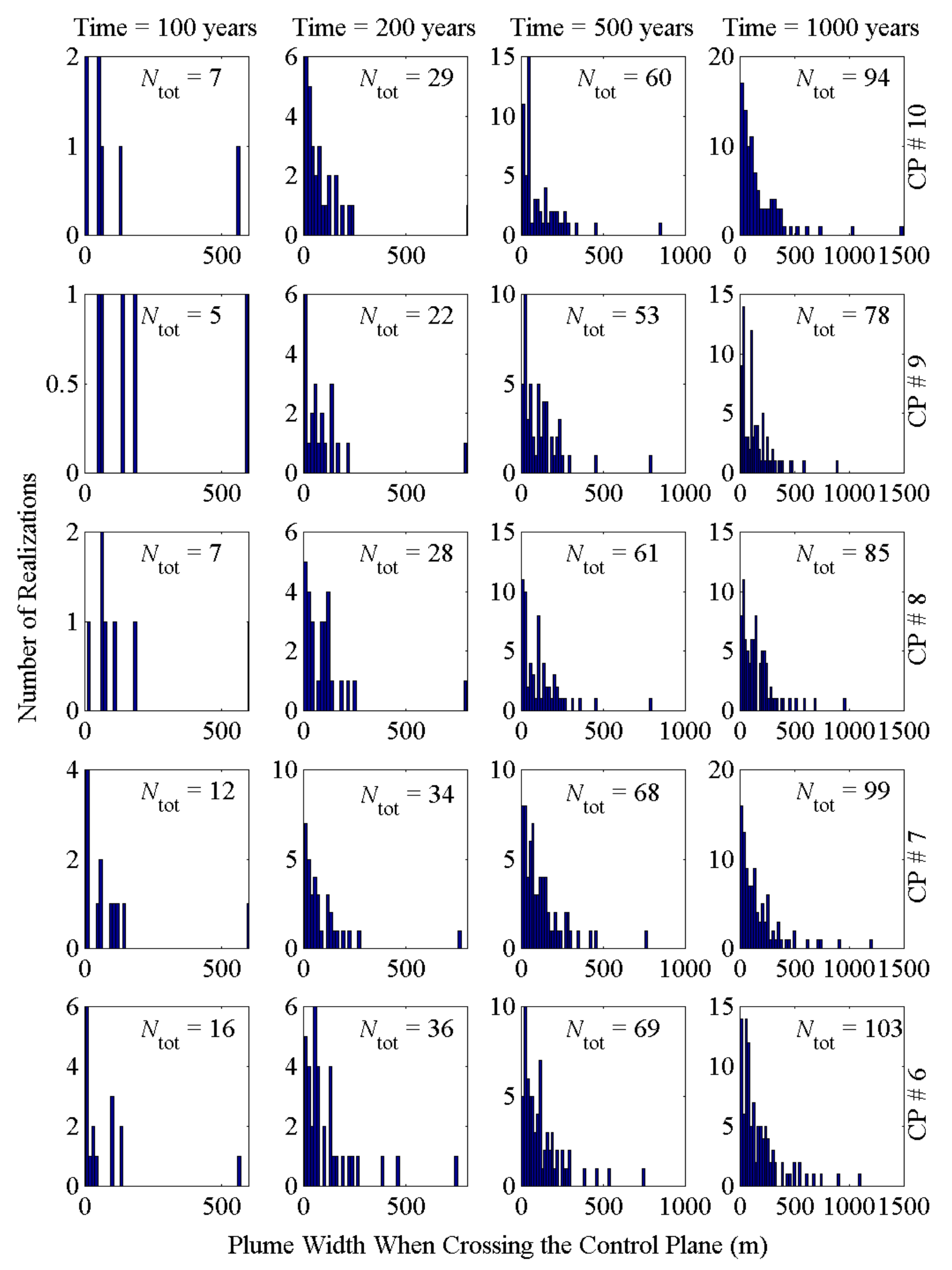

Figure 14. Plume width distribution for CP \# 6 through CP \# 10 at different times. 
Time $=100$ years Time $=200$ years $\quad$ Time $=500$ years Time $=1000$ years
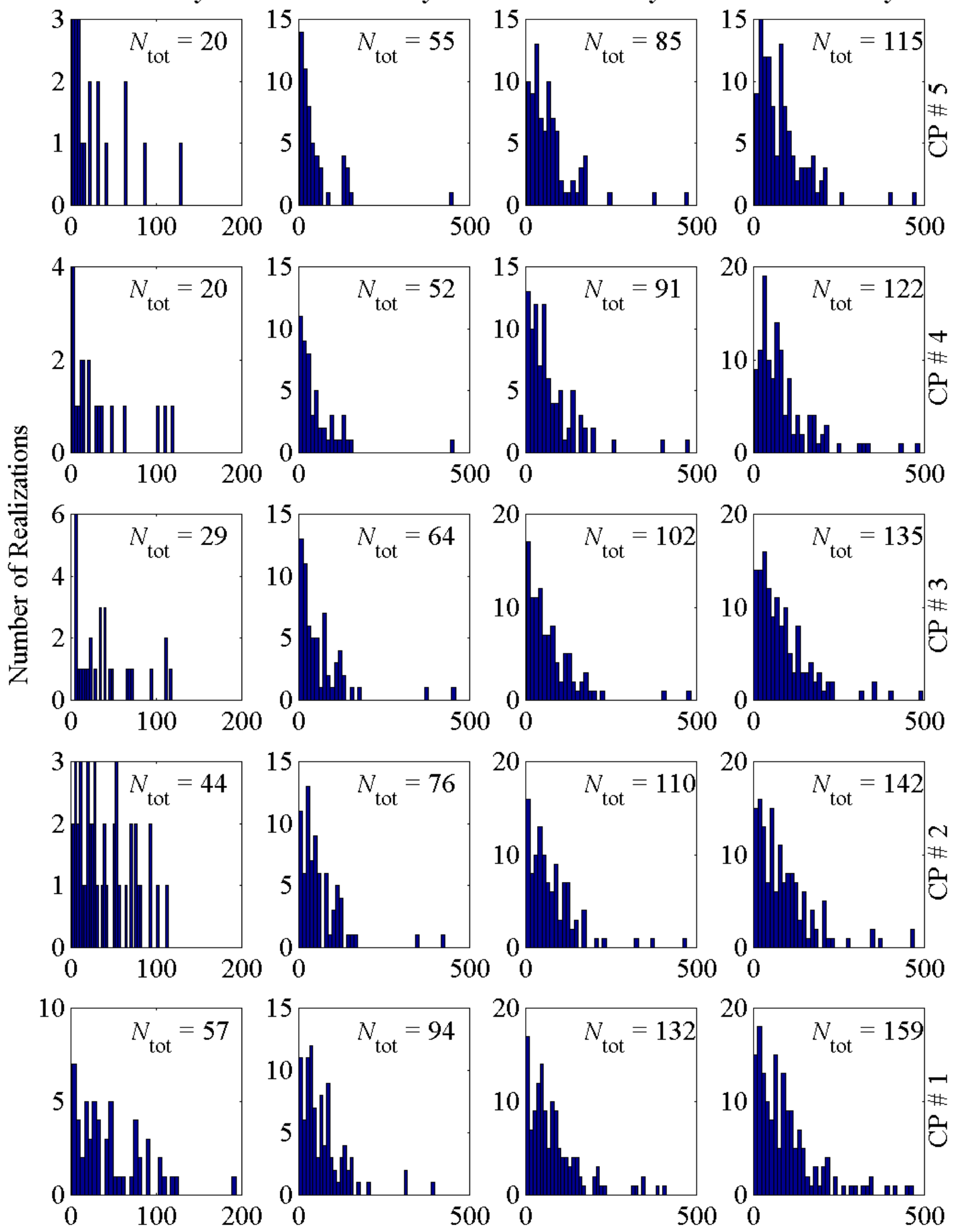

Plume Height When Crossing the Control Plane (m)

Figure 15. Plume height distribution for CP \# 1 through CP \# 5 at different times. 


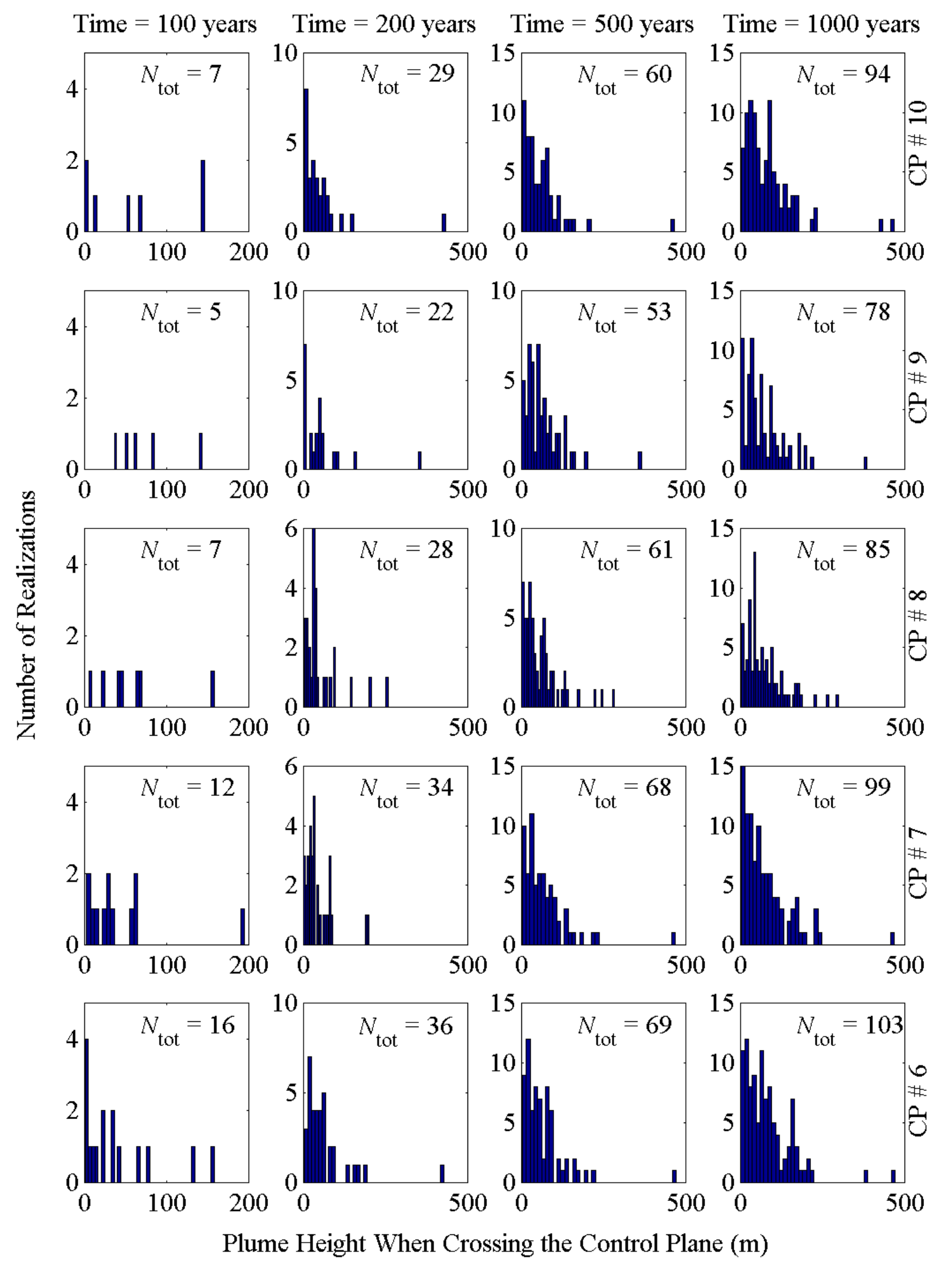

Figure 16. Plume height distribution for CP \# 6 through CP \# 10 at different times. 
Figures 17 through 20 show the distribution of the $X$ and $Z$ location of the plume center of mass when it crosses the CPs. The figures show that the center of mass in many realizations is at about $X=1,800 \mathrm{~m}$ from the domain origin, which coincides with the longitudinal centerline of the domain. In the $Z$ direction, the plume center of mass is more or less normally distributed with a central tendency around $Z=500 \mathrm{~m}$. This is about $100 \mathrm{~m}$ below the working point elevation. The distribution in the vertical $Z$ direction provides a guidance of where to sample the monitoring well for concentration measurements. It should be mentioned, however, that the variability of the $\mathrm{Z}$ location between realizations is partly a result of the uncertainty in the location of the densely welded tuff unit which is built into the CNTA model. Therefore, it is important to realize that most of the lateral flow to the north occurs through this welded tuff unit. The location of the sampling interval in any well should be tied to the location of the densely welded tuff unit when it is encountered in the field. If the unit is not encountered during drilling, then one would place the sampling intervals according to the guidance provided by the distributions in Figures 19 and 20.

The small cross-sectional size of the plume and the limited distribution of the center of mass location in multiple realizations suggest that an optimum placement can be realized by a single well (though even this well will have a low likelihood of plume detection due to the low likelihood of migration, as previously discussed). A greater degree of spreading, either through dispersion of the plume or variation in plume location from realization to realization, would require more wells for adequate coverage. The results also indicate that the location likely to encounter plume migration is along the longitudinal centerline of the domain downstream of the cavity. For early detection of fast migration pathways, one would place the monitoring well as close to the cavity as practically as possible. There are two reasons that limit the practicality of being close to the cavity. The first is the increased workers risk incurred by drilling into, or very near nuclear cavities where radionuclides can be injected by the blast. The second is that the Faultless model was constructed using "far-field" conditions. This means that features specific to effects from the nuclear test, such as faults and collapse structures, were not included in the model because it was assumed that radionuclide migration in the long term would be dominated by the characteristics of the natural groundwater system. Thus the accuracy of the model can be expected to be higher at greater distances from the cavity. Balancing the desire for proximity with those two considerations will control how close a well can be placed.

\subsection{Hydrogeologic Approach}

The monitoring well selection process described above relies on multiple simulations of the Faultless numerical model to identify locations with the highest probability of detecting contaminant migration. The model itself is built upon all available hydrogeologic data and also incorporates hydrogeologic analysis and intuition applied during the data analysis and calibration stages. Thus the hydrogeologic approach is incorporated within the model simulation approach.

In addition to the application of hydrogeologic knowledge through the modeling, the development of the monitoring network for CNTA will also be subject to the hydrogeologic approach during implementation. Insight developed from knowledge of the hydrogeologic environment will directly affect the final well completions. For example, transport through fractures in welded tuff is known to present a possible fast pathway. Though the simulation and probability-based approaches indicate that the best vertical location to sample is about $100 \mathrm{~m}$ below the working point, if a welded tuff unit is identified during drilling, it is likely to present a desirable location for a well screen, whether or not it is at that exact vertical location. Other 
factors that will be considered during drilling and testing any monitoring well are the hydraulic heads encountered and the identification of faults or other significant hydrogeologic features. As this information will only be available during the field work, it is likely to be incorporated in the monitoring well design through the use of the hydrogeologic approach, though it is possible that some additional numerical simulations could be performed as data are collected.

\section{CONCLUSIONS}

A multi-staged approach for development of the long-term monitoring well network for the Central Nevada Test Area (CNTA) is proposed. This multi-staged approach will proceed in parallel with the validation efforts for the groundwater flow and transport model of CNTA as described in Hassan (2003). The first stage of the plan is to use hydrogeologic insight combined with the simulation and probability-based approaches to select the first set of monitoring wells that will serve two purposes or objectives. The first objective is to place this set of wells in locations likely to encounter fast migration pathways so that the likelihood of the detection of plume migration is enhanced. The second objective is the collection of data for the validation of the groundwater flow and transport model, and thus benefiting from the wells in the validation process of the CNTA model. The first stage will be repeated according to the progress of the CNTA model validation processes. Wells are added sequentially and data are collected and used to evaluate the model and refine its predictions. When the research team, the model sponsor, and regulators reach an agreement that sufficient confidence has been built in the model through the validation process, the second long-term monitoring stage will start. In this stage an optimum design methodology should be used and should focus on augmenting the existing well network for the purpose of enhancing the probability of detecting contaminant migration away from the site boundaries.

The first-stage analysis is performed for locating the initial set of monitoring and validation wells using the refined CNTA model (Pohll et al., 2002). The probabilistic analysis indicated that the likelihood of migration away from the test cavity is very low and the probability of detecting radionuclides in the next 100 years or so is extremely low. However, this assumes that the current model predictions are close to reality. Therefore, it is recommended to place one well in the downstream direction along the model longitudinal centerline (i.e., directly north of the working point), which is the location with the highest probability of encountering the plume. This well will likely benefit the model validation process more than the monitoring process in the near future. In the long run, the well is going to be crucial for the long-term monitoring of the site (assuming that the flow model is validated), as it will be the most likely place to detect plume migration away from the cavity if it happens. 


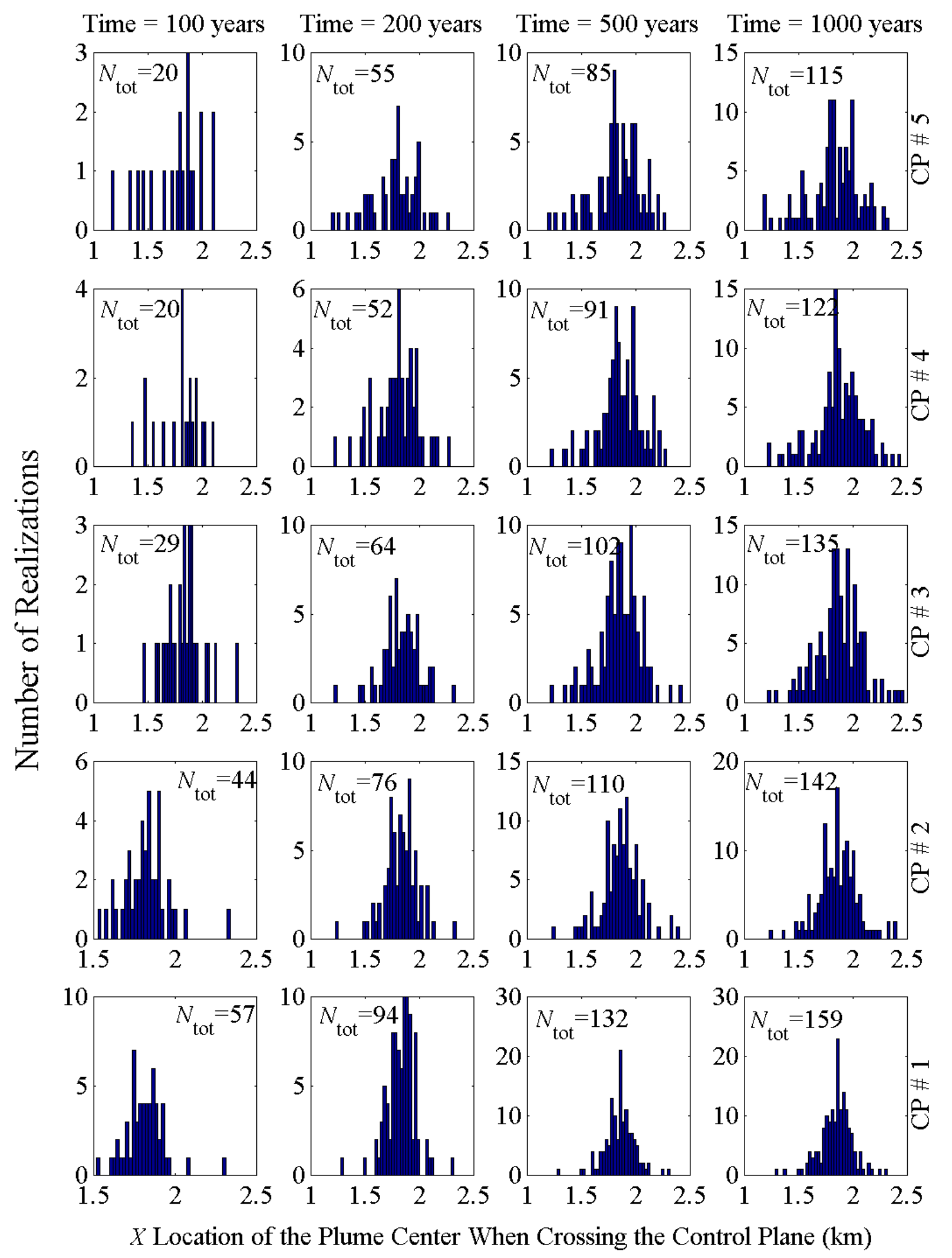

Figure 17. Distribution of the $X$ location of the plume center of mass when crossing CP \# 1 through CP \# 5 as average values from time zero to the given times. 
Time $=100$ years Time $=200$ years Time $=500$ years Time $=1000$ years
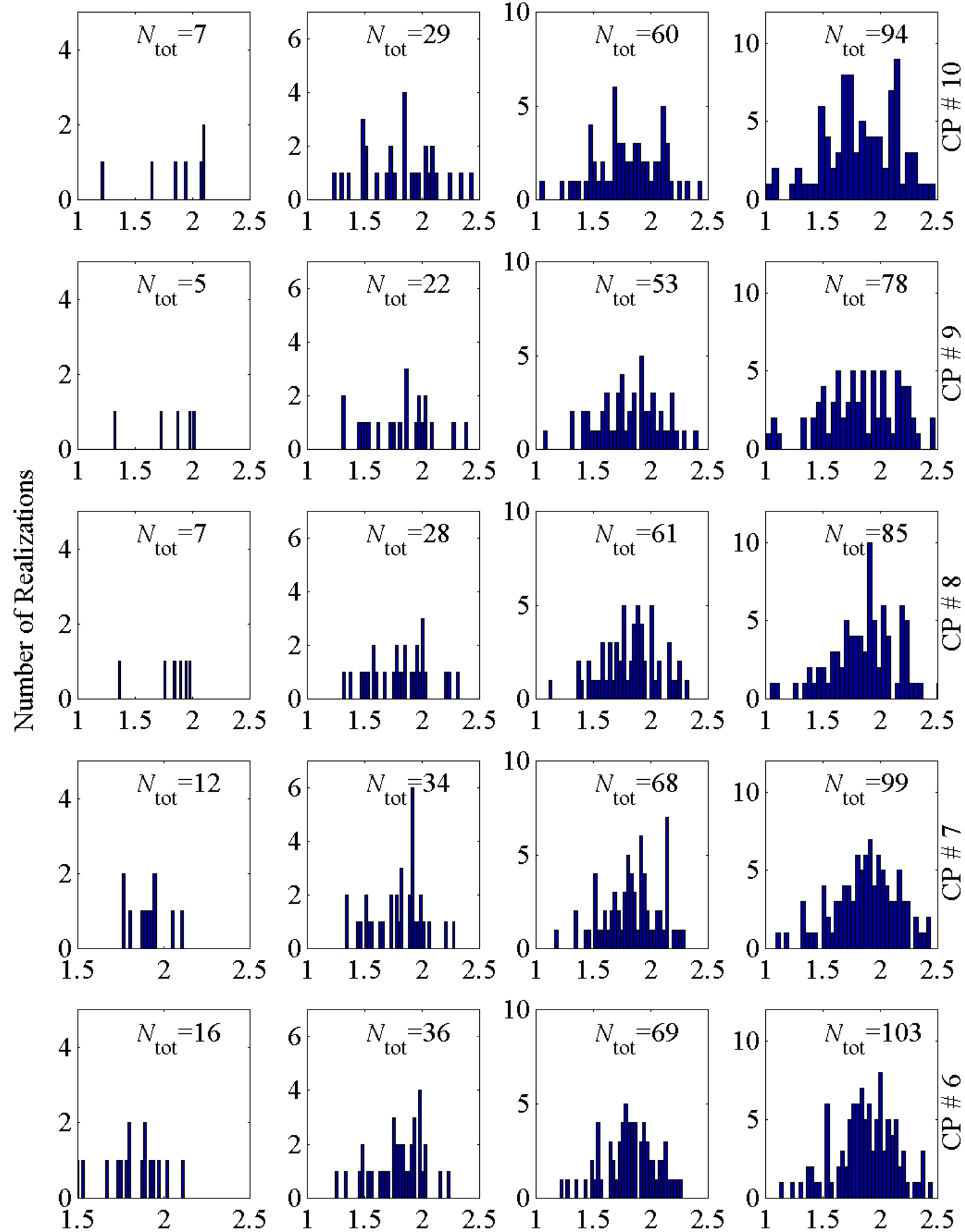

$X$ Location of the Plume Center When Crossing the Control Plane (km)

Figure 18. Distribution of the $X$ location of the plume center of mass when crossing CP \# 6 through $\mathrm{CP} \# 10$ as average values from time zero to the given times. 
Time $=100$ years Time $=200$ years Time $=500$ years Time $=1000$ years
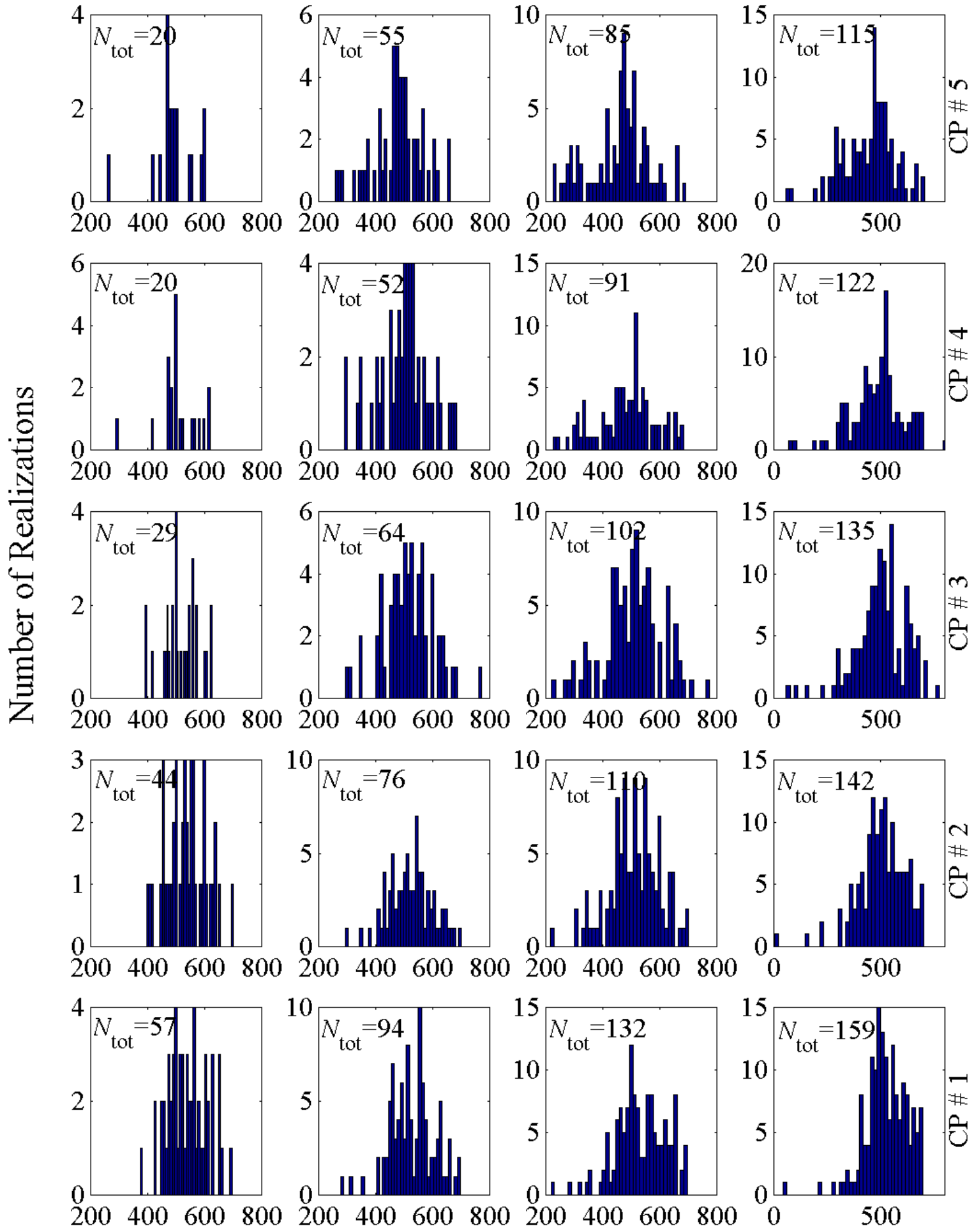

$Z$ Location of the Plume Center When Crossing the Control Plane (km)

Figure 19. Distribution of the $Z$ location of the plume center of mass when crossing CP \# 1 through CP \# 5 as average values from time zero to the given times. 
Time $=100$ years Time $=200$ years Time $=500$ years Time $=1000$ years
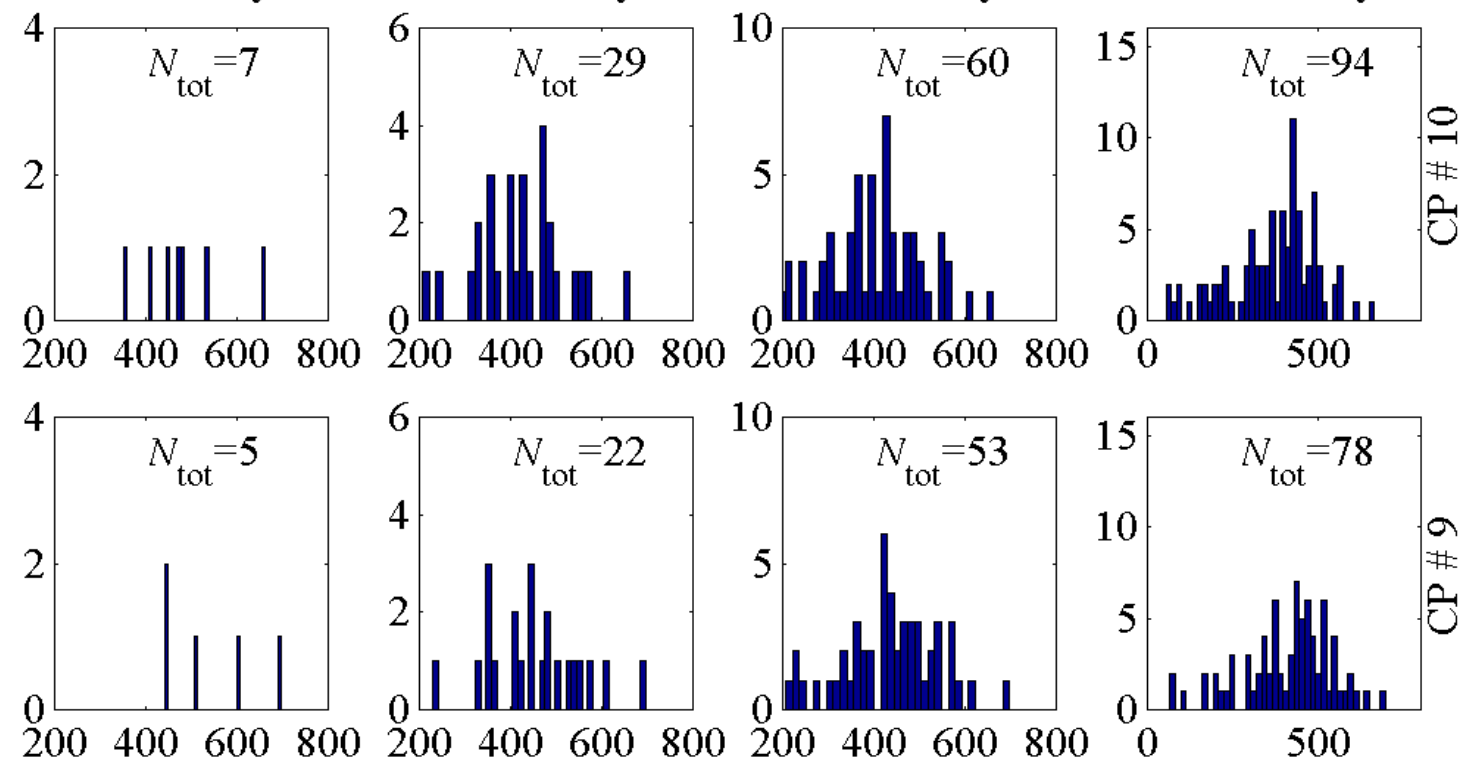

芯芯
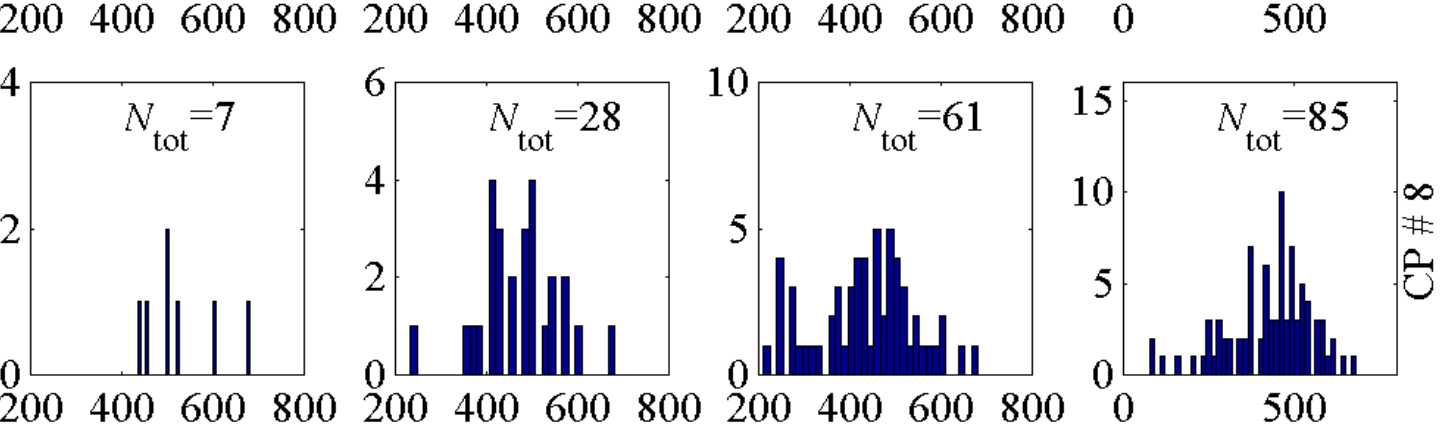

200400600800
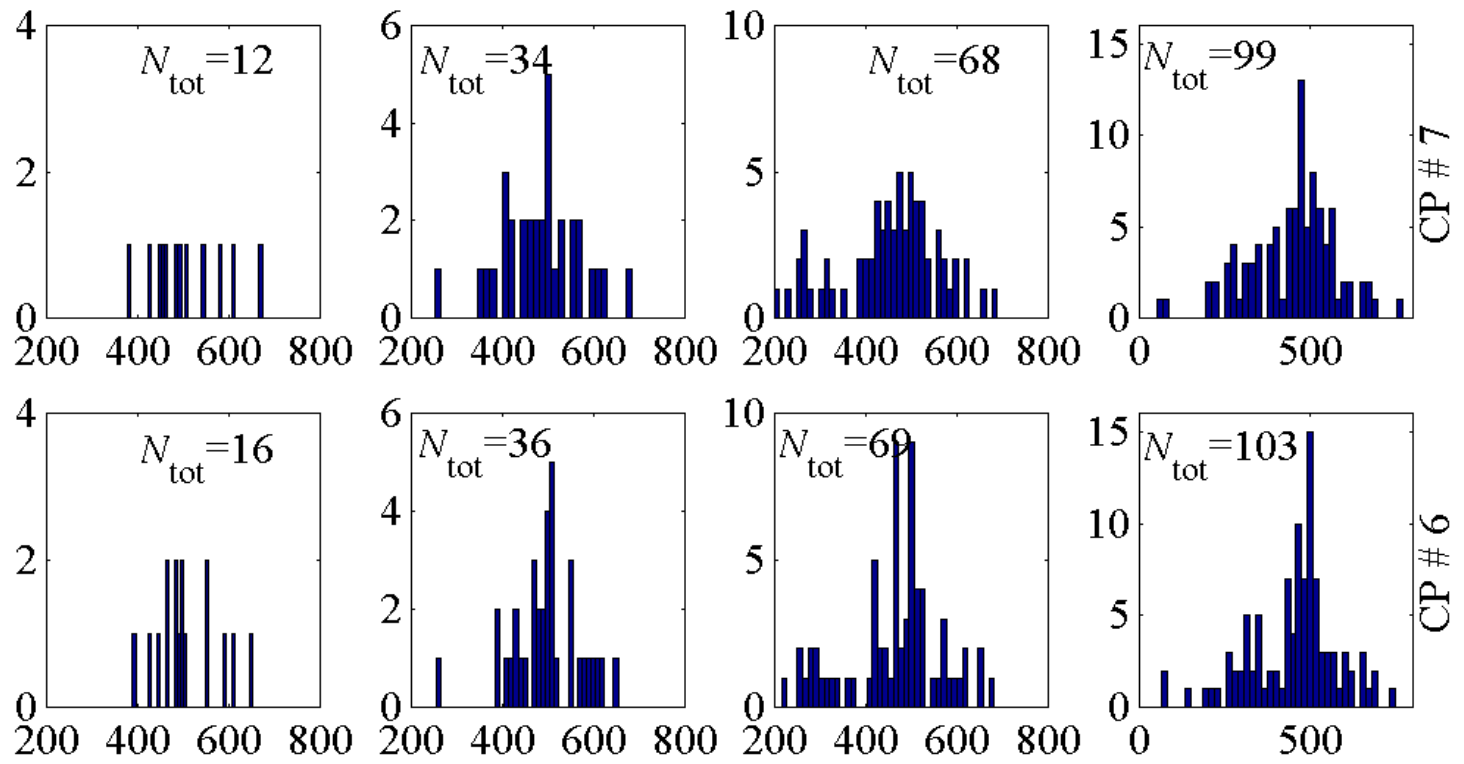

200400600800

$Z$ Location of the Plume Center When Crossing the Control Plane (m)

Figure 20. Distribution of the $Z$ location of the plume center of mass when crossing CP \# 6 through CP \# 10 as average values from time zero to the given times. 


\section{REFERENCES}

Aboufirassi, M. and M.A. Marino, 1983. Kriging of water levels in the Sauss Aquifer, Morocco. Mathematical Geology, 15(4), 537-551.

Ahlfeld, D.P. and G.F. Pinder, 1988. A groundwater monitoring network design algorithm. Report 87-WR-4, Department of Civil Engineering and Operations Research, Princeton University, Princeton, NJ.

Andricevic, R., 1989. Groundwater monitoring network: Analyses and design, Project Report \#294, St. Anthony Falls Hydraulic Laboratory, University of Minnesota, June.

Andricevic, R., 1990. Cost-effective network design for groundwater flow monitoring. Stoch. Stochastic Hydrology and Hydraulics, 4(1), 27-41.

Andricevic, R., 1996. Evaluation of sampling in the subsurface. Water Resources Research, 32(4), 863-874.

Andricevic, R. and E. Foufoula-Georgiou, 1991. A transfer function approach to sampling network design for groundwater contamination. Water Resources Research, 27(10), 27592769.

Ben-Jemaa, F., M.A. Marino and H.A. Loaiciga. 1994. Multivariate geostatistical design of ground-water monitoring networks. Journal of Water Resources Planning and Management, $120,505-522$.

Bernstein, B.B. and J. Zalinski, 1983. An optimum sampling design power tests for environmental biologists. Environmental Management, 16, 35-43.

Bogardi, I. and A. Bardossy. 1985. Multicriterion network design using geostatistics. Water Resources Research, 21, 199-208.

Bras, R.L. and I. Rodriguez-Iturbe. 1976a. Network design for the estimation of areal mean of rainfall events. Water Resources Research, 12, 1185-1196.

Bras, R.L. and I. Rodriguez-Iturbe. 1976b. Rainfall network design for runoff prediction. Water Resources Research, 12, 1197-1208.

Carrera, J., E. Usunoff and F. Szidarovszky, 1984. A method for optimal observation network design forgroundwater management. Journal of Hydrology 73, 147-163.

Chapman, J.B., K. Pohlmann, G. Pohll, A.E. Hassan, P. Sanders, M. Sanchez and S. Jaunarajs. 2002. Remediation of the Faultless underground nuclear test: Moving forward in the face of model uncertainty. In Proceedings of the Waste Management Conference, WM'02, Tucson, Arizona.

Chirlin, G.R. and G. Dagan, 1980. Theoretical head variogram for steady flow in statistically homogeneous aquifers. Water Resources Research, 16(6), 1001-1015.

Christakos, G. and R.A. Olea, 1988. A multiple-objective optimal exploration strategy. Journal of Mathematical and Computer Modeling, 11(4), 413-418

Cleveland, T.G. and W.W.G. Yeh. 1991. Optimal configuration and scheduling of ground-water tracer test. Journal of Water Resources Planning and Management, 117:37-51. 
Clifton, P.M. and S.P. Neuman, 1982. Effects of kriging and inverse modeling on conditional simulations of the Avra Valley aquifer in Southern Arizona. Water Resources Research, $18(4), 1215-1234$.

Datta B. and D.K. Purwar, 1992. Simulation Optimization Model for Groundwater Pollution Monitoring Network Design, Proceedings, VIII Asia Pacific Division - IAHR Congress, Pune, India

Datta, B. and S.D. Dhiman, 1996. Chance constrained optimal monitoring network design for pollutants in groundwater. Journal of Water Resources Planning and Management, ASCE, 122(3), 180-188.

Delhomme, J.P., 1979. Spatial variability and uncertainty in groundwater flow parameters: A geostatistical approach. Water Resources Research, 15(2), 269-280.

Delhomme, J.P. and P. Delfiner, 1973. Application of kriging in the optimization of monitoring network designs in arid regions. In Proceedings of Symposium on Design of Water Resources Projects with Inadequate Data. UNESCO, Madrid, Vol. 2, pp. 191-210.

Gambolati , G. and G. Volpi, 1979. Groundwater contour mapping in Venice by stochastic interpolations, 1, Theory. Water Resources Research, 15(2), 281-297.

Graham, W. and D. McLaughlin, 1989a. Stochastic Analysis of Nonstationary Subsurface Solute Transport: 1. Unconditional Moments. Water Resources Research 25:215-232.

Graham, W. and D. McLaughlin, 1989b. Stochastic Analysis of Nonstationary Subsurface Solute Transport: 2. Conditional Moments. Water Resources Research 25:2331-2355.

Grosser, P.W. and A.S. Goodman, 1985. Determination of groundwater sampling frequencies through Bayesian decision theory. Civ. Eng. Syst., 2, 186-195.

Hassan, A.E., 2003. A Validation Process for the Groundwater Flow and Transport Model of the Faultless Nuclear Test at Central Nevada Test Area. Desert Research Institute, Division of Hydrologic Sciences Publication \#45197.

Hassan, A.E. and K.H. Hamed, 2001. Prediction of plume migration in heterogeneous media using artificial neural network, Water Resources Research, 37(3), 605-623.

Hassan, A.E. and K.H. Hamed, 2000. Training neural networks for fast solution of stochastic groundwater flow and transport problems, In Computational Methods in Water Resources XIII, Bentley et al. (eds), Balkema Pub. Rotterdam, 495-502.

Haug, A., R.H. Petrini, G.E. Grisak and K. Klahsen, 1990. Synthetic semivariograms -- A novel approach to assessing positions and spacing of ground-water monitoring wells, Proceedings of Conference on Minimizing Risk to the Hydrologic Environment, American Institute of Hydrology, Minneapolis, MN, pp. 224-233.

Hsu, N.S. and W. Yeh, 1989. Optimum experimental design for parameter identification in groundwater hydrology. Water Resources Research, 25, 1025-1041.

Hsueh, Y.W. and R. Rajagopal, 1988. Modeling groundwater quality sampling decisions. Groundwater Monit. Rev., 8, 121-134.

Hudak, P.F. and H.A. Loaiciga, 1992. A location modeling approach for groundwater monitoring network augmentation. Water Resources Research, 28(3), 643-649. 
Hudak, P.F. and H.A. Loaiciga. 1993. An Optimization Method for Monitoring Network Design in Multilayered Groundwater Flow Systems. Water Resources Research 29:2835-2845.

Hudak, P.F., H.A. Loaiciga and M.A. Marino. 1995. Regional-scale ground water quality monitoring via integer programming. Journal of Hydrology (Amsterdam) [J. HYDROL. (AMST.)] 164:153-170.

Hughes, J.P. and D.P. Lettenmaier, 1981. Data requirements for kriging: Estimation and network design. Water Resources Research, 17(6), 1641-1650.

James, B.R. and S.M. Gorelick, 1994. When enough is enough: The worth of monitoring data in aquifer remediation design. Water Resources Research, 30(12), 3499-3513.

James, B.R. and A. Freeze, 1993. The worth of data in predicting aquitard continuity in hydrogeological design. Water Resources Research, 29(7), 2049-2065.

Journel, A.G. and C.J. Huijbregts, 1978. Mining Geostatistics. Academic Press, New York, N.Y., $600 \mathrm{p}$.

Keeney, R. and H. Raiffa, 1976. Decisions with Multiple Objectives: Preferences and Value Tradeoffs, 569 pp., John Wiley, New York.

Kinzelbach, W., 1988. The random walk method in pollutant transport simulation, In Groundwater Flow and Quality Modeling, eds. E. Custodio, A. Gurgui, J.P. Lobo Ferreira, D. Reidel, Norwell, Mass, 227-246.

Knopman, D.S. and C.I. Voss. 1988a. Discrimination Among One-Dimensional Models of Solute Transport in Porous Media: Implications for Sampling Design. Water Resources Research 24:1859-1876.

Knopman, D.S. and C.I. Voss. 1988.b Further Comments on Sensitivities, Parameter Estimation, and Sampling Design in One-Dimensional Analysis of Solute Transport in Porous Media. Water Resources Research 24:225-238.

Knopman, D., C.I. Voss and S.P. Garabedian, 1991. Sampling design for groundwater solute transport: Tests of methods and analysis of Cape Cod tracer test data. Water Resources Research, 27(5), 925-949.

LaBolle, E., G. Fogg and A.F.B. Tompson, 1996. Random-walk simulation of solute transport in heterogeneous porous media: Local mass-conservation problem and implementation methods. Water Resources Research, 32:583-593.

LaBolle, E., J. Quastel, G. Fogg and J. Gravner, 2000. Diffusion processes in a composite porous media and their integration by random walks: Generalized stochastic differential equations with discontinuous coefficients. Water Resources Research, 36:651-662.

Lee, G.F. and R.A. Jones, 1983a. Guidelines for sampling groundwater. Journal of Water Pollution Control Federation, 55(1), 92-96.

Lee, G.F. and R.A. Jones, 1983b. Active versus passive water quality monitoring programs for wastewater discharges. Journal of Water Pollution Control Federation, 55(4), 405-407.

Lee, S.-I. and P.K. Kitanidis. 1991. Optimal estimation and scheduling in aquifer remediation with incomplete information. Water Resources Research 27:2203-2217. 
Loaiciga, H.A. and R.L. Church, 1990. Linear programs for nonlinear hydrologic estimation. Water Resour. Bull., 26(4), 1-12.

Loaiciga, H.A., R.J. Charbeneau, L.G. Everett, G.E. Fogg, B.F. Hobbs and S. Rouhani, 1992. Review of groundwater quality monitoring network design. J. Hydraul. Eng., 118(1), 11-37.

Loaiciga, H., 1989. An optimization approach for groundwater quality monitoring network design. Water Resources Research, 25, 1771-1782.

Mahar, P.S. and B. Datta, 1997. Optimal monitoring network and groundwater-pollution source identification. Journal of Water Resources Planning and Management, 123(4), 199-207.

Mar, B.W., R.R. Horner, J.S. Richey, R.N. Palmer and D.P. Lettenmaier, 1986. Data acquisition. Environmental Science and Technology, 20(6), 545-551.

Marin, C.M., M.A. Medina and J.B. Butcher, 1989. Monte Carlo analysis and Bayesian decision theory for assessing the effects of waste sites on groundwater; I, Theory. Journal of Contaminant Hydrology, 5:1-13.

Massmann, J. and R.A. Freeze, 1987a. Groundwater contamination from waste management sites: The interaction between risk-based engineering design and regulatory policy. 1. Methodology. Water Resources Research, 23(2), 351-367.

Massmann, J. and R.A. Freeze, 1987b. Groundwater contamination from waste management sites: The interaction between risk-based engineering design and regulatory policy. 2 . Results. Water Resources Research, 23(2), 368-380.

McKinney, D.C. and D.P. Loucks. 1992. Network Design for Predicting Groundwater Contamination. Water Resources Research 28:133-147.

McLaughlin, D. and W. Graham, 1986. Design of cost-effective programs for monitoring groundwater contamination. In Integrated Design of Hydrological Networks, IAHS Publ. No. $158,231-246$.

Meyer, P. and E.D. Brill, Jr., 1988. A Method for locating wells in a groundwater monitoring network under conditions of uncertainty. Water Resources Research, 24(8), 1277-1282.

Meyer, P., A.J. Valocchi and J.W. Eheart, 1994. Monitoring network design to provide initial detection of groundwater contamination. Water Resources Research, 30(9), 2647-2659.

Meyer, P.D., R. Ranjithan, A.J. Valocchi and J.W. Eheart, 1989. Groundwater monitoring network design using coupled Monte Carlo simulation and optimization. In Proceedings of the 1989 National Conference on Hydraulics Engineering, M.A. Ports (Ed.), ASCE, New York, NY, 404-409.

Montas, H., R. Mohtar, A. Hassan and F. Al-Khal, 2000. Heuristic space-time design of monitoring wells for contaminant plume characterization in stochastic flow fields. Contaminant Hydrology, 43, 271-301.

Morisawa, S. and Y. Inoue, 1991. Optimum allocation of monitoring wells around a solid-waste landfill site using precursor indicators and fuzzy utility functions. Contaminant Hydrology, 7 , 337-370.

Olea, R.A., 1984. Sampling design optimization for spatial functions. Mathematical Geology, 16(4), 365-391. 
Pohll, G., K. Pohlmann, J. Daniels, A. E. Hassan, and J. Chapman, 2002. Contaminant and Compliance Boundaries at the Faultless Underground Nuclear Test, Division of Hydrologic Sciences Desert Research Institute, Publication No. 45196, pp. 50.

Pohlmann, K. F., A. E. Hassan, and J. B. Chapman, 1999. Evaluation of Groundwater Flow and Transport at the Faultless Underground Nuclear Test, Central Nevada Testing Area, Division of Hydrologic Sciences, Desert Research Institute, Publication No. 45165, pp. 129.

Purwar, D.K., 1991. Optimal Design Of Groundwater Quality Monitoring Network Incorporating Uncertainties, MTech thesis, Dept. of Civ. Eng., IIT, Kanpur, India

Reed, P., B. Minsker and A. Valocchi, 2000. Cost-effective long-term groundwater monitoring design using a genetic algorithm and global mass interpolation. Water Resources Research, 36(12), 3731-3741.

Rouhani, S., 1985. Variance-reduction analysis. Water Resources Research, 21, 837-846.

Rouhani, S. and M.B. Fiering. 1986. Resilience of a Statistical Sampling Scheme. Journal of Hydrology 89:1-11.

Rouhani, S. and T.J. Hall, 1988. Geostatistical scheme for groundwater sampling. Journal of Hydrology, 103, 85-102.

Sophocleous, M., J.E. Paschetto and R.A. Olea, 1982. Groundwater network design for Northwest Kansas using the theory of regionalized variables. Ground Water, 20(1), 48-58.

Storck, P., J. W. Eheart and A.J. Valocchi, 1997. A method for the optimal location of monitoring wells for detection of groundwater contamination in three-dimensional heterogeneous aquifers. Water Resources Research, 33(9), 2081-2088.

Szidarovszky, F., 1983. Optimal observation network in geostatistics and underground hydrology. Appl. Math. Modeling, 7, 25-32.

Todd, D.K., R.M. Timlin, K.D. Schmidt and L.G. Everett, 1976. Monitoring groundwater quality: Monitoring methodology. U.S. Environmental Protection Agency, Las Vegas, Nevada.

Tompson, A.F.B. and L.W. Gelhar, 1990. Numerical simulation of solute transport in threedimensional randomly heterogeneous porous media. Water Resources Research, 26(10):2541-2562.

Tucciarelli, T. and G.F. Pinder, 1991. Optimal data acquisition strategy for the development of a transport model for groundwater remediation. Water Resources Research 27:577-588.

U.S. Environmental Protection Agency (EPA), 1986. RCRA Groundwater Monitoring Technical Enforcement Guidance Document. Office of Solid Water Emergency Response, U.S. Environmental Protection Agency, Washington, D.C.

van Geer, F.C., 1987. Application of Kalman filtering in the analysis and design of groundwater monitoring network, Tech. Report PN 87-05, TNO-DGV Institute of Applied Geoscience.

Ward, R.C., J.C. Loftis and G.B. McBride, 1986. The data-rich but information-poor syndrome in water quality monitoring. Environmental Management, 10(3), 291-297.

Warrick, A.W., M.H. Young, P.J. Wierenga, 1998. Probabilistic analysis of monitoring systems for detecting subsurface contaminant plumes. Ground Water, 36(5):894-900. 
Wilson, C.R., C.M. Einberger, R.L. Jackson and R.B. Mercer, 1992. Design of ground-water monitoring networks using the Monitoring Efficiency Model (MEMO). Ground Water, 30:965-970.

Yeh, W.W.G., Y.S. Yoon and K.S. Lee, 1983. Aquifer parameter identification with kriging and optimum parameterization. Water Resources Research, 19(1), 225-233.

Yfantis, E.A., G.T. Flatman and J.V. Behar, 1987. Efficiency of kriging estimation for square, triangular, and hexagonal grids. Mathematical Geology, 19:183-205. 


\section{DISTRIBUTION}

Jenny Chapman

Division of Hydrologic Sciences

Desert Research Institute

755 East Flamingo Road

Las Vegas, NV 89119-7363

Brian Cherry

Shaw Environmental, Inc.

P.O. Box 93838, M/S 439

Las Vegas, NV 89193-3838

Darby Dieterich

Office of Business Affairs

Nevada Site Office

National Nuclear Security Administration

U.S. Department of Energy

P.O. Box 98518

Las Vegas, NV 89193-8518

Bruce Hurley

Hydrology Program Manager

Environment, Safety \& Health Division

Nevada Site Office

National Nuclear Security Administration

U.S. Department of Energy

P.O. Box 98518

Las Vegas, NV 89193-8518

David Stahl

Stoller-Navarro Joint Venture

P.O. Box 93838, M/S 439

Las Vegas, NV 89193-3838

Kenneth A. Hoar, Director

Environment, Safety \& Health Division

Nevada Site Office

National Nuclear Security Administration

U.S. Department of Energy

P.O. Box 98518

Las Vegas, NV 89193-8518

Marjory Jones

Division of Hydrologic Sciences

Desert Research Institute

2215 Raggio Parkway

Reno, NV 89512-1095
Randy Laczniak

U.S. Geological Survey

Water Resources Division

6770 S. Paradise Rd.

Las Vegas, NV 89119

Monica Sanchez

Environmental Restoration Division

Nevada Site Office

National Nuclear Security Administration

U.S. Department of Energy

P.O. Box 98518

Las Vegas, NV 89193-8518

Peter Sanders

Environmental Restoration Division

Nevada Site Office

National Nuclear Security Administration

U.S. Department of Energy

P.O. Box 98518

Las Vegas, NV 89193-8518

David Shafer

Division of Hydrologic Sciences

Desert Research Institute

755 E. Flamingo Road

Las Vegas, NV 89119-7363

Runore C. Wycoff, Director

Environmental Restoration Division

Nevada Site Office

National Nuclear Security Administration

U.S. Department of Energy

P.O. Box 98518

Las Vegas, NV 89193-8518

Nevada State Library and Archives

State Publications

100 North Stewart Street

Carson City, NV 89710-4285

Archives

Getchell Library

University of Nevada, Reno

DeLaMare Library/262

University of Nevada, Reno 


\author{
Document Section, Library \\ University of Nevada, Las Vegas \\ 4505 Maryland Parkway \\ Las Vegas, NV 89154 \\ Library \\ Stoller-Navarro Joint Venture \\ P.O. Box 93838, M/S 439 \\ Las Vegas, NV 89193-3838 \\ ATTN: Toni Miller, M/S 439 \\ Library \\ Southern Nevada Science Center \\ Desert Research Institute \\ 755 E. Flamingo Road \\ Las Vegas, NV 89119-7363 \\ Technical Library \\ Nevada Site Office \\ National Nuclear Security Administration \\ U.S. Department of Energy \\ P.O. Box 98518 \\ Las Vegas, NV 89193-8518 \\ Public Reading Facility \\ Nevada Site Office \\ National Nuclear Security Administration \\ U.S. Department of Energy \\ P.O. Box 98521 \\ Las Vegas, NV 89193-8521 \\ Office of Scientific and Technical \\ Information \\ U.S. Department of Energy \\ P.O. Box 62 \\ Oak Ridge, TN 37831-9939 \\ (electronic copy)
}

